Beltrán Villegas, ss.cc.*

\title{
En busca de Q. La fuente común de Mt y Lc
}

\section{INTRODUCCIÓN}

Santo Tomás de Aquino, con su invariable objetividad y desapasionamiento, enuncia, a propósito del principio Scientia Dei, causa rerum ("la ciencia de Dios es causa de las cosas"), como base de su respuesta positiva a esa pregunta, el siguiente principio: "Oportet quod quaecumque sunt similia ita se habeant, ut vel unum sit causa alterius vel ambo ex una causa causentur" ("Cuando dos cosas son semejantes, es rigurosamente necesario que o bien una sea causa de la otra o que ambas sean causadas por una sola y misma causa").

Ni sostengo ni niego que Sto. Tomás haya percibido personalmente el alcance de este principio para analizar las relaciones de dependencia literaria dentro de la literatura bíblica. Pero me parece inverosímil que haya tenido in mente el caso concreto de los fenómenos de semejanza dentro de los textos bíblicos y más específicamente en el caso de los evangelios sinópticos. Sea de ello lo que fuere, Sto. Tomás nos ha dejado, en las palabras que citamos, un principio que expresa la racionalidad con que debemos abordar el estudio de la "sinopticidad" de los tres primeros evangelios.

En las situaciones de sinopticidad con presencia de Mc, una aplastante mayoría de casos sugiere que Mc ha sido conocido y usado tanto por Mt como por Lc. Pero hay unos doscientos versículos en que se da "sinopticidad" entre Mt y Lc al margen de la concurrencia de Mc, lo que plantea la ineludible pregunta por su origen: ese material evangélico, ¿lo tomó Mt de Lc, Lc de Mt o ambos de un tercero (o, mejor dicho, de un "primero")? La opinión más común es que ni Lc usó a Mt ni Mt a Lc, y esto se basa en que hay casos en que el texto de Mt parece secundario (v.gr., cuando encontramos "Reino de los cielos" y no "Reino de Dios"), y otros en que obviamente es Lc el que presenta una lección secundaria (v.gr., cuando solo en el texto lucano aparece la mención del "Espíritu"). Esto sugiere que Mt y Lc han usado con cierta libertad una misma fuente.

Por otra parte, podemos constatar que en su uso de Mc, a veces Mt y a veces Lc presentan cambios más o menos importantes del texto marcano usado por ambos.

(1) El Padre Beltrán Villegas, ss.cc., fue, desde 1966 hasta el primer semestre de 1999, profesor en la Facultad de Teología y ejerció el servicio de Decano entre 1974 y 1976. Por sus relevantes méritos académicos, la Pontificia Universidad Católica de Chile le otorgó el Doctorado Honoris Causa. 
Es de esperar, por tanto, que los redactores de Mt y de Lc hayan hecho algo semejante en el uso de su segunda fuente (a la que habitualmente se designa con la sigla "Q", del alemán "Quelle", que significa "fuente").

Esta "fuente Q" se ha perdido y solo nos resulta accesible por la comparación cuidadosa de lo que encontramos en Mt y en Lc. Es obvio que en los casos es que la fraseología de Mt y de Lc concuerda, el texto de Q se puede considerar seguro. Pero cuando ellos se presentan con diferencias de fraseología o de vocabulario, la identificación del texto original de Q es inevitablemente hipotética. Pero la ponderación cuidadosa de los casos en que Mt y Lc difieren en su redacción, puede darnos indicaciones suficientes para detectar cuando estamos ciertamente ante una redacción secundaria, sea de Mt sea de Lc. Por cierto, es posible que tanto Mt como Lc se hayan apartado de la redacción de Q. Pero dentro de una dosis inevitable de incertidumbre, se pueden proponer hipótesis más o menos seguras, cuyo valor depende de la fuerza de las razones que se esgriman.

V. Taylor, en dos artículos muy convincentes (“The Order of Q", JTS 4, pp. 27-31, del año 1954, y "The Original Order of Q", en el volumen colectivo New Testament Essays, editado por A.J.B. Higgins en honor de T.W. Manson el año 1959 en Manchester, pp. 246-269), ha mostrado que el orden original de Q es el que conservó Lc. Por eso las ediciones sinópticas de Q se atienen al orden en que este material aparece en Lc, y aquí seguiremos el mismo procedimiento.

Para usar este trabajo es indispensable tener delante de los ojos una buena Sinopsis griega (v.gr., las de Huck-Lietzmann, de K. Aland, de Huck-Greeven, o de Boismard-Lamouille). Mejor todavía si se puede usar la obra de F. Neyrink, "Q Synopsis: Double Tradition Passages in Greek" (Lovaina, 1988), que facilita enormemente la compulsación de los textos.

Casi como un apéndice de nuestro trabajo, presentaremos una reconstrucción hipotética de Q, cuyo diverso grado de valor depende de los argumentos aportados en la discusión de cada unidad atribuible a nuestra hipotética fuente.

Sería injusto no expresar a Angélica Llona, teóloga penetrante y amiga entrañable, mi agradecimiento por el arduo y generoso trabajo que desplegó para descifrar mi manuscrito y para detectar los errores que en él había.

\section{LA FUENTE Q ESTUDIO ANALÍTICO}

\section{EL MENSAJE DEL BAUTISTA \\ Lc 3, 7-9 // Mt 3, 7-10}

Sinopticidad. Nuestro texto está situado por Mt y Lc en el mismo lugar del relato marcano. Es decir, lo que en ambos precede a estos verss. calza con Mc 1, 1-6, y lo que en ambos viene después de ellos calza con Mc 1, 7ss. Y es obvio que tanto Mt 3, 1-6 como Lc 3, 1-6 se basan en Mc 1, 1-6, si bien ambos introducen modificaciones; ante todo, ambos sitúan el contenido de Mc 1, 4 antes de la cita de "Isaías" (Mc 1, 23), y ambos también desplazan, en la cita bíblica de Mc, el vers. proveniente de 
Malaquías (Mc 1,2) situándolo en otros lugares (Mt 11, 10, y Lc 7, 27), y ambos, por último, tratan de situar "cronológicamente" el evento de Juan Bautista (aludido en Mc

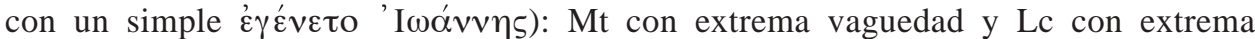
precisión (solo después de un largo sincronismo aparece la formulación), y además prolonga la cita de Isaías (tres verss., en vez de uno solo), y en cambio omite la descripción del Bautista hecha en Mc 1, 5-6 (levemente retocada en Mt 3, 4-6). Debe señalarse en estos verss. una concordancia Mt-Lc que no proviene de Mc: la expresión

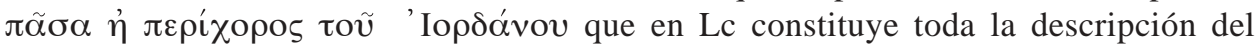
lugar de actividad del Bautista, mientras que en Mt entra malamente, como un añadido

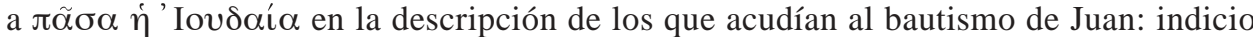
claro de que esta cláusula viene de Q. Antes de encontrarse ambos de nuevo con Mc 1, 7, Lc completa la enseñanza del Bautista (Lc 3, 10-14) y les antepone una introducción a los dichos de JB sobre su propio bautismo (Lc 3, 15-16a).

Texto. El grado de correspondencia es casi total. Hay solo tres pequeñas dife-

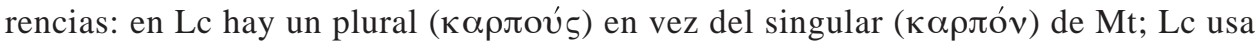

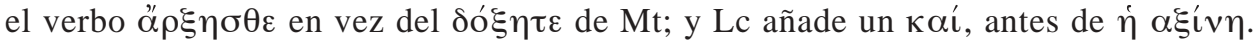
Nos parece casi seguro que en el primer caso el texto de $\mathrm{Q}$ es conservado por Lc, porque de sus 12 usos de карлós, solo aquí y en 12, 17 usa el plural, mientras que Mt recurre con igual frecuencia al singular o al plural; en cambio, en el segundo caso es Mt quien conserva el texto de Q, pues es la única vez donde en Mt aparece la construcción de otra parte, la fórmula $\alpha \rho \chi \chi \varepsilon \sigma \theta \alpha \iota$ con infinitivo es ampliamente usada tanto por Mt como por Lc; en el tercer caso, nos parece más probable que Lc haya añadido el

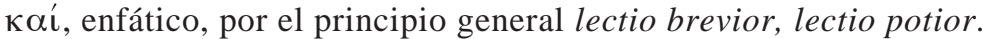

\section{EL BAUTISMO ANUNCIADO POR JUAN \\ Lc 3, 16b // Mt 3, 11b-12}

Sinopticidad. Nuestro texto se inserta fácilmente en el de Mc 1, 7-8a, pero tanto Mt como Lc le anteponen al comienzo del vers. 7 de Mc el contenido de $8 \mathrm{a}$, si bien con pequeñas diferencias que sugieren una doble tradición (Mc-Q) de todo el conjunto, dada su correspondencia con Mc 1, 7-8a. Parece imposible, sin embargo, reconstruir el texto de Q. Donde claramente encontramos material Q es en Lc 3, $16 \mathrm{~b}-17$ y Mc 3, 11b-12.

Texto. Con mucha probabilidad el orden de Mt y Lc corresponde al orden de Q,

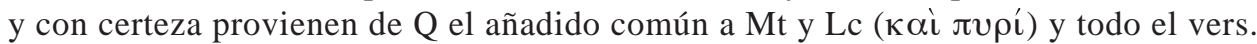
17 de Lc y 12 de Mt. La mención del fuego es coherente con la imagen desarrollada en los textos mateano y lucano. El desarrollo de esta imagen se lleva a cabo con fraseología casi idéntica; hay solo dos pequeñas diferencias: en Mt tenemos una construcción paratáctica (“... y limpiará ... y juntará...”), mientras que en Lc tenemos una construcción sintáctica que expresa finalidad (“... para limpiar ... y juntar ..."); y en Mt se habla de "su trigo" y de "la bodega", mientras que en Lc encontramos "el trigo" y "su bodega". Parece claro que en la primera diferencia Mt reprodu- 
ce mejor el texto de Q (la parataxis es más semítica), y que en la segunda cada uno añadió un "su": Lc a la bodega, y Mt al trigo, para concretizar más el dicho.

\section{LAS TENTACIONES DE JESÚS \\ Lc 4, 2-12 // Mt 4, 2-12}

Sinopticidad. El material ciertamente debido a Q se inserta tanto en Mt (4, 212) como en Lc (4, 2-12) en el orden marcano: entre el bautismo y el comienzo del ministerio en Galilea. Pero hay algo más: Mc incluye también aquí mismo (Mc 1, 12-13) un breve relato sobre Jesús tentado en el desierto, y cabe preguntarse por el origen de Mt 4, 1 y Lc 4, 1. Sería posible pensar que algunos elementos se debieran a Mc (desierto, Espíritu, tentación demoníaca, cuarenta días); pero hay entre Mt y Lc una serie de concordancias que no pueden explicarse como modificaciones del texto marcano: el uso de "Diablo" (en vez de Satanás) y -sobre todola caracterización de esos cuarenta días como de "ayuno" con la consiguiente "hambre" (elemento indispensable para la $1^{\text {a }}$ tentación de Q). Lo más verosímil es que Q solo contuviera las "palabras" del episodio, dejando la descripción de los hechos al narrador; y en tal hipótesis, tanto RMt como RLc pudieron usar ampliamente la narración que les ofrecía Mc, sin perjuicio de la tradición oral vinculada con los "parlamentos" del episodio.

Orden. El hecho más notorio es que la $2^{\mathrm{a}}$ tentación de Mt es la $3^{\mathrm{a}}$ de $\mathrm{Lc}$, y la $3^{\mathrm{a}}$ de Mt, la $2^{\mathrm{a}}$ de Lc. Es universalmente reconocido que Mt conserva el orden de Q, y ello por dos razones: a) en Lc, la $3^{\mathrm{a}}$ constituye un "anticlímax", pues la $2^{\mathrm{a}}$ de Lc es, per se, de carácter final; b) es conocido el afán lucano de presentar a Jerusalén como "meta" de Jesús en su historia terrena: desde el cap. 9 aparece Jesús en viaje a Jerusalén, y Jesús resucitado solo se manifiesta en Jerusalén y sus alrededores y ya no vuelve a Galilea (contra Mc, Mt y Jn 21).

Texto. De la $1^{\mathrm{a}}$. En el vers. $3^{\mathrm{a}}$ (descripción de la acción) Lc parece conservar mejor la redacción de Q: en efecto, Mt es muy aficionado al uso de la fórmula "y acercándose a Jesús" (o "a Él”), y es más explicable en Mt "el tentador" (en vez de "el diablo") por el afán de no repetir "el diablo" recién nombrado. En la segunda parte del vers., de nuevo Mt parece querer mejorar la construcción "di a ... que se convierta", que tenemos en Lc, escribiendo: "Di que se convierta". Y parece también (aunque es más discutible) que Mt, con sus plurales "estas piedras" y "panes", quiso atenuar lo que podía verse como demasiado concreto con el singular "esta piedra" y "pan". En el vers. 4, de nuevo Mt parece querer mejorar, alivianando, la redacción narrativa que ofrece Lc, y (y esto es más seguro) prolongar la cita bíblica puesta en labios de Jesús, ya que resulta inexplicable que Lc omitiera lo que encontramos en Mt.

De la $2^{\mathrm{a}}$ de Mt. En el vers. 5 (de Mt) la redacción mateana parece más original en la fraseología general y en el uso del presente histórico ("toma", "dice"); pero podría ser que el uso de "tomar" (en vez de "llevar") fuera redaccional, ya que el verbo "tomar" es muy mateano (16 veces en Mt contra 6 en Lc; pero hay que 
reconocer que "llevar" aparece 13 veces en Lc contra 4 en Mt); en todo caso, "ciudad santa" parece seguro que es redaccional, pues es una expresión que solo se vuelve a encontrar en un texto del RMt: 25, 33. En el vers. 6, Mt parece conservar el texto de Q, pues las diferencias que presenta Lc tienen altas presunciones de redaccionalidad: el añadido de "desde aquí", y las palabras que completan la cita del salmo. En el vers. 7, la redacción que tenemos en Lc parece obedecer al deseo de mejorar estilísticamente el texto y de evitar repeticiones.

De la $3^{\text {a }}$ de Mt. En lo correspondiente al vers. 8 de Mt, es evidente la intervención redaccional de Lc, destinada no solo a evitar repeticiones ("de nuevo", "toma", "el diablo") y a mejorar el estilo (sintaxis en vez de parataxis), sino a corregir la índole del evento: omitiendo lo del "traslado a un monte elevado" (cambiado en "llevándolo" sin especificar adónde), añadiendo lo de "en un instante de tiempo",

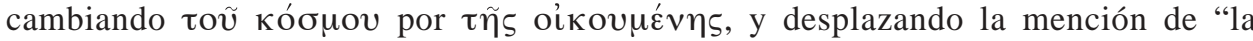
gloria" de los reinos a la proposición del tentador. En lo correspondiente al vers. 9 de Mt, parece claro que Lc precisó el complemento directo de "te daré": en vez de "esto" (= "todos los reinos y su gloria"), puso "todo este poder y la gloria de ellos", acentuando que lo que estaba en juego era la cuestión de "el poder y la gloria". También lo que se encuentra en el vers. 7 de Lc parece redacción lucana en torno al núcleo tradicional "si me adoras" (el "postrándote" de Mt 4, 9, por su parte, también tiene aire de añadido redaccional). El problema más serio de esta parte lo constituye el plus que se encuentra en Lc 4, 6b. Es difícil pensar que, dada su fuerte carga mitológica, pueda ser un añadido de RLc; parece, entonces, que debe reconocérselo como perteneciente a Q. En cuanto a lo correspondiente al vers. 10 de Mt, se debe reconocer que la expresión "retírate, Satanás" es un añadido de RMt, pues es idéntica a la de Mt 16, 23, tomada de Mc 8, 33.

\section{LAS BIENAVENTURANZAS \\ Lc 6, 20-22 // Mt 5, 3-12}

Sinopticidad. Tanto Mt como Lc sitúan este texto de manera similar: en ambos viene después de la mención de una muchedumbre que seguía a Jesús (Mt 4, 24-25; Lc 6, 17-19); y en ambos corresponde al inicio de un discurso bastante extenso (Mt 5-7; Lc 6, 20-49) y que termina con la misma doble parábola (Mt 7, 24-27; Lc 6, 47-49). Pero mientras que Lc lo sitúa en una llanura a la que baja Jesús desde una montaña donde había instituido a los Doce (Lc 6, 12-19), Mt lo sitúa en la montaña (fijarse en el artículo definido), a la cual Jesús sube para pronunciar su discurso (Mt 5, 1-2).

En ambos evangelios el texto consta de unas bienaventuranzas breves (ocho en Mt y tres en Lc) y de una larga y expresamente cristológica (Mt 5, 11-12; Lc 6, 2223), siendo visible que las mayores diferencias entre Mt y Lc se dan en las breves.

\section{Texto de las bienaventuranzas breves}

A. Comencemos señalando las diferencias más significativas entre los textos de Mt y de Lc. 
1) Solo en Lc (6, 24-26) hay unos "ayes" simétricos a las bienaventuranzas, incluyendo uno que corresponde a la bienaventuranza prolija y cristológica.

2) En cuanto al número de bienaventuranzas breves, en Mt tenemos ocho y en Lc tres.

3) En cuanto al contenido, las tres lucanas se encuentran también en Mt, pero con algunas diferencias: a) en cuanto al orden, la $2^{\mathrm{a}}$ y la $3^{\mathrm{a}}$ bienaventuranzas lucanas aparecen en Mt como $4^{\mathrm{a}}$ y $2^{\mathrm{a}}$, respectivamente; b) en cuanto a la terminología, la $3^{\mathrm{a}}$ lucana (que corresponde a la $2^{\mathrm{a}}$ mateana) habla de "llanto" y de "risa", mientras que en el texto mateano tenemos "aflicción" y "consuelo", y, por otra parte, en la $1^{a}$ petición, mientras Lc trae "Reino de Dios", Mt trae "Reino de los cielos"; c) por último hay que señalar que tanto Mt como Lc tienen algunas expresiones propias: Mt, en su primera petición, añade "de espíritu” a "pobres", y en su cuarta, a "hambrientos" le añade "y sedientos de justicia"; Lc, por su parte, en las bienaventuranzas $2^{\mathrm{a}}$ y $3^{\mathrm{a}}$, añade el adverbio "ahora" a los participios que expresan las ideas de "tener hambre" y de "llorar".

4) En cuanto a la índole global, Mt nos presenta un elenco de actitudes laudables, por lo que la "bienaventuranza" prometida tiene el carácter de "recompensa"; en cambio, Lc nos presenta un elenco de "situaciones deplorables", por lo que la "bienaventuranza" toma el carácter de una "compensación".

B. Veamos ahora los fundamentos de las opciones que se expresan en el texto que hemos propuesto como de $Q$ en las bienaventuranzas breves y no cristológicas.

1) Es primitivo el "elenco de situaciones" que nos ofrece Lc, y no el de "actitudes" que encontramos en Mt. En efecto: a) es incomprensible que un texto originariamente "espiritual" haya sido transformado en un texto "social", mientras que el proceso contrario es explicable, ya que resulta más fácil comprender que Jesús haya proclamado "bienaventurados" a los virtuosos que a los socialmente deprimidos; b) en el texto de Mt se perciben dos rasgos característicos del RMt: por una parte, la tendencia a "moralizar" lo escatológico-evangélico, como se puede ver comparando Mt 5, 25-26 con Lc 12, 58-59; Mt 18, 12-14 con Lc 15, 1-7; Mt 22, 1-14 con Lc14, 15-24; por otra, en el elenco de Mt aparece dos veces (en la $4^{\mathrm{a}}$ y en la $8^{\mathrm{a}}$ bienaventuranzas) el concepto de "justicia", que es propio de Mt en los Sinópticos. Si esto es así, se deben considerar como RMt los añadidos modificativos "de espíritu" y "de justicia", que afectan respectivamente a "los pobres" y a "los hambrientos", y todas las bienaventuranzas intrínsecamente "actitudinales" ("mansos", "misericordiosos", "limpios de corazón", "pacificadores", "perseguidos por tratar de ser justos").

2) Es primitivo el estilo de $3^{\mathrm{a}}$ persona que nos ofrece Mt, y no el de $2^{\mathrm{a}}$ que encontramos en Lc . En efecto: a) Mt tiene las ocho primeras en $3^{\text {a }}$ persona y la novena en $2^{\mathrm{a}}$, lo que muestra que él no quiso homogeneizar su texto desde este punto de vista; en cambio, es más verosímil que la $2^{a}$ persona de Lc se deba a un afán por homogeneizar el estilo del texto; b) el estilo normal de los macarismos es de $3^{\text {a }}$ persona (41/44 en BH, 57/60 en la LXX; 27/30 en el NT); y, en todo caso, las bienaventuranzas lucanas son anómalas, pues -contra la norma universal de los macarismos de $2^{\mathrm{a}}$ persona- su índole de macarismo de $2^{\mathrm{a}}$ persona solo viene a 
percibirse al leer la apódosis, y no ya desde la prótasis (cabe señalar que las traducciones soslayan esta anomalía, visible en el texto griego, añadiendo un "vosotros" en la prótasis: "bienaventurados vosotros los pobres"); c) el RLc es aficionado al estilo directo y personal: hay por lo menos una media docena de casos en que Lc trae la $2^{a}$ persona contra la $3^{a}$ de Mc y/o de Mt.

3) Es primitivo el orden "pobres, afligidos" de Mt, y no el de Lc: "pobres, hambrientos". En efecto: a) En el texto de Mt se percibe mejor la dependencia del logion de Jesús respecto de Is 61, 1-2 (texto clave para la autocomprensión de Jesús). b) En Lc hay una vinculación constante entre pobreza y falta de alimento, por una parte, y por otra, entre riqueza y placeres de la mesa (cf., v.gr., Lc $12,19 ; 16,19-21)$.

4) Es primitiva la terminología "aflicción-consuelo" de Mt, y no la de "llorar-reír" de Lc. En efecto: a) en los "ayes" de Lc $(6,24-26)$ aparece la "aflicción" (además del "llanto") en el simétrico de la bienaventuranza de los que lloran, y el "consuelo" en el simétrico de la bienaventuranza de los pobres; b) el uso de "reír" (" $\gamma \varepsilon \lambda \alpha \omega "$, "hapax" del NT) como característico de un estado de salvación no es conforme al uso bíblico que siempre le da a la "risa" (" $\gamma \varepsilon \dot{\varepsilon} \lambda \omega \varsigma$ ") un sentido peyorativo (cf. Sant 4, 9: "hapax" del NT; y ver, v.gr., Prov 10, 23; Qoh 2, 2; 7 , 3.6-7; 10, 19); en cambio, en el mundo helenístico el $\gamma \varepsilon \dot{\varepsilon} \lambda \omega \varsigma$ es la sonrisa feliz de

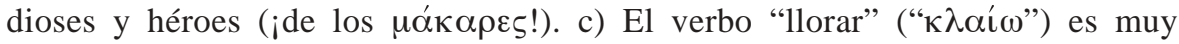
lucano (Mt: 2; Mc: 3; Lc: 11), y hay por lo menos un caso en que Lc altera su fuente para introducirlo (cf. QMt 11, 17, comparado con Lc 7, 32).

5) La "sed" parece haber sido introducida por el RMt como resultado de la "espiritualización" de esta bienaventuranza. En efecto, cuando se trata de una situación de carencia "fisiológica", en el AT se suele hablar simplemente de los "hambrientos"; cuando, en cambio, se trata de la salvación otorgada por Dios, ella aparece prometida a quienes tienen "hambre y sed" de ella (como en Is 49,10 y 65,13 ).

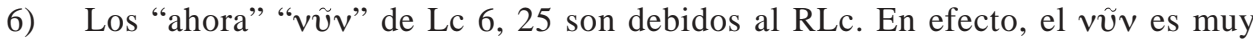
lucano (Mt: 4 veces; Mc: 3; Lc: 14; Hch: 25), y en nuestro texto aparece vinculado con la visión lucana de la "vuelta escatológica de la tortilla" (cf., v.gr., Lc 16, 19-25).

7) Los "ayes" de Lc $(6,24-26)$ son debidos al RLc. En efecto: a) no es raro que Lc "desdoble" un texto mediante un procedimiento de "calco" (cf., v.gr., Lc 7, 21; 9, 31; Hch 15, 19-21.28-29); b) el primer "ay" tiene toda la pinta de un texto "hechizo", pues la amenaza (destinada a ser simétrica con "vuestro es el Reino de Dios") parece construida a partir de un elemento ofrecido por la $2^{\mathrm{a}}$ bienaventuranza (la idea de "consuelo" $\pi \alpha \rho \alpha ́ \kappa \lambda \varepsilon \sigma \iota \varsigma)$, siendo de notar que este era el único "ay" que no se podía obtener por la simple "conversión" de la bienaventuranza correspondiente; c) si Mt conoció estos "ayes", no se explica por qué no los incluyó: si no aquí, al menos en su gran colección de "ayes" del cap. 23.

\section{Texto de la bienaventuranza prolija y escatológica}

Este es, sin duda alguna, un añadido de Q a una tríada más primitiva, destinado a darle a la trilogía original una aplicación actualizadora. En efecto, aparecen en 
esta bienaventuranza los temas dominantes de la teología de Q: Jesús como el Hijo del hombre, y los discípulos como profetas perseguidos.

El trozo consta de tres partes: la descripción de la persecución de los cristianos, la causa de esta persecución y la recompensa celestial.

En el primer punto, se le debe atribuir a RLc el añadido de toda la primera

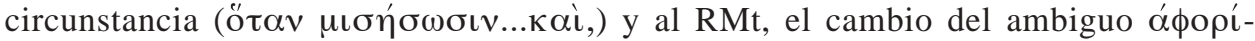

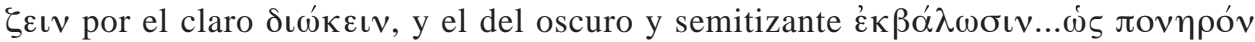
por el claro $\varepsilon ״ \pi \omega \sigma \iota v . . \psi \varepsilon \varepsilon \delta \delta o ́ \mu \varepsilon v o \iota$.

En el segundo punto, se le debe atribuir al RMt el cambio de "a causa del Hijo del hombre" (que es raro en Lc) por el más claro "a causa de mí", que tenemos en Mt.

En el tercer punto, Mt parece haber conservado el texto de Q (por ejemplo, el

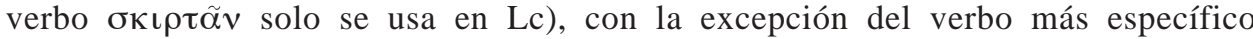
$\varepsilon \delta \delta i \omega \xi \alpha v$ que usa Mt, a diferencia del genérico éjoíovv que se encuentra en Lc.

\section{EL AMOR A LOS ENEMIGOS \\ Lc 6, 27-36 // Mt 5, 39-48 + 7, 12}

Contexto. En Lc está este trozo inmediatamente después de los "ayes" (6, 24-26), que son obra del RLc destinada a hacer contraste con las Bienaventuranzas de Q (Lc 6, 20-23). A pesar del "Pero yo os digo..." que lo introduce, no hay ninguna vinculación orgánica con lo que precede; en cambio, se relaciona mejor con lo que sigue ("No juzguéis ...:" Lc 6, 37ss). En Mt tenemos este material, fundamentalmente (e.d., todo, excepto Lc 6, 31), incluido como contenido de las dos últimas "antítesis" del cap. 5; y el RMt ha reordenado este material para lograr dos antítesis (necesarias para llegar a siete): una sobre las represalias (Mt 5, 38-42), y otra, la final, sobre el amor a los enemigos. Para esto, tomó los verss. que figuran en Lc 6, 29-30 y los puso en contraste con la ley del talión (Mt 5, 38-42); y el resto (Lc 6, 27-28.32-36, con particularidades que luego señalaremos), lo puso en contraste con “amarás a tu prójimo y aborrecerás a tu enemigo" (Mt 5, 43-48). Por mucho que se reconozca lo bien logrado que resultó el texto mateano, es imposible no reconocer que Lc reproduce mejor la estructura de Q; pero no significa esto que la fraseología de Lc sea también necesariamente más fiel al texto de Q que la de Mt. Se impone analizar cada caso en forma particular.

Texto. Verss. 27-28. Da la impresión de que Mt 5, 44 ha abreviado el texto, pues a los cuatro imperativos que tenemos en los verss. 27-28 de Lc corresponden los cuatro casos que figuran en los verss. 29-30 de Lc y que (incluso con un añadido) Mt recoge en 5, 39b-42; y parece claro que Mt ha cambiado "calumniar" por "perseguir", al que Mt es tan aficionado sin que Lc lo rehúya (Mt: 6 veces; Mc: 0;

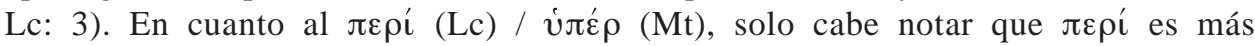
abundante en Lc (45 veces) que en Mt (28 veces), mientras que víć $\rho$ es poco usado en ambos ( 5 y 8 , respectivamente), de lo que parece desprenderse la mayor probabilidad de que Q tuviera úं غ́ $\rho$. 
Verss. 29-30. En el "cuarteto" de Lc se percibe una estructura retórica que aparece deformada en $\mathrm{Mt}$; esa estructura consiste en presentar dos veces la siguiente fórmula: "al que..." seguido de una orden en imperativo, y "del que..." seguido de una prohibición. Estructuras retóricas de este tipo son más hebreas que griegas, y esto juega a favor de la mayor originalidad de la estructura que ofrece Lc, como también, en general, de su fraseología. Sin embargo, en el asunto del manto y de la túnica hay dos cosas que parecen mejor conservadas en $\mathrm{Mt}$ : la presencia de un "pleito judicial" en torno a esto (cosa que está atestiguada en los ambientes judíos), y el orden "túnica-manto" (contra el orden "manto-túnica" de Lc); en este último punto, si no se trata de un juicio, primero se le arrebata a uno el manto (exterior) y después la túnica (interior); pero, en el plano judicial, el manto era inalienable (ver Ex 22, 25-26). Lc, además, parece no haber percibido la importancia del bofetón en la mejilla derecha, con el carácter despectivo que él tiene por ser propinado con el dorso de la mano.

Vers. 31. Este versículo es omitido aquí por Mt, pero es trasladado a 7, 12, donde ocupa un lugar relevante como fin del "cuerpo" central de su Sermón de la Montaña, mediante la mención de "la Ley y los Profetas" con que también lo había comenzado (Mt 5, 17). Y parece que la redacción de Mt, más enfática ( $\pi \alpha ́ v \tau \alpha$ ö $\sigma \alpha$

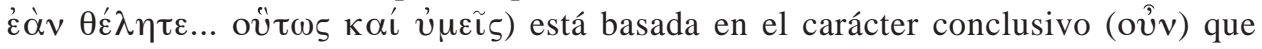
Mt le asigna.

Verss. 32-36. Ante todo hay que señalar que el contenido de Mt 5, 45b aparece muy simplificado en Lc 6, 35b, que Mt vincula directamente estos verss. al contenido de Lc 6, 27-28, que el contenido de Lc 6, 34-35 no aparece en Mt, y que el contenido de Lc 6, 35b (el carácter de "hijos de Dios" de los creyentes) aparece dos veces en el texto mateano: una vez como fundamentación del precepto $(5,45)$ y otra como conclusión del conjunto $(5,48)$.

En los verss. 32-34, Lc nos deja frente a una "cadena" de tres "estrofas" sinonímicas, fenómeno que se repite a menudo en el Sermón de la Montaña mateano y que sin duda alguna pertenece a la transmisión tradicional, pero que aquí Mt ha reducido a una cadena de solo dos estrofas un tanto simplificadas; pero, por otra parte, es claro que Lc introdujo el concepto genérico y no ofensivo de "pecadores" en vez de los "publicanos" y los "gentiles" que Mt no tuvo empacho en conservar, y que, en vez del "saludo a los solos hermanos" de Mt, usó una expresión más genérica ("hacer el bien solo a quienes nos hacen el bien"). Por último, da la impresión que Lc redujo las preguntas diferentes que tenemos en Mt (“paga” y "fuera de lo común”) a la única pregunta “¿qué gracia tenéis...?"

En el vers. 35, el contenido de la primera parte falta en Mt, pero parece, con sus tres miembros (amor, beneficencia, préstamo), que ella es la conclusión de Lc 6 , 32-34, y en ella se puede ver que RLc tenía a la vista el concepto de "paga". El contenido de 35b sobre la filiación divina aparece en Mt como una finalidad y en Lc como una consecuencia, lo que parece más primitivo. En todo caso, la frase "hijos del Altísimo" (Lc) es más primitiva que "vuestro Padre que está en los cielos", típica de la redacción mateana. Pero por lo que toca a que deben imitar sus hijos a Dios, la idea aparece en Lc expresada en términos muy abstractos, a los que se debe preferir los muy concretos que tenemos en Mt, en los cuales, además, cabe señalar la 
presencia de un procedimiento retórico muy hebraico: el quiasmo "malos/buenos" y "justos/injustos".

En el vers. 36 parece seguro que Lc quiso precisar el concepto demasiado amplio de la "perfección de Dios", retenido por Mt, recurriendo al de su "misericordia": y ello con un término griego que jamás se encuentra en la tradición evangélica; y es claro, además, que Mt añadió a "vuestro Padre" el adjetivo "celestial", como también la cláusula "por consiguiente vosotros".

\section{CON LA MISMA MEDIDA \\ Lc 6, 37-38 // Mt 7, 1-2}

Sinopticidad. Entre el contenido de Lc 6, 27-36 y el de esta unidad de tradición, el RMt intercaló, en su Sermón del Monte, todo el cap. 6 (si bien con material también proveniente de Q). El material Q recogido en Lc 6, 37-42 consta de cuatro dichos carentes de unidad de fondo: 6, 37-38; 6, 39; 6, 40; 6, 41-42. La primera unidad de Lc fue conservada por el RMt (Mt 7, 1-2) según el orden de Q, aunque reteniendo solo la idea de "no juzgar"; y al omitir aquí la $2^{\mathrm{a}}$ y la $3^{\mathrm{a}}$ unidad de Q (pasando su contenido a otros contextos), la parábola de la paja y de la viga le quedó como una ilustración del "no juzgar". De aquí viene la necesidad de abordar separadamente las cuatro unidades Q contenidas en Lc 6, 37-42.

Texto. Comencemos señalando que tenemos aquí un "traslapo" parcial con Mc 4, 24b.

En este trozo la mano de RMt se percibe en cuatro puntos. a) el cambio de "y no" en "para no", ya que la "parataxis" que tenemos en Lc es más semítica que la "sintaxis" que ofrece el texto mateano; b) la omisión de Lc 6, 37b-38a, ya que, en general, el RLc tiende a abreviar el estilo acumulativo de los dichos de Jesús, por lo que es impensable que aquí haya recargado el texto escueto de Mt; c) el añadido de la frase "con el juicio con que juzguéis seréis juzgados", debido al propósito de destacar la idea de "no juzgar", y llevado a cabo "calcando" la frase de Q (también retenida en Mt) "con la medida con que midiereis se os medirá"; d) la fraseología del principio de "la misma medida", homologada con la de Mc 4, 24b, pero sin incluir la idea de la "yapa".

La mano de RLc puede reconocerse en dos puntos: a) el añadido de la frase "y no condenéis y no seréis condenados", que no hace más que explicitar el sentido real de "no juzgar / no ser juzgados"; en favor del carácter redaccional del "no condenar" puede señalarse el carácter normalmente "ternario" de las exhortaciones de

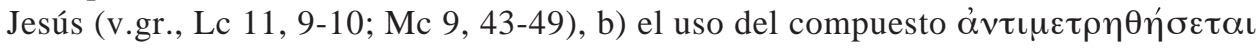
en vez del simple $\mu \varepsilon \tau \rho \eta \theta \eta ́ \sigma \varepsilon \tau \alpha \iota$, que acentúa la idea lucana de la "compensación" (v.gr., Lc 6, 24-26; 16, 19-25); por lo demás el uso de ávนí para crear verbos compuestos se encuentra 13 veces en Lc y solo 2 en Mt.

La cláusula sobre la "medida buena, apretada, sacudida, rebosante" (Lc 6, 38), ausente en Mt, es menester confesar que no calza bien con el principio de "la misma medida". Parece ser que esta fusión de dos dichos ya estaba en Q, como en el caso de QLc 12, 25, con el criterio de encontrarse en ambos textos un mismo término (en un caso "afán", y en el otro, "medida"). 


\section{CIEGO GUÍA DE CIEGO}

Lc 6, 39 // Mt 15, 14

El RMt utilizó este dicho en el contexto de una polémica antifarisaica de Jesús, introducida por él en el trozo marcano sobre lo puro y lo impuro (Mt 15, 12-14) y en la que este dicho aparece como principio que justifica la segunda frase puesta en boca de Jesús: "Dejadlos: son ciegos que guían a otros ciegos": frase sin duda creada por el RMt a partir del dicho tomado de Q que aquí tenemos.

Pocas dudas pueden caber sobre la mejor conservación del dicho en Lc: no hay nada que se oponga a la pertenencia a Q de la introducción "Y les dijo una parábola", y hay mucho a favor de la genuinidad de la doble interrogación que tenemos en su texto, ya que corresponde al estilo de Jesús (ver, v.gr., Mc 4, 30; QLc 13, 18: es interesante ver el texto mateano correspondiente).

Hay un punto de poca importancia, pero difícil de zanjar: si el uso del verbo compuesto (Lc) o el del verbo simple (Mt), para expresar la idea de "caer" en un hoyo, es el que viene de Q. Debe tomarse en cuenta que en Mt 12, $11 / / \mathrm{Lc} 14$, 5, en un contexto diferente, Mt usa el verbo compuesto con el mismo complemento que en nuestro texto ("en un hoyo"), mientras que Lc tiene el verbo simple con un complemento distinto ("en un pozo"). Me parece, personalmente, más verosímil que Q trajera aquí el verbo simple, pues no se ve por qué Mt iba a corregir el uso del verbo compuesto que en otro texto él iba a introducir o a mantener, siendo de notar que en Lc el otro uso de este verbo compuesto está en un trozo no perteneciente a $\mathrm{Q}$ (Lc 10, 36).

\section{EL LÍMITE DEL DISCÍPULO}

Lc 6, 40 // Mt 10, 24-25

Comencemos señalando un "traslapo" parcial con Jn 13, 16 (retomado en Jn $15,20)$.

El hecho más notorio es que Mt y Jn comparten la relación "esclavo-amo", que Lc omite, y que ambos le añaden a esta relación una paralela: Mt, la relación "discípulo-maestro", y Jn, la relación "enviado-mitente"; Mt sitúa la suya antes de "esclavo-amo", y Jn, la suya, después.

Por otra parte, el RMt sitúa este dicho en su $2^{\circ}$ gran discurso (el de la misión), a propósito de las dificultades que deberán enfrentar los discípulos enviados por Jesús, y que resultan lógicas si al "dueño de casa" lo califican de Beelzebul. Jn, a su vez, recurre al dicho a propósito de la acción "servil" realizada por el "Señor" Jesús. Se ve, entonces, que tanto Mt como Jn han visto aludida en el dicho la relación de los fieles con Jesús: relación "esclavo-amo" matizada con un añadido más "aceptable": el de la relación "discípulo-maestro" o el de la relación "enviado-mitente".

Así las cosas, cabe suponer que hubo una forma de la tradición que simplemente cambió la relación "esclavo-amo" en la relación "discípulo-maestro": forma de la tradición que sería la de Q conservada por Lc; pero la forma primaria de la tradición no desapareció, como consta por el texto de Jn, y podría haber sido conocida por el RMt todavía por vía oral. El RMt la habría redactado calcándola sobre la que le 
ofrecía Q, pese a que el destino del "esclavo" no es llegar a ser "como su amo" de una manera análoga a la que lleva al "discípulo" a ser "como su maestro". Dentro de esta hipótesis, cabe todavía señalar que la redacción de la segunda parte del dicho parece secundaria en Mt, por ser mucho más líquida que la de Lc para llegar al "como su maestro". El uso del $\pi \tilde{\alpha} \varsigma$ como sustantivo-sujeto se encuentra en Mc 9, 49

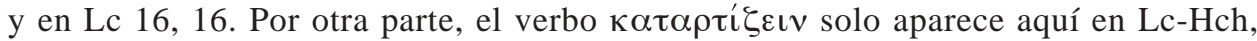
lo que también disuade de pensar que estamos ante una expresión debida al RLc.

\section{LA MOTA Y LA VIGA EN EL OJO \\ Lc 6, 41-42 // Mt 7, 3-5}

Ya dijimos más arriba que el RMt vio esta pequeña parábola como una ilustración del mal que hay en el "juzgar" (= condenar).

El grado de correspondencia verbal que ofrecen Mt y Lc en este caso es altísimo. Solo cabe señalar lo siguiente:

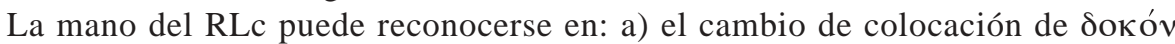

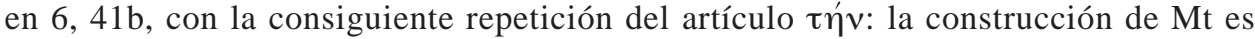
más elegante pero menos líquida, por lo que resulta inimaginable ver al RMt introduciendo este giro en vez del texto más llano que aparece en Lc; b) el cambio de

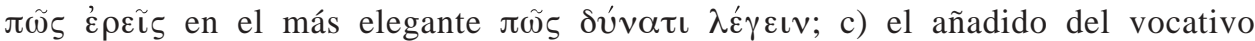

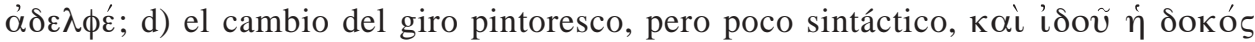

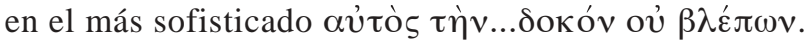

La mano del RMt, en cambio, solo es reconocible en dos casos: a) el uso de $\sigma \tilde{\omega}$ ó $\phi \theta \alpha \lambda \mu \tilde{\omega}$, ya que es en Mt donde más a menudo se encuentra esta forma; b) la

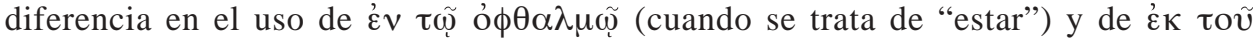
ó $\phi \theta \alpha \lambda \mu о \tilde{v}$ (cuando se trata de "sacar"), mientras que en Lc aparece las dos veces $\varepsilon v$ $\tau \tilde{\omega}$ junto con el verbo "sacar".

Me parece imposible determinar qué orden es más original: si el de Lc 6, 42b o

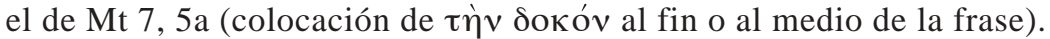

\section{EL ÁRBOL JUZGADO POR SU FRUTO \\ Lc 6, 43-44 // Mt 7, 16-18}

Hay que comenzar señalando el carácter obviamente redaccional de Mt 7, 15, como también de Mt 7, 19-20; es asimismo altamente probable que lo sea su vers. 17 (que no tiene paralelo en Lc). En cuanto al orden de los verss. (Mt 7, 16 corresponde a Lc 6, 44, y, en cambio, Mt 7, 18 corresponde a Lc 6, 43), parece claro que la colocación de Mt 7, 16 se debe a la "personalización" del dicho sobre los falsos profetas, buscada por el RMt en el vers. 16 ("los reconoceréis", dicho de ellos, en vez de "se conoce", dicho de cualquier árbol, como aparece en Lc): personalización hecha más fácil gracias al verbo "conocer" que aparecía en el vers. 44 de QLc, y que era indispensable para vincular todo este dicho de Q con el vers. 15 de Mt. Nos parece claro, por consiguiente, que el dicho de Q ha sido mejor conservado en general por Lc, siendo particularmente claras las modifica- 
ciones introducidas por el RMt en su vers. 16 para hacerlo coherente con lo dicho en el vers. 15.

Dentro de esta prioridad evidente del texto lucano respecto del mateano, cabe señalar algunos casos en que se pueden reconocer rasgos característicos sea de la redacción mateana sea de la lucana. Como rasgos típicos de RLc cabe señalar los siguientes: a) el $\gamma \alpha \dot{\rho}$ de los verss. 43 y 44, al que es mucho más aficionado Mt que

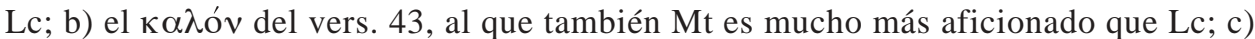

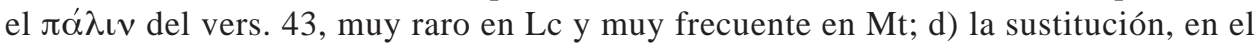
vers. 44, de la forma interrogativa de Mt 7, 16, característica de Jesús, por una forma asertiva; e) la introducción de un segundo verbo al final del vers. 44; f) el cambio, en el vers. 44, de $\tau \rho$ íßo tomado por Lc de Mc en Lc 20, 37 y usado dos veces en Hch (7, 30.35).

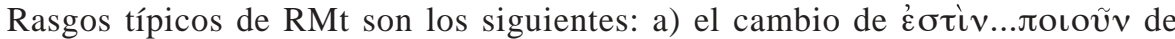

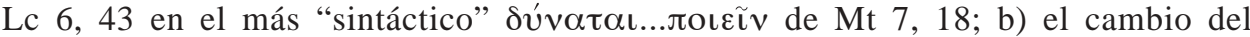

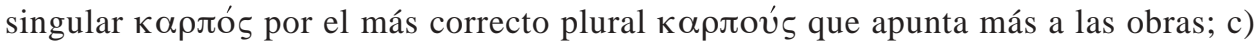

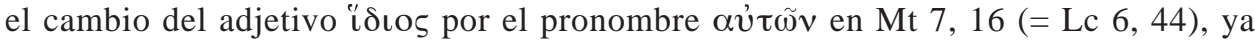
que es Mt quien hace más uso de í̇ıs.

Parece imposible discernir entre variantes menores que se encuentran en cerca de una media docena de casos. Hemos optado por tomar siempre el texto lucano.

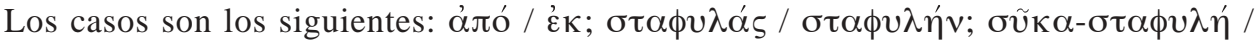
$\sigma \tau \alpha \phi v \lambda \alpha \varsigma_{-}-\sigma \tilde{\kappa} \kappa \alpha$. ¿Y con qué se vincula la uva?, ¿con los espinos (Mt) o con la zarza (Lc)? Y los higos, ¿con los espinos (Lc) o con los cardos (Mt)?

El trozo Lc 6, 43-44 tiene en Mt, no solo el paralelo ya mencionado de 7, 16.18, sino también el de 12, 33. El centro de interés de este otro texto mateano es la necesidad de situar en la calidad del ser la raíz de la del actuar, pero con el corolario de considerar la calidad del actuar como revelación de la calidad del ser. Da toda la impresión de que Mt 12, 33 se basa en una forma de comprender el logion de Jesús distinta de la de Q (cuyo sentido parece bien conservado en Lc); y todo sugiere que Mt 12, 33 nos conserva una formulación o estructura más antigua que la de $\mathrm{Q}, \mathrm{y}$ análoga, v.gr., a la de Mt, 6, 24.

\section{EL CORAZÓN, FUENTE DEL BIEN Y DEL MAL Lc 6, 45 // Mt 12,34b-35}

Contexto y orden. No hay duda de que el RMt tuvo razón al separar lo que en Lc aparece unido: Lc 6, 45 no debe entenderse en función del tema abordado en 6, 43-44; pero hay que reconocer que el contexto que el dicho tiene en Mt (a pesar del $\gamma \alpha \dot{\rho} \rho$ que lo introduce) tampoco arroja mucha luz para su comprensión.

El orden original de las dos partes del dicho parece conservado, a pesar de la oscuridad de la relación con lo precedente, en Lc; y parece alterado por el RMt para darle a 34b un sentido más concreto en función del contenido de Mt 12, 36a.

Texto. Parece claro que fue el RLc quien introdujo mayores cambios en el texto de Q. Es claro que se le deben atribuir los siguientes elementos de su texto: a)

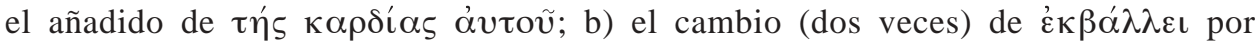




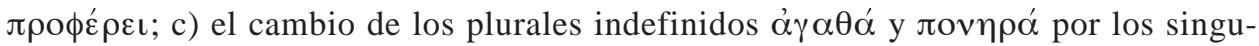

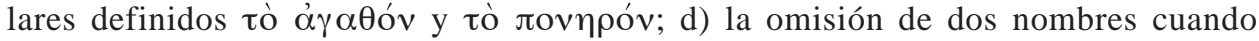

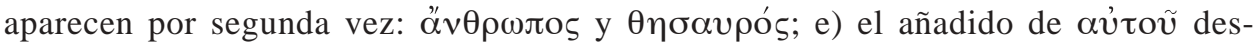
pués de $\tau$ ò $\sigma \tau o ́ \mu \alpha$.

A RMt, en cambio, solo se le puede atribuir un añadido: el del artículo antes de

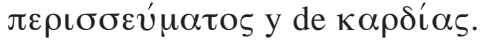

\section{DECIR “SEÑOR, SEÑOR”, Y NO HACER \\ Lc 6, 46 // Mt 7, 21}

En ambos evangelistas este dicho se encuentra antes de la parábola final del Sermón (del monte en Mt, y de la llanura en Lc): en Lc, inmediatamente antes; en Mt, separado por un logion (7, 22-23) que comparte con el nuestro el rechazo a la mera invocación de Jesús como "Señor, Señor". Pero parece obvio que no hay entre el contenido del presente versículo (ni de su añadido en Mt) ninguna relación orgánica con la mencionada parábola, y que -por tanto- nuestro dicho constituye un logion autónomo que debe estudiarse solo por su contenido propio.

No habría, al parecer, nada en el texto de Mt 7, 21 que obligara a atribuírselo a Q, excepto el contraste entre llamar a Jesús "Señor, Señor" y no "hacer" lo que corresponde (con gran diferencia de vocabulario y de construcción). Pero está la ubicación del dicho en ambos evangelios hacia el final del gran Discurso. Admitido el hecho del uso por ambos evangelistas de un material proveniente de Q, es muy fácil reconocer en el texto mateano algunos elementos característicos del RMt: ante todo, dos expresiones típicas de su estilo: "entrar en el reino de los cielos" y "la voluntad de mi Padre que está en los cielos"; también debe tomarse en cuenta la opción estructural del RMt de concluir su gran discurso inicial en $3^{\mathrm{a}}$ persona tal como lo había comenzado (Mt 5, 3-10), lo que explica los cambios de persona que se constatan en Mt 7, 21 (comparado con Lc 6, 46), en Mt 7, 22 (comparado con Lc 13, 26-27), y en Mt 7, 24 (comparado con Lc 6, 47). Pero, por otra parte, en Lc 6, 46 se encuentra el verbo $\kappa \alpha \lambda \varepsilon \tilde{\imath} v$ en vez del $\lambda \varepsilon \dot{\varepsilon} \gamma \varepsilon \nu$ de Mt, lo que sugiere la intervención del RLc, ya que el primer verbo se encuentra 43 veces en Lc y solo 26 veces en Mt.

\section{CONSTRUIR SOBRE ROCA O SOBRE ARENA LC 6, 47-49 // MT 7, 24-27}

Contexto. En ambos evangelios este trozo constituye el fin del "discurso inaugural" de Jesús. El tiene como tema la necesidad de dar cumplimiento efectivo a su enseñanza. Las dos diferencias más perceptibles son: a) que el texto mateano consta de dos partes opuestas y simétricas en su estructura, mientras que el texto lucano ofrece también dos partes opuestas pero no simétricas; y b) que en Lc se mantiene el uso de la $2^{a}$ persona (ver vers. 47), mientras que en Mt solo aparece la $3^{\mathrm{a}}$ persona. 
Texto. En términos generales se puede tener como seguro que la estructura paralela de Mt es la original, pues el RLc no es aficionado a esas estructuras estrictamente paralelas frecuentes en la retórica hebrea.

La mano del RMt puede reconocerse en Mt 7, 24 en: a) el añadido de oúv, y el uso del pronombre indefinido + indicativo en vez del participio con artículo (esto se

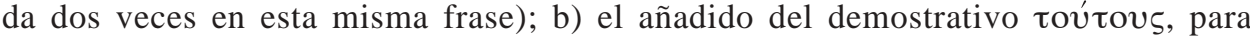
aplicar específicamente al Sermón de la Montaña el dicho que se va a citar; c) el uso del verbo ómoı $\theta \dot{\gamma} \sigma \varepsilon \tau \alpha \iota$, por el recurso, aquí y en vers.26, a la forma verbal (8 veces en Mt contra solo 3 en Lc), y también al futuro, que destaca el carácter escatológico del suceso; d) el cambio de $\alpha ้ v \theta \rho \omega \pi$ s por $\alpha \dot{v} \eta \dot{\rho} \rho$, pues si el original fuera este último, Lc (que lo usa 27 veces contra 8 de Mt) lo habría conservado; e)

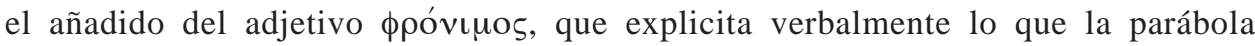
expresa con una acción; f) la explicitación de que se trata de "su casa" (artículo y posesivo), innecesaria. En Mt 7, 26 la redacción mateana puede reconocerse en el

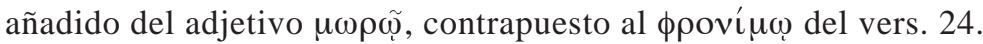

La mano del RLc puede reconocerse en Lc 6, 47 en el añadido ó દ’ $\rho \xi o ́ \mu \varepsilon v o \varsigma$ $\pi \rho o ́ \varsigma ~ \mu \varepsilon \kappa \alpha i$, que desequilibra la simetría de las dos partes de la parábola. En Lc 6, 48

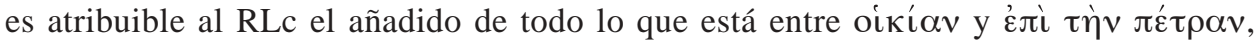
por no corresponder a lo que se hacía en Palestina, y también la mención de "la crecida del río", que tampoco corresponde a la situación de Palestina. En Lc 6, 49 son atribuibles al RLc: a) la introducción del aoristo en los verbos "oír" y "hacer"; b) el

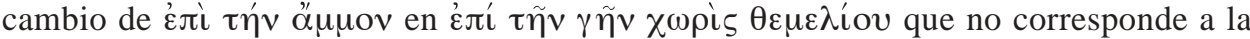
situación de Palestina; c) la reducción del proceso descrito en Mt 7, 27, desde "cayó la lluvia" hasta "batieron contra aquella casa" al simple "sobre la que se desbordó el río": al RLc no le gustan las repeticiones propias de las "series de estrofas" tan

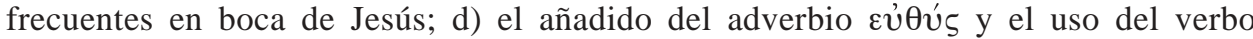

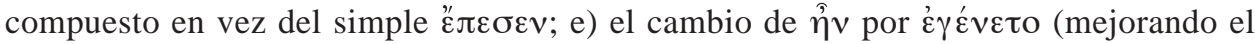
estilo) y de $\pi \tau \tilde{\omega} \sigma \iota \varsigma$ por $\dot{\rho} \tilde{\gamma} \gamma \mu \alpha$, para adecuarse al uso de $\pi \rho \sigma^{\prime} \varepsilon \rho \eta \chi \varepsilon v$ en la frase anterior (en un papiro se usa esta palabra para referirse a la ruptura de un dique del Nilo); f) el uso aquí de "la casa aquella" que había omitido en la cláusula precedente.

\section{DESPLAZAMIENTO A CAFARNAÚM \\ Lc 7, $1 / /$ Mt 7, 28a}

En ambos evangelios esta frase se encuentra inmediatamente después del "Discurso inaugural". Es fácil observar que no hay ninguna correspondencia verbal entre el texto de uno y otro, pese a su semejanza de contenido y de relación con el gran "Discurso". Tampoco hay correspondencia o semejanza entre lo que cada uno pone a continuación de esta frase, como es fácil comprobarlo.

Parece seguro que la fraseología del texto mateano es debida al RMt. En efecto, este recurrió a una formulación inspirada en Dt 32, 45 (y ver 31, 24) que va a repetir con pequeñas variaciones al final también de los otros cuatro grandes discursos de su evangelio (Mt 11, 1; 13, 53; 19, 1; 26, 1): procedimiento obviamente ordenado a atribuirle a Jesús la autoría de cinco discursos, correspondientes a los cinco libros del Pentateuco mosaico. 
No hay ningún indicio que permita atribuir algunos elementos de Lc 7,1a al RLc o negárselos a Q.

\section{EL SIERVO DEL CENTURIÓN \\ Lc 7, 6b-9 // Mt 8, 8-10}

Es notorio que el texto de Lc anterior a 7, 6b es muy diferente del que se encuentra en Mt 8, 5-7, como también, que lo es Lc 7, 10 de Mt 8, 13. Apenas hay coincidencia en "entrar a Cafarnaúm", "centurión" y "rogar" ( $\pi \alpha \rho \alpha \kappa \alpha \lambda$ cív). La diferencia mayor es que en Lc el centurión no va personalmente donde Jesús (como en Mt), sino que le envía unos emisarios. En cambio, la fraseología de Mt 8, 8-10 coincide en gran medida con la de Lc 7, 6b-9.

La explicación de este estado de las cosas sugiere que Q solo contenía las palabras del centurión y la respuesta de Jesús, quedando la descripción del hecho confiada a la tradición oral. El texto de Q, entonces, solo puede buscarse en Mt 8, 8-10 y Lc 7, 6b-9. Es más probable, a mi juicio, que el relato de Lc esté más cerca de lo ocurrido.

La mano del RLc, en 6b, se percibe en el cambio de "̌ $\phi \eta$ por $\lambda \dot{\varepsilon} \gamma \omega \nu \alpha \hat{v} \tau \tilde{\omega}$ y en

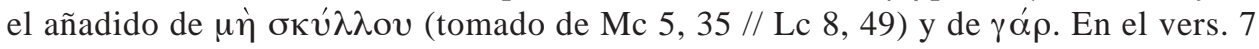
es claro que el comienzo depende de la versión lucana de lo sucedido, y parece claro que RLc sustituye el futuro pasivo por el más orgánico imperativo pasivo i $\alpha \theta \eta j \tau \omega$. En el vers. 8 el RLc parece haber añadido el participio $\tau \alpha \sigma \sigma o ́ \mu \varepsilon v o \varsigma$ para hacer más explícita la expresión muy gráfica conservada en Mt. En el vers. 9 también parecen

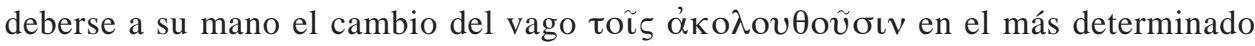

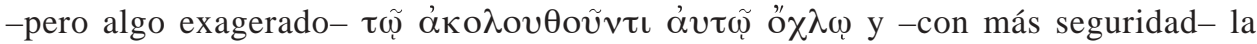

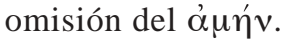

La mano del RMt, en el vers. 8 de su texto, puede reconocerse en el añadido de uóvov (el que es bastante más frecuente en Mt que en los otros sinópticos: Mt, 7 veces; Mc, 2 ; Lc, 1). En el vers. 10, la redacción (con el $\pi \alpha \rho$ ' oủ $\delta \varepsilon v i$, ) parece deberse al RMt, pues es claro que obedece al deseo de "personalizar" un poco el aserto de Jesús como aparece en Lc. Es ligeramente más probable, a mi juicio, que la frase "no soy digno..." haya sido alterada, en cuanto a su orden, por el RLc: en la primera mitad, debido a la introducción del $\gamma \alpha \rho$, y en la segunda (colocación del $\mu o v)$, a fin de tener una sintaxis menos sofisticada.

\section{LA PREGUNTA DEL BAUTISTA \\ Lc 7, 18-23 // Mt 11, 2-6}

Contexto. Después de haber recurrido a Q para obtener, con la curación del siervo del centurión, el segundo de la serie de milagros antepuestos al "Discurso de misión" (Mt 10), el RMt vuelve a aquella fuente siguiendo su orden desde Mt 11, 2 a 11, 19 (// Lc 7, 18-35): conjunto que tiene como tema a Juan Bautista. Este conjunto incluye tres unidades: Lc 7, 18-23.24-28.31-35. Como se ve, de Lc 7, 2930 no se puede determinar si figuraba en $\mathrm{Q}$ y fue omitido por el RMt, o si fue añadido por el Rlc. 
Texto. Como en la unidad anterior, lo narrativo aparece con muchas variaciones en ambos textos, teniendo en común solo el "envío", por parte de "Juan" y a través de "discípulos suyos", de un recado a Jesús. La diferencia mayor en lo narrativo está en los verss. 20-21 de Lc 7, cuyo contenido todo el mundo se lo atribuye al RLc. El texto de Q, pues, solo puede ser buscado, dentro de Lc, en la última línea de 7, 19 y en los verss. 22-23. Pero en este núcleo la concordancia textual es casi total:

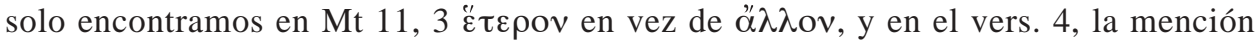

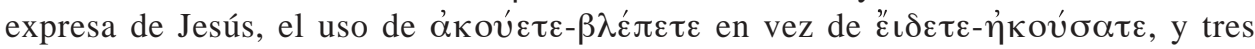
omisiones de $\kappa \alpha i$, por parte de Lc.

En el primer caso, sin duda Q traía "̌ $\tau \varepsilon \rho o s$, pero el RLc, a pesar de lo mucho

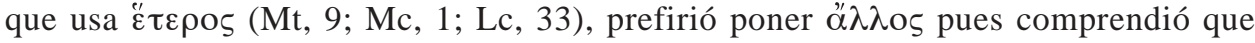
no era bueno permitir que pudiera entenderse que había para el Bautista una alternativa precisa ("el otro", entre dos) y que era mejor dejar en claro que se trataba de una opción "abierta" ("otro", entre muchos). En la "Koiné" la diferencia entre

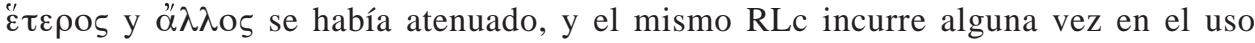

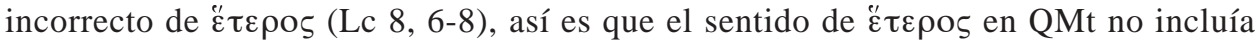
necesariamente la idea de una alternativa precisa. En cuanto a la mención expresa de "Jesús", parece deberse a RMt. Y en cuanto a la tercera diferencia, referente al uso de los tiempos verbales, parece claro que los aoristos lucanos dependen de lo dicho en Lc 7, 21, y son por tanto RLc; por la misma razón se debe considerar debida al RLc la prioridad dada al "ver"; también se debe reconocer que, si los verbos de Q

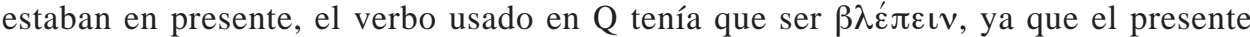
indicativo de ó $\rho \tilde{\alpha} v$ no se usa jamás ni en Mc ni en Q. Finalmente, por lo que toca a las omisiones del $\kappa \alpha i$ en Lc, es también bastante claro que se deben al redactor lucano, quien no advirtió la estructura literaria del trozo, compuesto por tres parejas

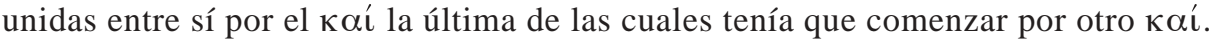

\section{GRANDEZA Y LUGAR DEL BAUTISTA \\ Lc 7, 24-28 // Mt 11, 2-6}

De nuevo el enlace narrativo está redactado de manera diferente en cada uno de los dos textos. No obstante, ambos subrayan la relación entre esta perícopa y la precedente, como también recurren a un genitivo absoluto. La fraseología de Lc parece más "redaccional" que la de Mt.

La mano del RLc se echa de ver sobre todo en el vers. 25, donde es claro que

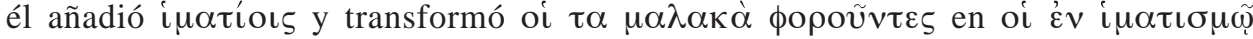

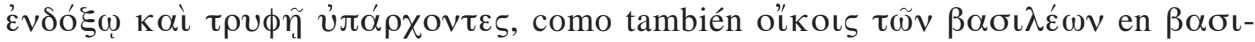

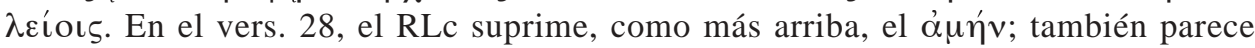
que se debe a él la redacción de la primera parte del vers. 28, porque el giro oúk $\dot{\varepsilon} \gamma \eta \dot{\gamma} \gamma \varepsilon \rho \tau \alpha \iota$ '́ $v$... de Mt es muy semítico, y porque la construcción de Lc soslaya el fuerte contraste $\mu \varepsilon i ́ \zeta \omega v-\mu \iota \kappa \rho o ́ \tau \varepsilon \rho o \varsigma$ que ofrece Mt y que le da su fuerza al dicho.

La mano del RMt puede reconocerse en la introducción del nombre "Jesús" en el vers. 7, y en la del apelativo "el Bautista" en el vers. 11. Y de todos modos a él se le debe la habitual sustitución, en el mismo vers., de "Reino de Dios" por "Reino de los cielos". 


\section{UNA GENERACIÓN DE NIÑOS TAIMADOS}

\section{Lc 7, 31-35 // Mt 11, 15-19}

Ya dijimos más arriba $\left(\mathrm{N}^{\circ} 16\right)$ que no se puede llegar a ninguna certeza acerca de si fue el RMt el que omitió de Q los versículos que aparecen en Lc 7, 29-39, o si, por el contrario, fue el RLc quien los introdujo en la trama de Q.

La introducción de Jesús al dicho mismo parece mejor conservada, con su estructura de doble pregunta, en Lc: Mt la omite aquí como en otros casos; en cambio, la fraseología parece mejor conservada en Mt: el RLc quiso evitar el paso del singular "esta generación" al plural "niños", por lo que cambió "esta generación" por "los hombres de esta generación", con los plurales correspondientes en los

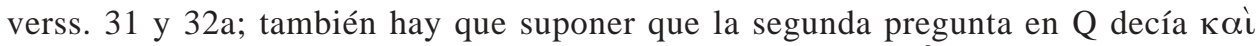

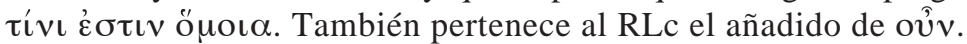

En la parábola misma y su aplicación se percibe la mano del RLc en muchos casos. En el vers. 32: a) la introducción del giro manierístico de poner el artículo antes del adjetivo que afecta a un sustantivo indefinido; b) el cambio del plural definido ("en las plazas") por un singular indefinido ("en una plaza"); c) una construcción más "sintáctica" de toda la primera parte del vers., que disimula un poco el uso del plural en construcciones verbales cuyo sujeto es un plural neutro; d) el

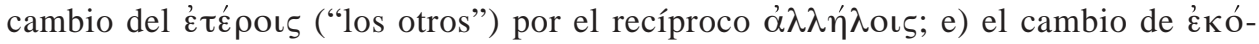
$\psi \alpha \sigma \theta \varepsilon$ por el muy lucano $\varepsilon ́ \kappa \lambda \alpha ́ v \sigma \varepsilon \tau \varepsilon$. En el vers. 33 (y también en el 34), el cambio del aoristo $\hat{\eta} \lambda \theta \varepsilon v$ por el perfecto $\varepsilon \lambda \eta \dot{\eta} \lambda v \theta \varepsilon v$ que es más correcto. En el vers

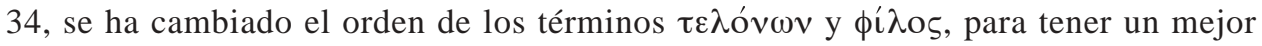
orden para los complementos de фí̀os.

En cambio, la mano del RMt solo se puede descubrir con seguridad en la simplificación del oscuro final que tenemos en Lc, por el cambio de $\tau \dot{\varepsilon} \kappa \nu \omega \nu$ en $\varepsilon \rho \gamma \omega v$ y la eliminación de $\pi \alpha ́ v \tau \omega v$.

\section{EXIGENCIAS DEL SEGUIMIENTO DE JESÚS \\ Lc 9, 57-60 // Mt 8, 19-20}

Contexto. En Lc, entre 7, 35 y 9, 57, se sitúan un par de trozos propios de Lc (7, 36-50; 8, 1-3) y algún material entresacado de $\operatorname{Mc}(8,4$ - 9, 50). Entre el último trozo de origen marcano y el que ahora estamos abordando se sitúa el trozo propio sobre las aldeas samaritanas $(9,51-56)$, y vienen después, hasta 18, 14, unidades no marcanas, a veces de Q y a veces propias de Lc.

El RMt sitúa esta unidad como una de las dos que versan sobre la "vocación" y que él intercaló entre los diez milagros que llenan los capp. 8, 2 - 10, 34, para distribuirlos en tres grupos (uno de cuatro, y dos de tres). Una tercera unidad sobre la "vocación" (el episodio de Leví) es situada por el RMt en 9, 9-17.

Texto. Hay dos diferencias considerables entre Mt y Lc: la más visible es que en Lc hay tres episodios, y en Mt, solo dos; la otra es que en Mt el diálogo no lo inicia nunca Jesús, mientras que en el segundo episodio de Lc es Jesús quien lo inicia. Las "reglas del juego" nos obligan a no tomar en cuenta a Lc 9, 61-62, 
aunque no hay razones decisivas para sostener que no figuraba en $\mathrm{Q}$, si bien cabe señalar que el tercer episodio no añade nada sustancialmente diferente al segundo. ¿Se tratará de otra tradición (L) del $2^{\circ}$ dicho?

Como en otros casos, el marco narrativo (e.d., el comienzo de Lc 9, 57 y de Mt $8,19)$ parece dejado a la libre redacción de cada cual: solo los dichos tienen fijeza, sin que importe mucho quiénes, dónde o cuándo interpelaron a Jesús. En el primer

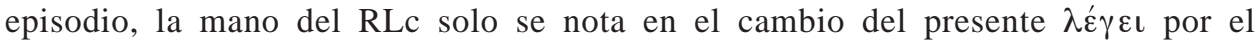
aoristo $\varepsilon \hat{\imath} \pi \varepsilon v$; en cambio, la del RMt se reconoce en el vocativo $\delta \iota \delta \alpha ́ \sigma \kappa \alpha \lambda \varepsilon$. En el segundo episodio parece que es el RMt quien le sigue atribuyendo la iniciativa a alguien que no es Jesús; en efecto, resulta extraño que se pongan las palabras de Q en labios de "otro de los discípulos de Jesús": palabras en las que el $\pi \rho \tilde{\omega} \tau o v$ no tiene una función clara; y resulta extraño también que el verbo clave ( $\alpha \kappa o \lambda \circ v \theta \varepsilon \tilde{v} v$ ) aparezca solo al fin. Parece, pues, que Q presentaba dos casos: el de uno que se ofrece y el de otro que es llamado, para poner de relieve en ambos el radicalismo del seguimiento de Jesús. Pensamos, pues, que la fraseología de Lc corresponde a la de Q. Pero la mano del RLc se deja ver en dos puntos: en la sustitución de la "para-

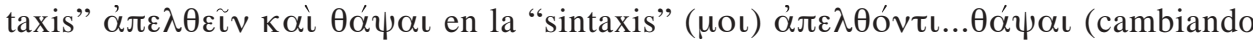

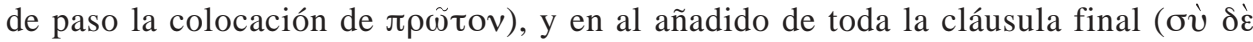
$\alpha \dot{\pi} \varepsilon \lambda \theta \dot{\omega} v \ldots)$.

\section{SIEGA GRANDE, OBREROS POCOS}

Lc 10, 2 // Mt 9, 37-38

En ambos evangelios este dicho está vinculado con las instrucciones dadas por Jesús a sus discípulos al enviarlos como "emisarios" suyos. Pero en Lc forma parte de las mismas instrucciones, mientras que en Mt está separado por 10, 1-5 y por algunas instrucciones que no aparecen en Lc. Lo más probable es que Lc 10, 2-12 constituyera una sola unidad en Q, y que su separación sea debida al Rmt.

La única diferencia entre los dos textos está en el orden de los términos ć $\rho \gamma \alpha ́ \tau \alpha \varsigma$ y

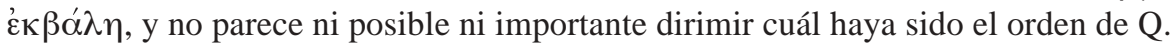

\section{CONSIGNAS PARA LA MISIÓN}

Lc 10, 3-12 // Mt 10, 7-16

Orden. Lo más notorio es que el comienzo de Lc (vers. 3) aparece al final de Mt (vers. 16), donde introduce la sección de las instrucciones misionales, destinada a subrayar sus dificultades (Mt 10, 17-31); y también, que el mensaje sobre la cercanía del Reino aparece al comienzo y con mucha riqueza en Mt (verss. 7-8) y solo hacia el final y con poco relieve en Lc (vers. 9; aunque ver el vers. 11b). El texto de Lc tiene un orden bastante claro: después del envío propiamente dicho (vers. 3), se describe el equipamiento (vers. 4), y luego se aborda primero el tema de la llegada a una casa con el don de la paz (verss. 5-7) y después el de la llegada a una ciudad con el anuncio del Reino de Dios (verss.8-12) con su doble eventualidad de acogida (verss. 8-9) o de rechazo (verss. 10-12). En cambio, el texto de Mt (que 
ya ha situado el envío en los verss. 5-6) nos ofrece el contenido de la comisión como mensaje y actuación (verss.7-8), el equipamiento (verss. 9-10), las normas para actuar en caso de acogida (verss 11-13a) y de rechazo (verss. 13b-15), sin separar "casa" de "ciudad". El grado mayor de concordancia en cuanto a fraseología y ubicación se tiene en Mt 10, 15 // Lc 10, 12.

Texto. Creo que el RLc abrevió drásticamente lo del equipamiento: todo lo del dinero lo redujo a "no llevar bolsa" (cabe señalar al respecto dos hechos muy significativos: el sustantivo $\beta \alpha \lambda \lambda \alpha \dot{v} \tau$ เov es exclusivamente lucano, y el verbo $\beta \alpha \sigma \tau \alpha \dot{\zeta} \varepsilon \iota v$ lo es predominantemente), y lo del vestido, a no llevar ni "alforjas" ni "sandalias", dejando de lado las "dos túnicas" y el "bastón"; pero juntando el "camino" (para el que se necesita alforja) y el "saludar" (que corresponde a la llegada a una casa), creó el "no saludar a nadie en el camino".

Creo que el RMt desarrolló considerablemente el contenido que tenemos en Lc 10, 9, invirtiendo el orden de la "curación de los enfermos" y de la "cercanía del Reino", enriqueciendo el "decidles" (convertido en "al ir, proclamad diciendo") y añadiendo otras acciones milagrosas a la "curación de los enfermos"; este vers. 8 de Mt está ordenado a destacar que los discípulos son enviados a hacer lo mismo que había hecho ya Jesús.: "evangelizar el Reino de Dios".

Y creo, enseguida, que el RLc ordenó lo que tenemos en Mt 10, 11-14, eliminando el asunto del buscar en la ciudad o aldea a alguien digno para alojar en su casa y cómo actuar en ella (Mt 10, 11b-13), y distinguiendo dos situaciones: la llegada a una casa (Lc 10,5-7), donde incluye la idea de la "paz", y -basándose en la idea del "sustento"- la de comer y beber como "jornal del que es digno el obrero": distinción cuya artificialidad resulta bastante clara.

Creo, finalmente, que resulta imposible reconstruir con serias probabilidades la fraseología concreta de Q en lo que toca a los verss. 11-14 de Mt y sus paralelos en Lc 10, 5-8.10-11. Solo cabe señalar que en Q ciertamente se usaron las siguientes expresiones: "cualquiera", "ciudad", "casa", "entrar/salir", "acoger" y no hacerlo, "vuestra paz", "digno es el obrero de su (sustento)", y "el polvo de los pies".

En el versículo más semejante se nota la mano del RMt en el cambio de "aquel día" por "el día del juicio" (expresión que en los evangelios solo aparece

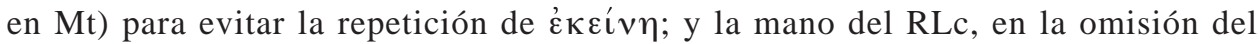

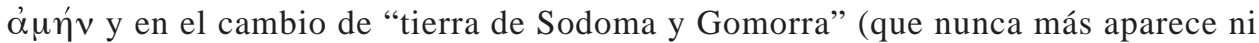
en Mt ni en Lc) por "Sodoma" (que es la única forma usada, fuera de aquí, no solo por Lc sino también por Mt, lo que hace inverosímil que el RMt la haya introducido aquí).

\section{AYES CONTRA LAS CIUDADES DE GALILEA Lc 10, 13-15 // Mt 11, 21-23}

En Lc viene esta unidad inmediatamente después de la perícopa precedente. En Mt el dicho está unido, mediante un versículo redaccional ("entonces comenzó..."), a la perícopa sobre el rechazo generalizado que encontraron Juan Bautista y el Hijo del hombre (Mt 11, 16-19). 
Las diferencias entre Mt y Lc son apenas cinco: 1. La mano del RMt se reconoce en el $\lambda \varepsilon^{\prime} \gamma \omega$ v́$\mu \tilde{v} v$, debido al contexto que se le ha dado al dicho, y en el cambio de "el juicio" por su fórmula "día de juicio". 2. Los otros tres casos son imposibles de dirimir. El caso más difícil es el que toca al uso del aoristo medio (Mt) o pasivo (Lc) en la primera mitad del primer versículo; en efecto, el uso del aoristo pasivo de yívoual es más frecuente en Mt que en Lc; por consiguiente, no resulta explicable que el RMt haya recurrido al aoristo medio; pero, por otra parte, no resulta explicable tampoco que el RLc haya dejado de lado el uso más correcto de la voz media para introducir un giro tardío y reprochado por los puristas. La presencia (Lc) o ausencia (Mt) del participio к $\alpha \theta \eta$ jevvo puede explicarse igualmente como un añadido de RMt o como una omisión del RLc; y de la presencia (Lc) o ausencia (Mt) del artículo antes de ö́ov puede decirse lo mismo.

\section{ACOGER A JESÚS EN SUS DISCÍPULOS Y EN JESÚS AL PADRE Lc 10, 16 // Mt 10, 40}

En Lc aparece este dicho inmediatamente después de la unidad recién vista. En Mt, en cambio, se encuentra incorporado en el "Discurso de misión".

Parece claro que la estructura de dos dísticos paralelos y con una antítesis, que tenemos en Lc, tiene todos los visos de ser la original de Q, del cual se nos ofrece una versión simplificada en Mt. Y se debe atribuir al RMt el cambio del verbo

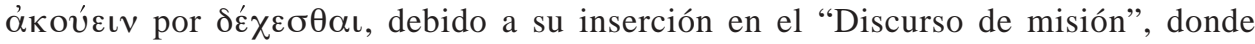
este último verbo tiene una gran importancia (ver Mt 10, 14 y 41). Es, en cambio,

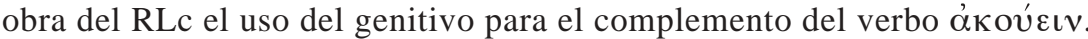

\section{JESÚS, HIJO DEL PADRE}

Lc 10, 21-22 // Mt 11, 25-27

En Lc antes de este dicho se sitúa la perícopa sobre el regreso de los 70 (72). En Mt se encuentra inmediatamente después de las imprecaciones contra las ciudades que no acogieron a Jesús.

Como de costumbre, la introducción al dicho es en ambos evangelios de evidente carácter redaccional: carácter particularmente visible en Lc (igozo y Espíritu Santo!). En el texto mismo hay tres diferencias de muy diversa importancia.

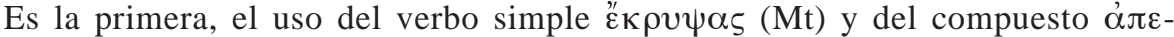
$\chi \rho v \psi \alpha \varsigma$ (Lc); aquí no parece dudoso que estemos ante la mano del RLc, dado que, por una parte, el RLc usa en general más verbos compuestos con $\alpha$ jó, y que, por otra, en Mt se encuentra más a menudo $\alpha \dot{\pi} о \kappa \rho u ́ \pi \tau \omega$ que en Lc: indicio claro de que Q no traía el compuesto, $\alpha \dot{\tau} \varepsilon ́ \kappa \rho v \psi \alpha \varsigma$ y que el RLc lo introdujo para acentuar el contraste con $\alpha \dot{\pi}$ Q $\alpha \lambda \hat{u} \pi \tau \varepsilon \iota v$.

La segunda diferencia está en la primera parte del último versículo, donde Mt usa el verbo compuesto é $\pi \iota \gamma \iota v \omega ́ \sigma \kappa \varepsilon \iota v$ con acusativos como complementos directos

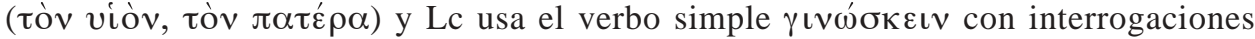

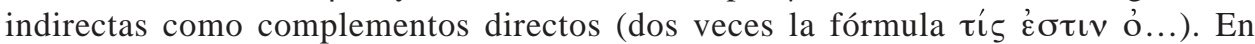


general se piensa que Q tenía el verbo simple (como Lc) y los complementos directos con acusativo (como Mt). En favor de lo primero se puede señalar la mayor abundancia de verbos compuestos en Lc (y especialmente con $\varepsilon \pi i$, : 45 veces en Lc y 25 en Mt), por lo que resulta inexplicable que el RLc hubiera suprimido el $\varepsilon$ í, si estaba en Q. En favor de lo segundo está la presencia de otros casos en que el RLc introduce la construcción con oraciones subordinadas en vez de usar un complemento directo (comparar, por ejemplo, Lc 22, 60 con Mc 14, 71).

La tercera diferencia está al comienzo de la segunda parte del mismo versículo, donde (fuera del acusativo versus la interrogación indirecta) Mt tiene la construc-

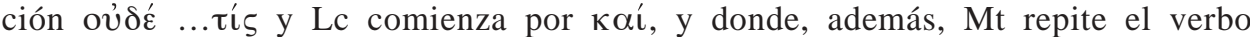
"conocer" mientras Lc lo omite. Parece bastante claro que el texto de Lc obedece a la voluntad del RLc de mejorar el estilo pesado que encontramos en Mt.

\section{DICHOSOS LOS QUE VEN LO QUE PROFETAS Y REYES QUISIERON VER Lc 10, 23-24 // Mt 13, 16-17}

Contexto. En Lc se encuentra este trozo como continuación de Lc 10, 21-22, pero gracias a una introducción obviamente redaccional (23a). Esto nos hace pensar que en $\mathrm{Q}$ los dos dichos se encontraban contiguos, pero que el RLc buscó relacionarlos como partes de un mismo momento de la enseñanza de Jesús. El RMt situó el dicho en el capítulo de las parábolas (Mt 13), y más concretamente, como parte de la teoría que les da a las parábolas el carácter de ocultadoras para la muchedumbre, pero hechas claras para los discípulos por una explicación del mismo Jesús (Mt 13, 10-17).

Texto. En primer lugar parece evidente que el primer versículo incluía "los oídos que oyen" en paralelismo con "los ojos que ven", como lo exige el vers. siguiente. Pero parece igualmente evidente que el RMt, debido al contexto en que situó el dicho, alteró el texto, vinculando directamente la "bienaventuranza" con los ojos y oídos de los discípulos, sin mencionar que la bienaventuranza les viene a los ojos y oídos por lo que ven u oyen, y no porque ven u oyen, como -de nuevo- viene exigido por la segunda parte del dicho mediante su "en efecto" ( $\gamma \alpha \dot{\alpha} \rho)$. En cuanto al

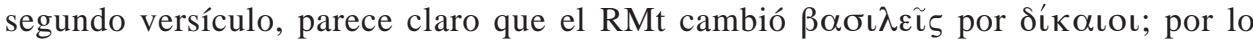
que toca al verbo usado en esta misma frase, parece claro que el $\varepsilon$ $\pi \imath \theta v \mu \varepsilon \tilde{\imath} v$ de Mt debe preferirse al $\theta \dot{\varepsilon} \lambda \varepsilon \iota v$ de Lc, ya que aquel es usado solo una vez más en Mt (y cuatro en Lc), mientras que $\theta \dot{\varepsilon} \lambda \varepsilon \iota v$ es mucho más usado tanto por Mt (42 veces) como por Lc (28 veces).

\section{LA ORACIÓN ENSEÑADA POR JESÚS \\ Lc 11, 2-4 // Mt 6, 9-13}

Contexto. El RLc interpone, entre el anterior texto de $\mathrm{Q}$ y el presente, el episodio sobre el amor al prójimo (Lc 10, 25-37) y la escena de Jesús en casa de Marta y María (11, 38-41), y le antepone una pequeña introducción redaccional (11, 1-2a); además, le dio a la oración enseñada por Jesús el carácter de primera parte de 
un conjunto sobre la oración (que se extiende hasta 11, 13). El RMt, en cambio, como es bien sabido, le da lugar a la "oración del Señor" en su Sermón de la Montaña: concretamente, dentro de una unidad referente a cómo se deben realizar las "buenas obras" no prescritas por la Ley (la limosna: 6, 2-4; la oración: 6, 5-15; el ayuno: 6, 16-18); salta a la vista que la Oración del Señor (5, 9-13) es introducida como un "cuerpo ajeno" dentro de 6, 5-15.

Texto. Lo más claro y seguro es que los elementos que se encuentran solo en $\mathrm{Mt}$ son añadidos redaccionales: el "nuestro que estás en los cielos" acusa, por una parte, una voluntad de darle uso comunitario a la plegaria (con cierto olvido del "Abbá" usado por Jesús y conservado en Mc 14, 36; Rom 8, 15; Gal 4, 6), y, por otra parte, el énfasis en la celestialidad de Dios, típica del RMt; la petición "Hágase tu voluntad..." no es más que una expresión en otro lenguaje de la petición "Venga tu reinado". Y el "Líbranos del mal" (o "del Maligno") es la expresión en términos positivos y más claros de la petición precedente, expresada en forma negativa y de más difícil comprensión.

Todo el mundo está de acuerdo en reconocer la mano del RLc en tres casos de

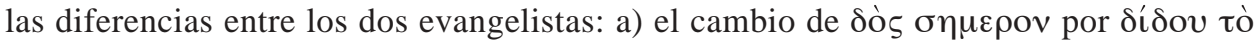
$\kappa \alpha \theta^{\prime}$ үं $\mu \varepsilon^{\prime} \rho \alpha$, destinado a subrayar que se trata de continuar Dios haciendo algo que habitualmente hace, y no de "comenzar hoy" algo que hasta ahora no ha hecho; b) el

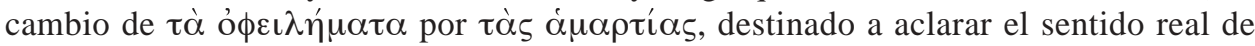
un hebraísmo (que, sin embargo, se mantiene en la segunda parte de la petición al

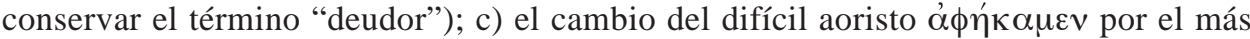

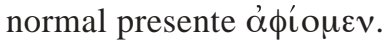

Hay un caso en que es un poco menos seguro que se trate de una modificación

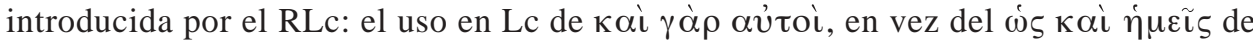

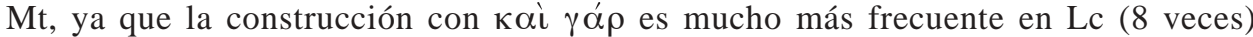
que en Mt ( 2 veces), y esta opción lucana hacía necesario el cambio de $\dot{\eta} \mu \varepsilon \tilde{\iota} \varsigma$ en $\alpha u ̛ \tau o \tilde{\imath}$. Hay, finalmente, un caso en que sería imposible llegar a una certeza, pero en el cual tiene que jugar la plena fidelidad que ha mostrado el RMt en todo lo demás

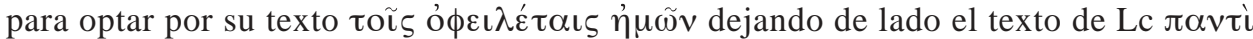

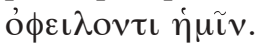

\section{LA PETICIÓN DE LOS HIJOS CIERTAMENTE ACOGIDA POR EL PADRE} Lc 11, 9-13// Mt 7, 7-11

Contexto. Ya dijimos que en Lc, dentro de la sección sobre la oración $(11,1$ 13), y entre la Oración del Señor y este trozo, se encuentra la parábola del Amigo importuno, no incluida en Mt. En Mt, además, el paralelo de Lc 11, 9-13 forma parte del Sermón de la Montaña, pero sin ninguna relación con el Padrenuestro.

Texto. Verss. 9-10. Estos verss. son absolutamente idénticos a Mt 7, 7-8, solo con las palabras introductorias $\kappa \dot{\alpha} \gamma \tilde{\omega} \dot{v} \mu \tilde{\imath} \nu ~ \lambda \dot{\varepsilon}^{\prime} \omega \omega$ ausentes en Mt, y que parecen obviamente debidas al RLc.

Verss. 11-12. Estos verss. aparecen con muchas diferencias en Mt y en Lc en lo referente a las cosas que un hijo puede pedirle a su padre (y, consecuentemente, 
en las que un padre no puede darle a su hijo): Mt habla de pan / piedra, y de pez / culebra; en cambio, Lc habla de pez / culebra, y de huevo / escorpión A mi juicio, lo más probable es que en $\mathrm{Q}$ hubiera habido una serie de tres elementos: (pan, pez y huevos, en correspondencia con "pedir, buscar y golpear" de los verss. 9-10), y que tanto RLc como RMt hayan eliminado uno: RLc el primero, y RMt el último. En efecto, pan, pescado y huevos constituían la comida habitual de la gente pobre en Galilea, y no se explica el cambio de pan-piedra por huevos-escorpión (cambio que también afectaría a su diferente ubicación respecto de pez-culebra).

Por lo que toca a la fraseología del vers. cuyo contenido se encuentra tanto en Mt como en Lc, parece claro ante todo que el RLc corrigió el anacoluto que tenemos

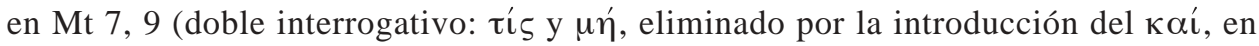
vez del segundo interrogativo); también al RLc se le debe la construcción que

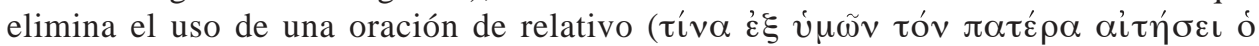

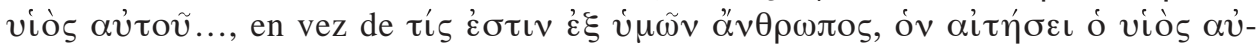
$\tau o \tilde{v} . .$.$) , con el resultado negativo de que no aparece nunca un nominativo correspon-$ diente al sujeto del muy importante verbo "dar"; en cambio, la construcción de Lc, aunque pesada y poco fluida, deja en su debido relieve al protagonista de la situación parabólica, como un "sujeto" cuya acción se va a destacar. Parece que Mt conserva también el orden

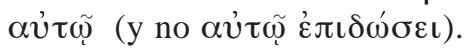

Vers. 13. En este versículo final (13 de Lc, y 11 de Mt) es clara la mano del

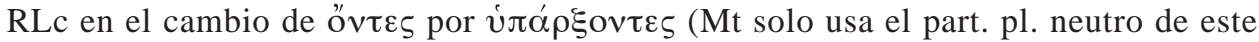
verbo, con el sentido de "posesiones": y ello solo 3 veces; en cambio en Lc se usa 15 veces), y en el cambio de $\alpha \gamma \alpha \theta \alpha \dot{~ p o r ~} \pi v \varepsilon \tilde{v} \mu \alpha \ddot{\alpha} \gamma \iota v$. La mano del RMt se

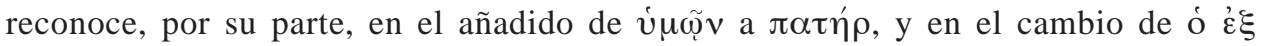

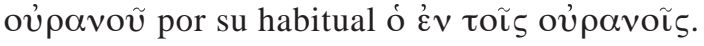

\section{8. ¿QUIÉN ESTÁ DETRÁS DE LOS EXORCISMOS DE JESÚS? \\ Lc 11, 14-20 // Mt 12, 22-28}

Sinopticidad. Estamos, con la controversia sobre Beel Zebul, ante un caso claro de traslapo Mc-Q. En efecto, por una parte, el contenido de Lc 11, 14-22 (perteneciente al gran conjunto de material no marcano de Lc) se encuentra también en Mc 3, 22-30, y por otra, se encuentra dos veces en Mt: una vez en el mismo contexto marcano (Mt 12, 22-32) y otra vez en contexto no marcano (Mt 9, 32-34), siendo de notar que es mucho más semejante al contenido de Lc el texto de Mt situado en el contexto no marcano.

El texto. En el marco narrativo (Lc 11, 14 // Mt 12, 31-32 // Mt 9, 32), parece claro que el RMt en 12, 22, para evitar la identidad con 9, 32, introdujo la ceguera de este endemoniado; parece claro también que la atribución de la mudez, no al demonio, sino al hombre mudo endemoniado, corresponde a una corrección del

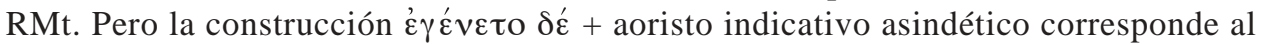

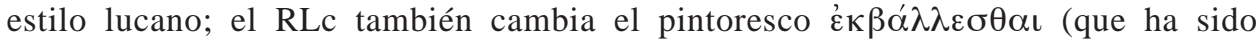
conservado en Mt 12,33) por el más “correcto" $\varepsilon \xi \varepsilon \lambda \theta \varepsilon \dot{\imath}$. 
En la acusación contra Jesús (Lc 11, 15-16 // Mt 12, 24 // Mc 3, 22), cabe notar ante todo que en Mc hay una doble acusación (tener a Beel Zebul, y echar los demonios con ayuda del príncipe de los demonios), mientras que en Lc y en Mt solo se le imputa echar los demonios con ayuda de Beel Zebul, el príncipe de los demonios, pero añadiendo Lc la petición de una señal del cielo (situada en Mc 12, 38); parece bastante evidente que el traslado de la petición de una señal celestial se debe al RMt, que quiso ponerla más cerca del dicho de Jesús en que se queja de quienes le piden señales (Mt 12, 38-39, comparado con Lc 11, 16 y 11, 29). En la acusación referente a Beel Zebul,

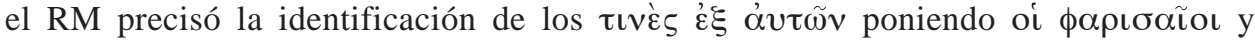

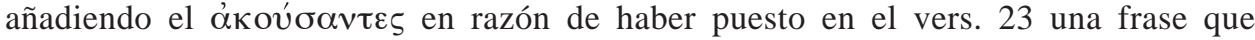
expresara la admiración por el exorcismo; y en virtud del carácter polémico resultante recurrió a la redacción exclusiva "éste no ... más que...", conservando en todo lo demás la fraseología de Q, bien conservada en Lc 11, 15. Por lo que toca a la petición de una señal en el cielo, tenemos también un traslapo Mc-Q: Mc 8, 11 // Mt 16, 1; el RMt, pues, nos presenta un duplicado del dicho, pero -con mucha perspicacia- eliminó en 12, 38 la mención de la señal "desde el cielo", ya que Mt 12, 39 // Lc 11, 29 habla solo de "señal", sin mención de su celestialidad; no hay, entonces, razones para dudar de que Lc 11, 16 conserva bien el texto de Q.

En la respuesta de Jesús (Lc 11, 17-20 // Mt 12, 25-28 // Mc 3, 23-26) se nota en el

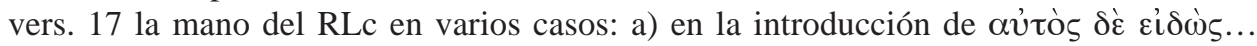

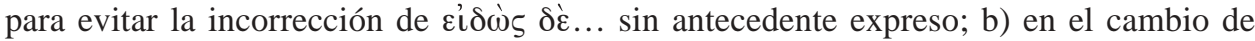

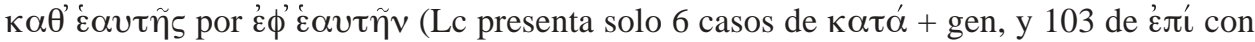
acus.); c) en el uso del compuesto $\delta \propto \alpha \varepsilon \rho \rho^{\prime} \zeta \varepsilon \iota v$ (el RLc es muy aficionado al uso de verbos compuestos); d) en la eliminación del paralelismo en la $2^{\mathrm{a}}$ parte del dicho. Y la

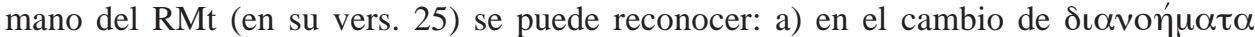

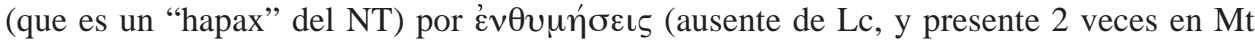

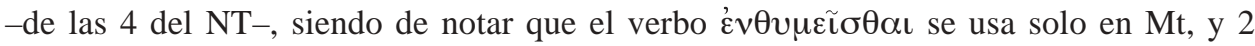

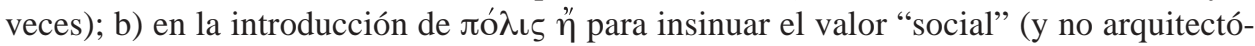
nico) de "casa"; c) en el cambio de oíkos por oíkí $\alpha$ (huella de Mc); d) en el cambio de

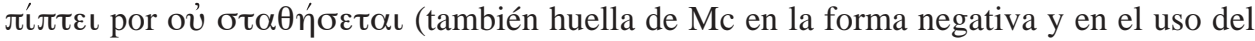

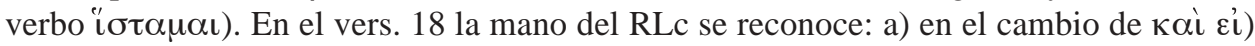

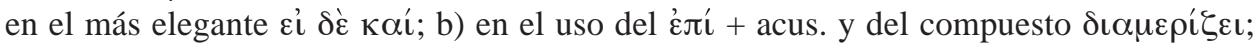
c) en el añadido explicativo de la última parte del vers. Y la mano del RMt (en su vers.

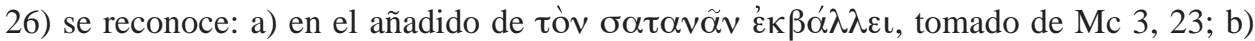

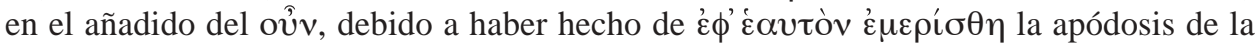

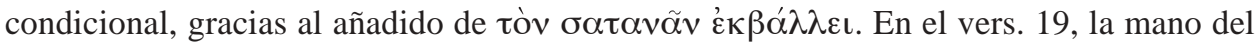

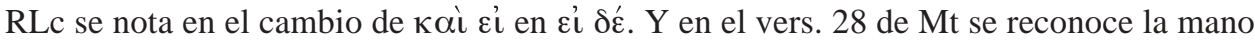
del RMt en el cambio de $\dot{\varepsilon} v \delta \alpha \kappa \tau v^{\prime} \lambda \omega$ por $\dot{\varepsilon} \nu \pi v \varepsilon \dot{\varepsilon} \mu \tau \tau$ (resulta impensable que, si Q

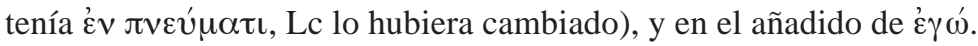

\section{EL FUERTE Y EL MÁS FUERTE \\ Lc 11, 21-22 // Mt 12, 29}

Aquí es claro que el RMt tomó como base el texto de Mc, sin que haya ningún caso de concordancia Mt-Lc al margen de Mc. De modo que Lc parece basarse en el 
texto de Q, sin que nos sea posible asegurar que Lc reproduce siempre exactamente

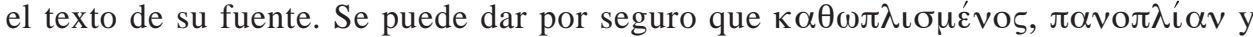

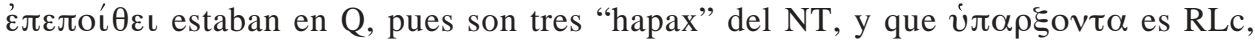
pues es un término muy lucano; pero hay, por otra parte, otros tres términos que son casi exclusivos de Lc.

\section{NO ESTAR CON JESÚS}

Lc 11, 23 // Mt 13, 20

Este es el único caso en que los textos de Mt y de Lc son absolutamente idénticos, y en que, por lo mismo, no cabe duda ninguna sobre el texto de Q.

\section{LA VENGANZA DEL DEMONIO DESALOJADO}

\section{Lc 11, 24-26 // Mt 12, 43-45}

Contexto. En Lc está inmediatamente después de la unidad precedente, con la que se vincula por el tema del "espíritu malo" (= "Beel Zebul" = "Satanás" = "un demonio") y por el contraste entre el "espíritu malo" y el "Espíritu de Dios" del trozo precedente. En Mt se encuentra separado de esa unidad textual por los verss. 31-42 (temas de la blasfemia contra el Espíritu Santo, del árbol bueno y el malo, y de la petición de un signo y del espíritu de Jonás), sin que sea fácil percibir la razón de tal ubicación.

Texto. Pocas veces se tiene tan alto grado de identidad de vocabulario y fraseología. Lo más seguro es que la última frase del texto mateano es debida al

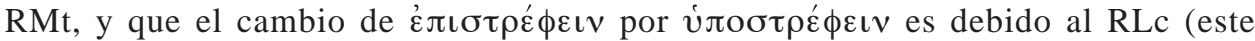
verbo no se encuentra jamás en Mt, y 21 veces en Lc). Al RLc parece deberse la omisión de $\sigma \chi 0 \lambda \alpha ́ \zeta o v \tau \alpha$ (que es un "hapax" en los sinópticos) y del superfluo

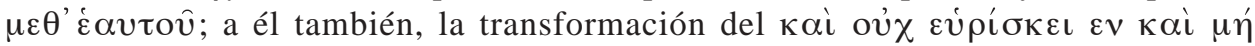

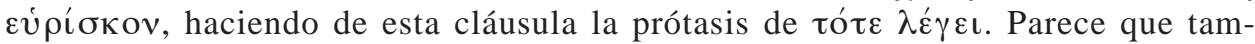
bién el orden de la última línea en Lc 11, 24 se debe al RLc, pues no cabe imaginarse al RMt introduciendo un hipérbaton como el que tenemos en su texto. De igual modo parece deberse al RLc la colocación de $\dot{\varepsilon} \pi \tau \alpha$ al fin de la frase, pues corresponde a un giro lucano.

\section{EL SIGNO DE JONÁS}

Lc 11, 29-32 // Mt 12, 39-42

Contexto. En Lc, entre la unidad precedente $(11,24-26)$ y esta, se sitúa la "anécdota" sobre la mayor bienaventuranza de los creyentes que la de la madre de Jesús (11, 27-28), que no tiene paralelo en Mt. Mt, por su parte, la pone inmediatamente antes de esa misma unidad, y la introduce con el vers. 38, inspirado en QLc 11,16 , pero que es entero del RMt, con alguna huella de Mc 8, 11 (mención de los 
fariseos), percibiéndose el uso de Q solo en la cercanía contextual con el orden de Lc y en el hecho del "duplicado" (cf. Mt 16,1). Es plausible que el orden cronológico de Lc lo haya cambiado el RMt para dar mayor topicidad al dicho sobre el signo de Jonás. Pero el orden de Mt explicaría mejor el hecho de la yuxtaposición de los dos temas: el del signo de Jonás y el de los que vinieron de lejos (Jonás - Reina), comparados con el que es más que Jonás y que la Reina del Sur (ver la omisión de Lc 11, 30 por Mt). El cambio del RLc se explicaría por el afán de clausurarlo todo con la penitencia y de darle al dicho sobre Jonás cierto aire sapiencial (ver Lc 7, 35). Parece difícil llegar a una certeza en este punto.

El texto. La introducción directa de las palabras de Jesús (Lc 11, 29a y Mt 12, 39a) es obviamente redaccional en ambos evangelios.

La afirmación básica de Jesús (Lc 11, 29b // Mt, 39b) nos ofrece otro traslapo Q-Mc (cf. Mc 8, 12, con paralelo en Mt 16, 2-4). La diferencia mayor entre Mc y Q está en que según Mc Jesús se niega a dar cualquier "señal" a "esta generación", mientras que en Q Jesús afirma que solo se le dará "el signo de

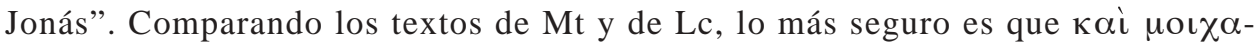
$\lambda i ́ \varsigma$ es un añadido de RMt (está presente en Mt 12 y 16, y falta en Mc y en Lc), y lo mismo cabe decir sobre el compuesto é $\pi \iota \zeta \eta \tau \varepsilon \tilde{\imath} v$ (presente las dos veces en

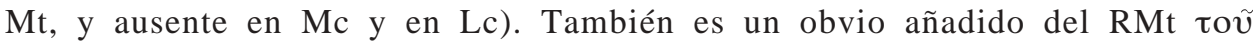
$\pi \rho \circ \phi \eta \dot{\tau o v}$ después de 'I $\omega v \tilde{\alpha}$.

En la explicación del signo de Jonás (Lc 11, 30 // Mt 12, 41-42) lo único común a ambos textos se encuentra en los elementos básicos de la comparación:

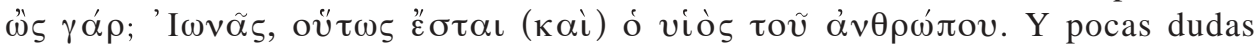
pueden caber acerca del carácter redaccional del texto mateano; en cambio, en el texto lucano, fuera de unos pocos elementos fácilmente detectables como redac-

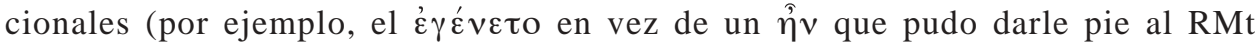

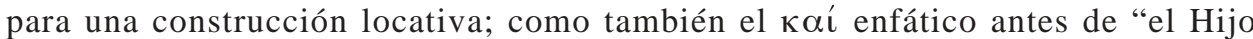
del hombre"), no hay manera de reconocer otros cambios eventuales hechos al texto de $\mathrm{Q}$.

En cambio, en el texto sobre la Reina del Sur y los hombres ninivitas (Lc 11, 31-32 // Mt 12, 41-42) la fraseología es casi enteramente idéntica en ambos evangelios, con la sola excepción de un pequeño cambio consistente en hablar Mt de "los hombres de esta generación", en vez de "esta generación" (como dice Lc), y en decir - por consiguiente- que Dios "los condenará", en vez de "la condenará"; hay plena unanimidad en reconocer aquí la mano del RMt; pero, si el lenguaje es prácticamente idéntico, el orden es diferente: en Mt aparecen primero "los hombres de Nínive" y después "la Reina del Sur", y en Lc es al revés. La decisión sobre el orden original no es fácil: por una parte, el orden mateano es más fluido en su relación con el vers. anterior, y eso podría hacer pensar que el RMt quiso mejorar el orden del original; pero, por otra parte, el orden lucano se atiene a la cronología (Salomón anterior a Jonás), y permite no solo atenerse al orden histórico, sino sobre todo terminar con la conversión debida a la predicación de Jonás: y esto podría hacer pensar que el RLc pudo alterar el orden de Q conservado en Mt. La segunda hipótesis me parece más probable. 


\section{LA LÁMPARA, PARA ALUMBRAR \\ Lc 11, 33 // Mt 5, 15}

Sinopticidad. De nuevo tenemos aquí un traslapo de Mc con Q, que ha generado esta vez un duplicado en Lc. En efecto, este dicho se encuentra en Mc 4, 21, y siguiendo el orden de Mc se encuentra en Lc 8, 16. Mt lo omite al usar a Mc: de hacerlo hubiera tenido que ponerlo inmediatamente después de Mt 13, 23; pero lo sitúa al comienzo de su Sermón de la Montaña (Mt 5, 15) con una fraseología obviamente más cercana a la de Lc 11, 33 que a la de Mc.

Texto. Es visible que el RLc homogeneizó la redacción del comienzo del dicho

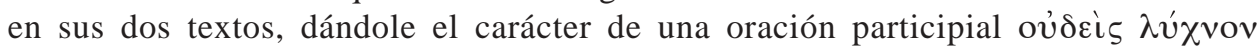
$\ddot{\alpha} \psi \alpha \varsigma$, siendo de notar que la voz activa de $\ddot{\pi} \tau \varepsilon \iota v$ es propia de Lc-Hch en el NT. Y es también visible que el RLc añadió en ambos casos, para terminar, una cláusula

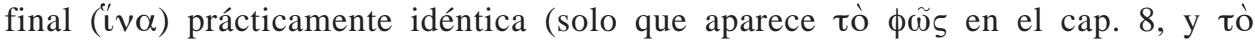

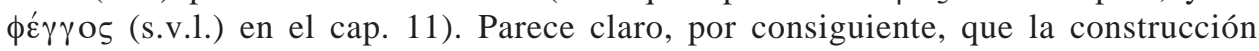
paratáctica (encender, poner y alumbrar) que tenemos en Mt reproduce mejor el texto de Q. La única pregunta es si Q tenía el plural indeterminado ("encienden" y "ponen") que encontramos en Mt, o el pronombre negativo singular ("nadie que enciende ... pone...") que tenemos en Lc. El plural indeterminado lo tenemos una vez en Q (Lc 6, 44 // Mt 7, 16) y cinco veces en Lc $(6,38 ; 12,20.48 ; 16,9 ; 23,31)$ y es un arcaísmo conocido, lo que muestra que el RLc podía no tener dificultad para acoger esta construcción. Por otra parte el "nadie" en una función como la que tenemos aquí solo se encuentra en Lc cuando lo toma de Mc (Lc 5, 36.37.39; 18, 29). El tratamiento de Mc 2, 21 que hace el RLc en 5, 36, tan semejante al que

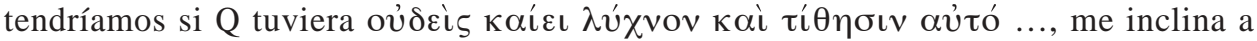
pensar que esta era la forma existente en Q. Por lo que toca a la frase final del texto mateano, no hay nada que se oponga a su presencia en Q: el hecho de que el RLc haya añadido las dos veces una cláusula más al texto que ofrecía Mc, lleva a pensar que su otra fuente tenía una conclusión, pero que no le resultó comprensible (el texto como aparece en Mt supone una "casa" de un solo espacio, única forma de que la lámpara pueda alumbrar a todos los que están en ella), y le asignó otra formulación al hecho de encender una lámpara y de ponerla sobre un candelero.

\section{OJO SANO Y OJO ENFERMO}

Lc 11, 34-35 // Mt 6, 22-23

Contexto. En Lc, esta unidad está puesta inmediatamente después de la unidad precedente, con la que aparece vinculada a través del término $\lambda$ úxvos. Mt, por su parte, la sitúa dentro del tema de las riquezas (Mt 6, 19-34 // Lc 12, 22-34), más concretamente al subrayar que entre las riquezas celestiales y las terrenas hay que elegir, sin que haya posibilidad de abrazar ambas a la vez; situado inmediatamente antes del dicho sobre los dos señores (Mt 6, 24), el dicho parece en Mt tener presente una enfermedad precisa de los ojos: el estrabismo, que lleva a mirar simultáneamente dos objetos. 


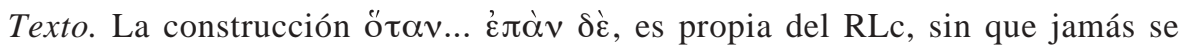
encuentre en el NT, fuera de aquí y de Lc 11, 21-22. (No es imposible que Q tuviera

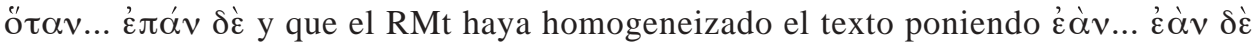
dada su afición por $\dot{\varepsilon} \dot{\alpha} v$ : aparece en Mt el doble de veces que en Lc; pero parece más probable que Q tuviera la construcción retenida por Mt). También es debido al RLc el uso del verbo бколєг̃ $v$, que le da a la conclusión final del dicho un carácter directamente exhortativo. Asimismo parecen deberse al RLc: a) el añadido del oov

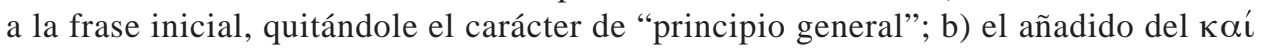
enfático antes del ö $\lambda$ ov $\tau$ ò $\sigma \tilde{\omega} \mu \alpha$ y antes de la repetición de esta misma frase sin

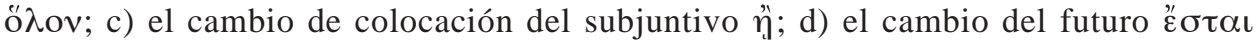
por el presente $\varepsilon \sigma \tau i ́ v$ y su omisión la $2^{a}$ vez, en la apódosis de la condicional; d) la omisión de ó ó $\phi \theta \alpha \lambda \mu$ ó $\sigma o v$ en la segunda condicional. Parece bastante seguro que es creación del RLc todo el vers. 36.

\section{PRIMEROS “AYES” CONTRA ESCRIBAS Y FARISEOS}

Lc 11, 39b-44 // Mt 23, 23-27 + 6-7

Sinopticidad. Tenemos de nuevo aquí un caso de traslapo parcial de Q y de Mc. En efecto, Mc tiene en 12, 37b-40 una puesta en guardia contra los escribas, y en Lc, que se atiene allí al orden marcano, encontramos un texto obviamente fundado en el marcano, con las habituales pequeñas modificaciones (Lc 20, 45-47). En Mt 23, 1-36, también atenido allí al orden marcano, encontramos en cambio un largo texto en que se funde ese material marcano con material no marcano; ahora bien, gran parte de ese material no marcano tiene paralelos evidentes con el contenido de Lc 11, 39b-52. Fuera de otras diferencias entre Mt 23, 1-36 y Lc 11, 39b-52, está el que Mt tiene su contenido dirigido indistintamente contra los "escribas y fariseos", mientras que Lc distingue dos secciones: una contra los fariseos $(11,39 \mathrm{~b}-44)$ y otra contra los escribas $(11,46 \mathrm{~b}-52)$. Otra cosa que debe destacarse es que, con excepción de los verss. 4 y 13 (que tienen paralelo en Lc 11, 46 y 52, respectivamente), toda la primera parte del discurso mateano (hasta el vers. 22) solo incluye material marcano, y material no marcano sin paralelo en Lc 11. En cambio, todos los dichos de Jesús que tenemos en Lc 11, 39b-52 se encuentran en Mt 23. Señalemos, finalmente, que la división en dos partes que presenta la versión lucana se le debe al RLc, como se echa de ver por el carácter obviamente redaccional de Lc 11, 37-39a y 45-46a, lo que no quita que el orden de los dichos en Lc 11, 39-42 conserve el orden que presentaba $\mathrm{Q}$.

Parece evidente que el texto de Q (= Lc 12,39b-52) era ya un texto heterogéneo, cuyo núcleo era una colección de "ayes" (Lc 12, 39b-44.46-48.52), que había ya recibido un añadido (Lc 12, 49-51), y a la que el RLc parece haber añadido el vers. 45 .

Texto. Parece evidente que Lc, 11, 39b (// Mt 23, 25) en su fraseología inicial (incluyendo el ö $\tau$ ) es obra del RLc (debido a su relación con 38-39a), y que Mt

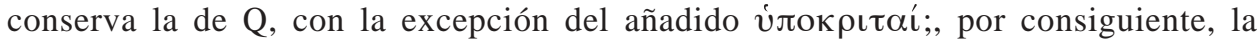
ubicación original del verbo es también la de Mt; parece asimismo seguro que el 
$\pi i v \alpha \xi$ de Lc corresponde a una corrección del RLc, ya que el uso de $\pi \alpha \rho \psi^{\prime}$ ' , con el sentido de "platillo" (y no de "entremés") que tiene en Mt, era reprobado por los buenos escritores. La última parte del vers. 39 de Lc parece también mejor conservada en Mt en cuanto al sujeto del verbo $\gamma \dot{\varepsilon} \mu \omega$ (los vasos y los platillos, y no los fariseos), y asimismo la omisión del ’ $ٌ \xi \xi$ corresponde al afán de enmendar una construcción incorrecta de Q, conservada por Mt; finalmente, la $\alpha \kappa \rho \alpha \sigma i ́ \alpha$ de Mt debe

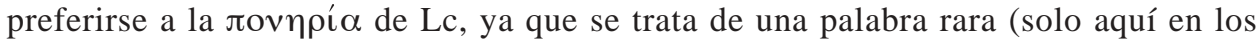
evangelios, y una vez más en todo el NT), mientras que la palabra usada por Lc es algo más frecuente (usada incluso por $\mathrm{Mc}$ y $\mathrm{Hch}$ ), y -por lo demás- tiene, en su uso

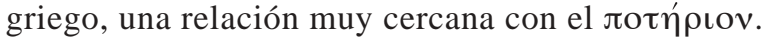

En cuanto a Lc 11, 40-41 (// Mt 23, 26), la correspondencia verbal se reduce a

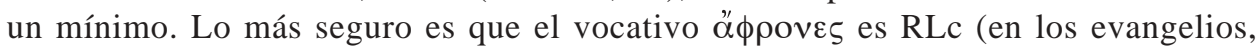
solo en Lc); en cambio, el vocativo de Mt en singular ( $\left.\tau v \phi \lambda \hat{\varepsilon}^{\prime}\right)$ incluye un término frecuente en Q. El resto del vers. es oscuro, pero su forma interrogativa arguye en favor de su originalidad, y el contenido de sus expresiones $\tau$ ò $\varepsilon \xi \omega \theta \varepsilon v$ y $\tau$ ò "

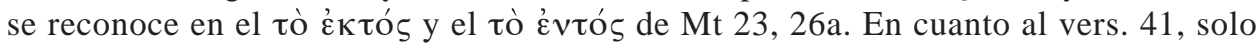
tiene en común con Mt la idea de un resultado de "pureza" mediante el adjetivo neutro к $\alpha \theta \alpha \rho$ óv usado en contextos muy diversos; parece claro, entonces, que resulta imposible llegar con alguna verosimilitud al texto de Q que pudo estar detrás de Lc 11, 41 y de Mt 23, 26.

En cambio, en Lc 11, 42 // Mt 23, 23 estamos ante un grado de correspondencia verbal que nos garantiza el uso de una fuente común por ambos evangelios. Con suficiente seguridad podemos reconocer a $Q$ en la primera mitad del versículo como aparece en Mt, con la excepción del añadido cierto, por parte del RMt, de ن́локрt$\tau \alpha i ́$ y de la identificación que en él encontramos de las dos últimas plantas sobre las

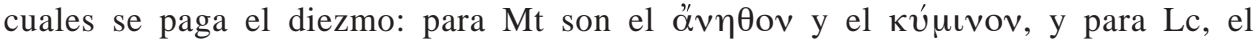
$\pi \eta ́ \gamma \alpha v o v$ y $\pi \tilde{\alpha} v \lambda \alpha ́ \chi \alpha v o v$. Dado que no estaban sujetos a diezmo ni la menta ni la ruda, ni menos "cualquier clase de hierbas", el texto de Lc tiene a su favor su coherencia con la praxis judía al reprocharles a los fariseos un rigor que los llevaba a pagar ostensiblemente diezmos sobre especies no sujetas a diezmo; en cambio, el texto de Mt le añade a la menta (exenta de diezmo) el hinojo y el comino, que sí estaban sujetos al diezmo. Es posible que el RMt haya mezclado con Q alguna tradición propia en que se les echaba en cara a los fariseos una excesiva preocupación por exigencias mínimas pero reales (el diezmo sobre el hinojo y el comino). La segunda mitad del versículo aparece en Mt recargada al comienzo por la cláusula $\tau \dot{\alpha}$

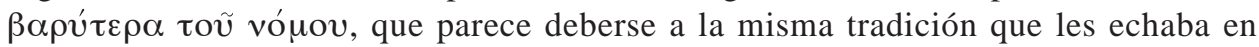
cara a los fariseos su preocupación por las cosas más leves de la ley. Donde parece

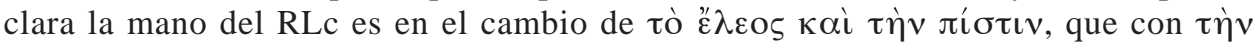

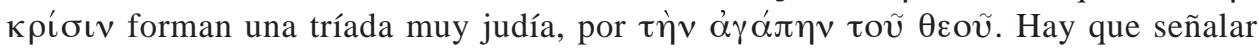
la diferencia entre los verbos usados por Mt ( $\alpha \dot{\phi} \iota \dot{\varepsilon} v \alpha \iota$, dos veces) y por Lc ( $\pi \alpha \rho$ $\varepsilon \rho \chi \varepsilon \sigma \theta \alpha \iota$ y $\pi \alpha \rho \varepsilon \tilde{\imath} v \alpha \iota)$; es más probable que aquí el RMt haya homogeneizado los

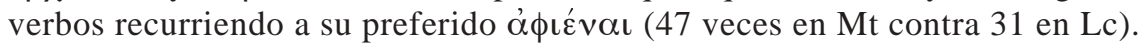

En Lc 11, 43 (// Mt 23, 6) parece claro: a) que el comienzo tiene que haber

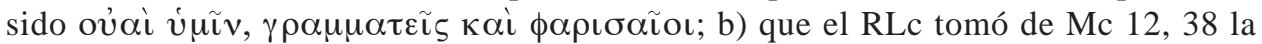
$\pi \rho \omega \tau о \kappa \alpha \theta \varepsilon \delta \rho i ́ \alpha v$; c) que en $\mathrm{Q}$ el verbo estaba en $2^{\mathrm{a}}$ persona plural introducida por ö $\iota$; y d) que en $\mathrm{Q}$ el verbo debe haber sido $\phi \iota \lambda \varepsilon \tilde{\imath} v$, cambiado en $\alpha \gamma \alpha \pi \tilde{\alpha} \nu$ por el 
RLc, quien tiene una marcada preferencia por este verbo (13 veces, contra solo 2 usos de $\phi \iota \lambda \varepsilon \tilde{\imath} v)$. El final del vers. en Mt parece deberse al RMt, pues rabbi no figura nunca en $\mathrm{Q}$.

En Lc 11, 44 (// Mt 23, 27), lo mismo que en Lc 11, 40-41 (// Mt 23, 26), prevalecen las diferencias sobre las semejanzas, y no parece que ambos textos dependan de una fuente común. Pero aquí hay mayor verosimilitud en reconocer a $\mathrm{Q}$ en Lc, posiblemente con algunas modificaciones redaccionales menores.

\section{MÁS “AYES” CONTRA ESCRIBAS Y FARISEOS \\ Lc 11, 46-48 // Mt 23, 4.29-32}

Contexto. Lo necesario ha quedado ya dicho en el $\mathrm{N}^{\mathrm{o}}$ precedente

Texto. 46. Q debe haber comenzado con el consabido ov่ $\alpha \grave{\imath} \dot{u} \mu \tilde{\imath} v, \gamma \rho \alpha \mu \mu \alpha \tau \varepsilon \tilde{\iota} \varsigma$

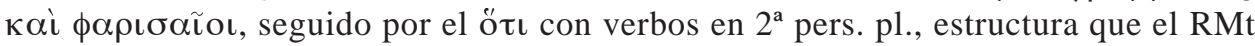
no pudo reproducir aquí, dado el contexto en que situó el dicho. El vouıкoí de Lc es ciertamente redaccional, el RLc lo usa a menudo (6 veces, contra $1 \mathrm{de} \mathrm{Mt),} \mathrm{en} \mathrm{vez}$ de $\gamma \rho \alpha \mu \mu \alpha \tau \varepsilon \tilde{\iota} \varsigma$, pues sugiere mejor que este el papel efectivo de los "escribas", que era el de expertos en la Ley (y no el de "escribientes").

La primera parte del dicho como aparece en Mt 23, 4ab (con su estructura paralela) parece más original que la ofrecida por Lc 11, 46: el RLc no es aficionado al paralelismo de la retórica semítica y suele simplificarlo; pero parece seguro que la

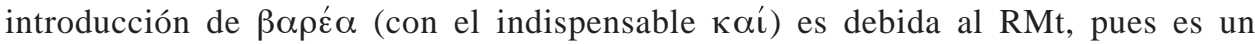
término que -dentro del material sinóptico- solo aparece (y 2 veces) en Mt. El problema más difícil es el planteado por el verbo atribuible a $\mathrm{Q}$, pues en Mt encontramos el verbo $\delta \varepsilon \sigma \mu \varepsilon v ́ \varepsilon \iota v$, usado una sola vez tanto en Mt (aquí) como en Lc (8, 29, que es "hapax" lucano, añadido a la frase de Mc), y en Lc encontramos el verbo $\phi о \rho \tau i \xi \varepsilon \iota v$, usado también una sola vez tanto en Lc (aquí) como en Mt (11, 28: texto sin paralelo). Creo más probable que sea Lc el que conserva el texto de $\mathrm{Q}$, y que el

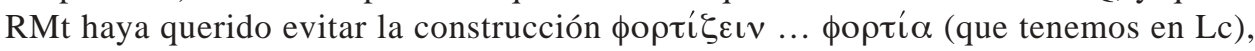

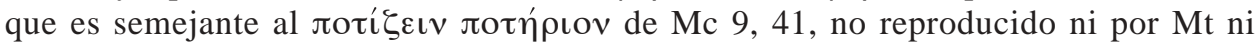
por Lc. En la $2^{\text {a }}$ parte del dicho (Lc 11, 46de // Mt 23, 4cd) parece claro que غ̇vi $\tau \tilde{o} v$ $\delta \alpha \kappa \tau u ́ \lambda \omega v$ es una formulación enfática debida al RMt; por otra parte, parece también claro que el RMt quiso evitar la repetición de $\tau \dot{\alpha} \phi o \rho \tau i ́ \alpha$ y recurrió al pronombre $\alpha u ̛ \tau \alpha$. De nuevo, el problema mayor es el del verbo usado en Q: en Mt tenemos

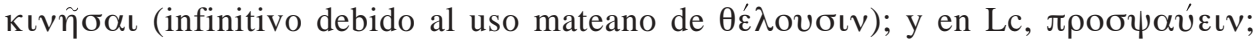
aquí es más difícil que el RLc haya recurrido a un verbo que es un "hapax" del NT, por lo que se lo suele considerar como el usado por Q; en cuanto al uso de $\theta \varepsilon \dot{\varepsilon} \lambda \varepsilon \iota v$, parece deberse al RMt, pues se trata de un verbo muy mateano (42 veces en Mt, frente a los 28 de Lc y a los 24 de Mc).

47-48. Por lo que toca a Lc 11,47a (// Mt 23, 29a), ya dijimos que el texto de

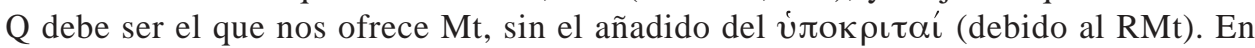
cuanto a Lc 11, 47b (// Mt 23, 29bc), da la impresión de que el RMt desdobló en dos

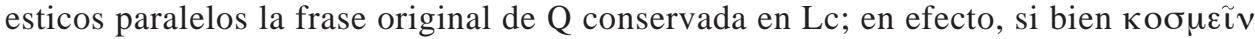
se usa casi tanto en Mt como en Lc (3 y 2 veces, respectivamente), díkaıo es 
bastante más lucano (17 veces en Lc, frente a 11 en Mt), y $\tau \alpha \dot{\phi} \phi o s$, que aparece 6 veces en Mt, no es nunca usado por Lc. Lo que con seguridad es del RMt es Mt 23, 30, y también todo lo que en los verss. 31-32 constituye un recargo ideológico de los hechos desnudos que encontramos en Lc 12, 47-48. Donde sí debe reconocerse la prioridad del texto mateano es en Lc 11, 47a // Mt 23, 31b, Si, en efecto, el verbo

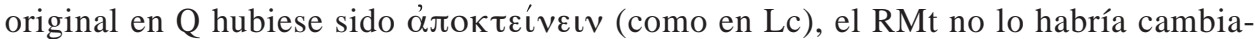

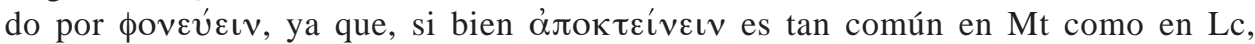

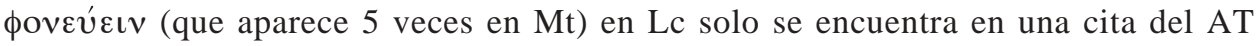
(Ex 20, 13, citada en Lc 18, 20).

\section{LA SABIDURÍA Y SUS INVITADOS}

Lc 11, 49-51 // Mt 23, 34-36

Contexto. En Lc esta unidad está inmediatamente después de la que acabamos de analizar. Mt, en cambio, introduce un vers. $(23,33)$ que continúa la línea de la "conclusión en imperativo" que el RMt le había puesto a la misma unidad, dándole un alcance cristológico. Debido a lo cual, el RMt pone en boca del mismo Jesús, y dirigido a sus oyentes, lo que Q pone en labios de la sabiduría de Dios hablando en pasado y en tercera persona.

Texto. En el vers. 49 (// Mt 23, 34) se contienen el anuncio del envío de "emisarios" y el de la suerte que tendrán. En cuanto al primer anuncio, con seguridad Q tenía el futuro (como en Lc), y no el presente (como en Mt), ya que el presente es exigido por la atribución a Jesús del anuncio; por la misma razón es

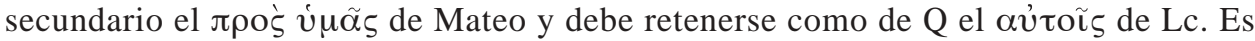
dudoso quiénes eran en $\mathrm{Q}$ los enviados distintos de los profetas; lo que parece seguro es que el ooфoús de Mt es una huella del carácter "sapiencial" del dicho en $\mathrm{Q}$, con lo que el problema se reduce a la elección entre $\gamma \rho \alpha \mu \mu \alpha \tau \varepsilon \tilde{\iota} \varsigma$ (de Mt) y

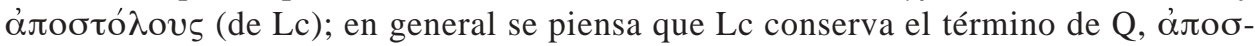
$\tau$ ó $\lambda o v s$, en el sentido no técnico de "mensajeros" (al que el RMt solo recurre una vez: Mt 10, 2); esto se confirma viendo el texto de QLc 13, 34 // Mt 23, 37:

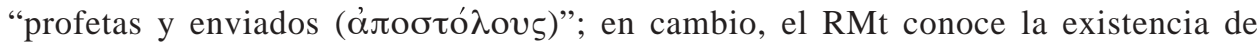
$\gamma \rho \alpha \mu \mu \alpha \tau \varepsilon \tilde{\imath} \varsigma$ cristianos $(7,29 ; 13,52)$. Por lo que toca a la suerte de los enviados, es obvio que $\mathrm{Q}$ la expresaba con verbos en $3^{\mathrm{a}}$ persona, como en Lc, y no en $2^{\mathrm{a}}$ persona como en Mt. Es muy difícil pensar que Q pudiere usar el verbo "crucificar", dado que era un procedimiento de ejecución típicamente romano; por otra parte, los "azotéis en las sinagogas" (de Mt) parecen un detalle que refleja lo que fue la suerte en las sinagogas de los judíos convertidos al cristianismo. (cf. 2 Cor 11, 24); en cuanto al "de ciudad en ciudad", parece también redacción mateana, pues solo en un texto propio de Mt se encuentra una idea parecida (Mt 10, 23). Parece, pues, que Lc ha conservado fielmente el texto de Q.

En los verss. 50-51 (// Mt 23, 35-36) se expresa, mediante una construcción fina (Lc con ìv $\alpha$, Mt con el más mateano ö $\pi \omega \varsigma$ ), el resultado del rechazo que sufrirán los enviados de la Sabiduría de Dios, que es asumir la responsabilidad de toda la sangre derramada en la historia bíblica. En ambos evangelios encontramos 
primero un planteamiento detallado y luego una confirmación breve. La diferencia mayor consiste en que Mt habla de que esa sangre "llegará" a esta generación, y Lc, de que esa sangre le "será cobrada" a esta generación; parece que el verbo que emplea Lc calza mejor con "la sangre derramada", como se echa de ver por su uso en Gn 9, 5 y 42, 22, con un sentido que no vuelve a aparecer en los otros textos del Nuevo Testamento que expresan la idea; por otra parte, el uso de 23, 36 lleva a un cambio en el enfoque de la cosa: así es que optamos por reconocer en esto el tenor de Q. Otra diferencia está en que Lc habla de "la sangre de todos los profetas"; y Mt, de "toda la sangre justa (e.d., inocentemente derramada)"; de nuevo preferimos el texto lucano, pues ofrece una dificultad que aparece obviada en Mt: las personas que se nombran (Abel y Zacarías) no son profetas. Una tercera diferencia está en que Mt habla de "sangre derramada sobre la tierra", y Lc, de "sangre derramada desde la fundación del mundo"; de nuevo el texto de Mt parece una corrección del texto pleonástico y mal construido que ofrece Lc (tres complementos con ájó, seguidos). En cambio, parece deberse al RLc la omisión del (erróneo) añadido "hijo de Baraquías" para caracterizar a Zacarías. El asesinato de Zacarías se expresa en Lc mediante el uso poco común del verbo

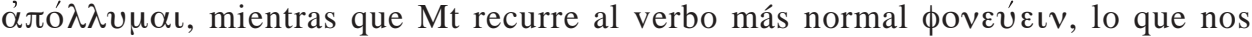
lleva a preferir como texto de $\mathrm{Q}$ el que nos ofrece Lc. De todo lo anterior se desprende la fidelidad de Lc a $Q$ en el versículo 51: incluso el uso de vai $\lambda \varepsilon_{\varepsilon} \gamma \omega$ $\dot{v} \mu \tilde{\imath} v$, claramente atestiguado en Lc 7, 26// Mt 11, 9; en Mt el $\alpha \dot{\mu} v \lambda^{\prime} \varepsilon \dot{\gamma} \omega \dot{v} \mu \tilde{\iota} v$, se encuentra unas 50 veces, contra 6 de Lc.

\section{8. ÚLTIMO “AY” CONTRA ESCRIBAS Y FARISEOS \\ Lc 11, 52 // Mt 23, 13}

Contexto. Como es visible, el último "Ay" de los seis de Lc es el primero de los siete de Mt; dos "Ayes" en Mt no tienen correspondencia en Lc: el referente a la búsqueda de prosélitos (Mt 23,15) y el de los guías ciegos que pervierten la ley en su casuística (Mt 23, 16-22); pero en Lc aparece como un "Ay" el de los que imponen cargas que no ayudan ellos a llevar (Lc 11, 26; Mt 23, 4).

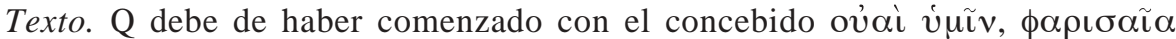

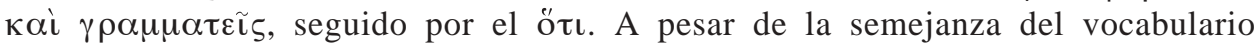
("llave" / "echar llave", "no entrar"/"no dejar de entrar"), el sentido concreto es bastante diverso en Mt y en Lc: en Mt se les atribuye a los fariseos y escribas el cerrar con llave la puerta del Reino de los cielos delante de los hombres, lo que manifiestamente alude a la oposición desplegada por ellos contra Jesús y su invitación a entrar en el Reino; lo verosímil es que el RMt haya querido darle un alcance concreto y presente a un dicho que tenía como núcleo un concepto algo impreciso y abstracto ("la llave del conocimiento") y cuya acción es situada en el pasado (los tres verbos en aoristo). Estamos afirmando, pues, que el texto de Lc reproduce en lo sustantivo el de Q; pero en cuanto a vocabulario, parece que el uso de $\kappa \omega \lambda u^{\prime} \varepsilon \iota v$ es del RLc, pues es un verbo muy lucano (de los 23 usos en todo el N.T., 12 son de Lc$\mathrm{Hch}$, frente a una sola vez en Mt, tomada de Mc). 


\section{LA LUZ SE IMPONDRÁ}

Lc 12, 2-7 // Mt 10, 26-31

Sinopticidad. Entre Mc 2, 22 (// Mt 9, 19) y 2, 23 (// Mt 12, 1) inserta el RMt tres relatos de milagros (Mt 9, 18-34) y, después del "sumario" de 9, 35 (cf. 4, 23), prolongado en un cuadro situacional $(9,36-10,5 a)$, nos presenta el segundo de sus grandes discursos: el Discurso de misión (10, 5b-42); y luego, todavía más material no marcano $(11,1-30)$; esta opción del RMt lo llevó a omitir en su lugar el texto de Mc 6, 6-13 (// Lc 9, 1-6), insertando algo de ese material marcano en su Discurso de misión. En el centro de este discurso (entre los vers.19 y 33), el RMt utiliza todo el material Q que se encuentra en Lc 12, 2-12 (excepto el vers. 10 utilizado en Mt 12, 32). Lo curioso es que el material de Lc 12, 11-12 se encuentra en el discurso mateano antes que el material de Lc 12, 2-9. Es bastante claro que los verss.11-12 de Lc 12 le servían al RMt para insertar este material en su Discurso, ya que acababa de mencionar los peligros que encontrarían los discípulos en las sinagogas y las cortes (Mt 10, 17-18).

El RLc, por su parte, después de una conclusión narrativa relacionada con los “Ayes" (11, 53-54), le creó a este material Q una breve situación narrativa $(12,1$ a) y comienza la exhortación de Jesús con un dicho sobre la levadura de los fariseos (12, 1b: traslapo con Mc 8, 15); el resto (lo usado en Mt 10) es una invitación a no temer.

Texto. En Lc 12, 2 (// Mt 10, 26) estamos de nuevo ante un traslapo de Q con Mc, y en su sección marcana Lc reproduce también el texto de Lc 8, 17 (uno de los pocos duplicados lucanos). Es muy claro que Mt 10, 26b ( $\mu \grave{\eta}$ oûv $\phi o \beta \eta \theta \eta \dot{\tau \varepsilon} \alpha \hat{v}-$

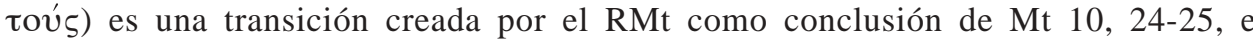
inspirada en el vers. 5 del texto lucano (retomado en Mt 10, 28), y esto obligaba a usar el $\gamma \alpha \dot{\rho}$ para el gran enunciado que encontramos casi idéntico en Lc 12, 2 y en Mt 10, 26b. Las únicas diferencias en este dicho son la colocación de éotív (después del participio en Lc y antes de él en Mt) y el uso del verbo compuesto en Lc y del simple en Mt. La última diferencia se debe atribuir al RLc, más aficionado a los verbos compuestos, sobre todo con oúv (23 casos en Lc -sin contar Hch- contra solo 4 en Mt); pero no me parece posible definir cuál orden corresponde al original:

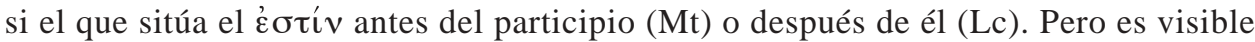
que al dicho el RLc le da un alcance amenazante, como se echa de ver por la relación que establece entre lo "velado" y "escondido" con la "hipocresía" de los fariseos (mencionada en el vers.1); en cambio, en el contexto mateano el dicho constituye un estímulo escatológico para los evangelizadores.

En Lc 12, 3 (// Mt 10, 27) parece seguro que la forma original de Q es la que

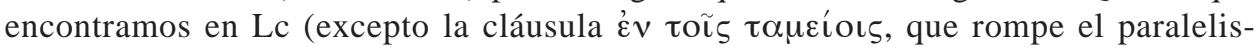
mo), y que el RMt adaptó el dicho para integrarlo en su discurso de misión como una exhortación a los discípulos a proclamar lo que han aprendido en la intimidad de Jesús. En efecto, es bastante oscuro el sentido -sin aire de amenaza- que tiene en Lc, a menos que aparezca dirigido a los adversarios de Jesús (lo que podría calzar con el vers. 4, pero de ningún modo con el vers. 1, donde la $2^{\mathrm{a}}$ persona plural está referida a los discípulos); lo que parece seguro es que la vinculación de este dicho con el precedente a través de la expresión conjuntiva $\alpha \dot{v} \theta^{\prime} \omega^{\uparrow} v$ es debida al RLc, pues 
se trata de una fórmula que en el N.T. solo se encuentra en Lc-Hch y en 2 Tes. Es posible que se trate de un dicho autónomo añadido -ya en Q- al anterior por la analogía que hay entre el contraste "oscuridad/luz" y el "velar/revelar".

En Lc 12, 4-5 (// Mt 10, 28), pienso que la frase inicial del vers. 4 de Lc -al

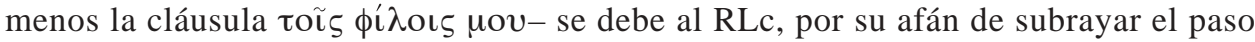
de la amenaza al aliento en el discurso; por lo demás, el término фí $\lambda$ os es muy lucano (15 veces en Lc y 3 en Hch, dentro de un total de 29 veces en todo el N.T.); es claro, por otra parte, que el RMt lo habría omitido en caso de encontrarse en Q, por las exigencias de su propio contexto. Es posible que Q solo pusiera $\lambda \varepsilon_{\varepsilon} \gamma \omega \delta$ غ̀ úũv. En la frase principal del dicho parece que el RLc cambió el presente del verbo $\phi о \beta \varepsilon ́$ co $\mu \iota$ (que supone la existencia del temor en los destinatarios) por el aoristo

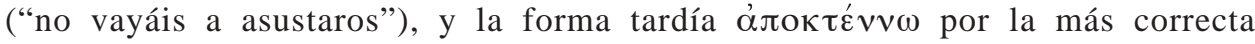

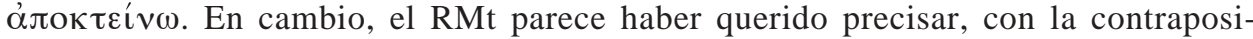
ción "matar el cuerpo" y "matar el alma", la formulación que encontramos en Lc, según la cual los que matan el cuerpo, "después de esto no pueden hacer nada más". Esto implica considerar como más original la conclusión del dicho que se encuentra en Lc 12, 4-5, y no la de Mt 10, 28b. La respuesta enfática con que termina el vers. 5 de Lc le sirvió al RMt para introducir esta unidad de Q en su Discurso de misión.

En Lc 12, 6-7 (// Mt 10, 29-31) la comparación con los gorriones se presenta con claras diferencias entre ambos textos, sobre todo en cuanto a las cifras de su número y de su precio y en cuanto a la relación de Dios con ellos. Referente a lo primero, parece claro que el texto de Lc (cinco por dos) difícilmente puede ser concebido como el fruto de una corrección del texto como aparece en Mt (dos por uno), mientras que este puede serlo de una voluntad de simplificación; por otra parte, el número de "cinco" gorriones no es arbitrario, pues los judíos no compraban objetos pequeños por "docenas" o por "medias docenas", como nosotros, sino por "manos" (e.d. de a cinco unidades), y sabemos que a fines del siglo III el precio máximo de "dos manos" (una decena) de gorriones era de siete $\alpha \sigma \sigma \alpha \rho \iota \alpha$; la modificación introducida por el RMt alcanzó también al número (plural) del verbo que figura en Lc, el que en buen griego debe ir en singular (como está en Mt) si su sujeto es un neutro en plural. En cuanto a la segunda diferencia, también la forma lucana (no olvido por Dios de un pajarillo) resulta difícilmente explicable como fruto de una modificación del texto como lo tenemos en Mt ("no caer a tierra sin intervención de Dios"), mientras que resulta explicable el texto mateano como eliminación de un antropomorfismo excesivo; en cualquier caso, es del RMt el cambio de "Dios" por "vuestro Padre"; lo que

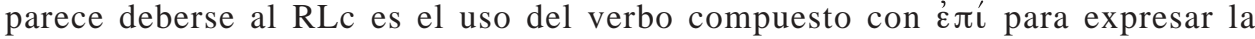

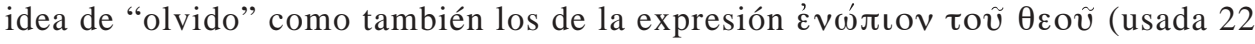

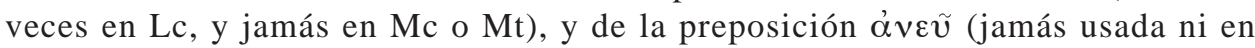

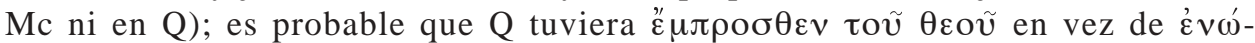

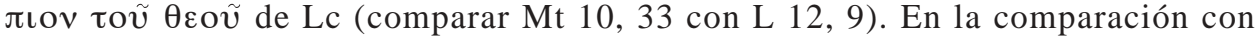
los cabellos de la cabeza, las diferencias entre Mt y Lc son mínimas: el uso de $\delta \varepsilon ́$ en Mt y de $\alpha \lambda \lambda \alpha$ en Lc, la colocación de $\dot{v} \mu \tilde{\omega} v$ al comienzo (Mt) o después de $\tau \tilde{\eta} \varsigma \kappa \varepsilon \phi \alpha \lambda \tilde{\eta} \varsigma(\mathrm{Lc})$, y el uso del perfecto pasivo con (Mt) o sin (Lc) recurso al participio acompañado de cíoív; en los tres casos se puede reconocer un mejoramiento estilístico por parte del RMt; lo mismo cabe decir de las diferencias en la 


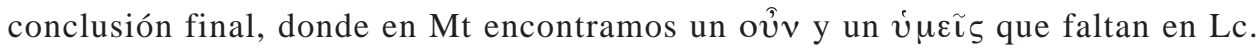
Por consiguiente, nos parece que el entero vers. 7 de Lc reproduce más fielmente el texto de Q que Mt 10, 30-31.

\section{CONFESAR O NEGAR A JESÚS}

Lc 12, 8-9 // Mt 10, 32-33

Lo más probable es que el $\lambda \varepsilon^{\prime} \gamma \omega \delta$ غ̇ v́ũ̃v estuviera en Q y que el RMt lo haya omitido para mantener la secuencia redaccional -señalada con la introducción del ov̂v- de su Discurso de misión. La segunda parte del logion mismo se encuentra también en Mc 8, 38 (pero con la idea de "avergonzarse" en vez de "negar"), lugar en el que Lc lo reproduce con la omisión de la cláusula "en esta generación adúltera y perversa" (Lc 9, 26). La fórmula introductoria de la primera parte del logion comienza en Lc con $\pi \tilde{\alpha} \varsigma$ ős áv más subjuntivo, formulación que solo aquí se encuentra, y se debe suponer que es la original; en Mt se encuentra la fórmula, también pleonástica,

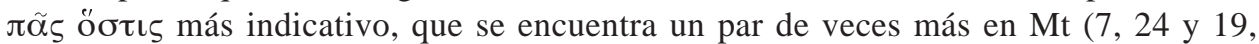
29). Se puede dar por evidente que en Q el sujeto de la confesión celestial era el "Hijo del hombre" y no "yo", y que esa confesión tendría lugar "delante de los ángeles de Dios" y no "delante de mi Padre que está en los cielos".

Por lo que toca a la segunda parte del logion, parece claro que el RLc se pasó a la construcción participial (a la que es tan aficionado), y -por la fórmula mateana

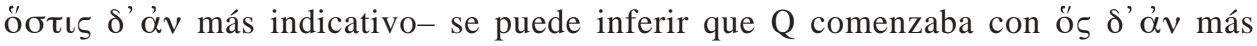
subjuntivo. En esta segunda parte del logion el RLc cambia, según su tendencia,

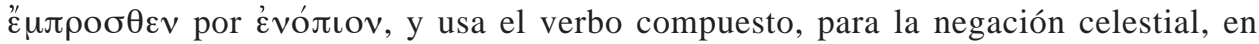
vez del simple. Es verosímil que el RLc haya cambiado "el Hijo del hombre lo negará" por la forma pasiva indeterminada "será negado": en "pasivo teológico" en referencia a "el Hijo del hombre", algo difícil de concebir en Q.

\section{LA PALABRA IMPERDONABLE CONTRA EL ESPÍRITU SANTO Lc 12, 10 // Mt 12, 32}

Sinopticidad. Ya dijimos que este logion de Q, que en Lc aparece en continuidad entre 12, 2-9 y 12, 11-12, fue situado por el RMt en el contexto en que el mismo logion es presentado por Mc: es decir, en Mt 12, 32 (// Mc 3, 29), dentro del contexto de la controversia acerca de Beelzebul; pero es claro que Mt 12, 32 toma de Q la contraposición entre "la palabra contra el Hijo del hombre", perdonable, y la "blasfemia contra el Espíritu Santo", imperdonable (en Mc la contraposición de la "blasfemia contra el Espíritu Santo" la constituían "cualesquiera pecados o blasfemias cometidos por los hijos de los hombres": vers. 28). Parece evidente que este logion debió existir en forma independiente, y que su colocación por Q dentro del contexto que tiene (basada, sin duda alguna, en la mención de "el Hijo del hombre", nombrado en el logion precedente) no fue la más acertada, porque se acababa de insistir sobre la necesidad de "confesar a Jesús", con consecuencias escatológicas. 
Texto. El comienzo de la primera parte del dicho de Lc ( $\pi \tilde{\alpha} \varsigma$ ö $\varsigma$ más indicativo), que se diferencia del de Mt (ő $\varsigma$ çóv más subjuntivo), tiene alguna mayor probabilidad de corresponder al original de Q, por cuanto difiere de las construcciones que se encuentran en los verss. 8-9 y 12 (åv más subjuntivo). También parece del RMt el

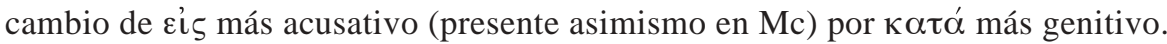

En la segunda parte del dicho es claramente del RLc el paso a la construcción

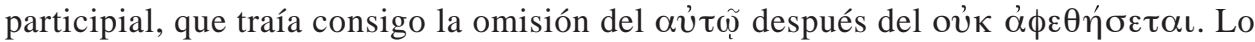

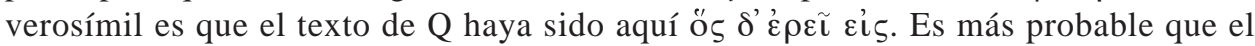
original tuviera la construcción no muy correcta $\tau$ ò $\ddot{\alpha} \gamma \iota$ เo $\pi v \varepsilon \tilde{v} \mu \alpha$, corregida por el

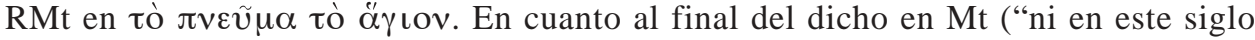
ni en el venidero"), es muy difícil que hubiera sido omitido, de estar en Q, por el RMt, pues es en Lc donde encontramos el uso de "este siglo", contrapuesto al "siglo por venir" (Lc 16, 8; 18, 30; 20, 34.35); pero se debe reconocer, por otra parte, que en Mt jamás vuelve a aparecer esa construcción. Creo que, sumando y restando, es más probable la no presencia de esta cláusula en Q.

\section{EL ESPÍRITU AYUDARÁ A LOS DISCÍPULOS PERSEGUIDOS Lc $12,11-12$ // Mt 10, 19-20}

Sinopticidad. En Mt, como ya lo dijimos, este logion final del conjunto de Q Lc 12, 2-12, fue el elegido para insertar este material Q en el Discurso de misión, donde encontraba un contexto adecuado en Mt 10, 16-18. En cuanto a su ubicación en Q, este logion, que debió existir como autónomo, fue situado donde está, por la mención del Espíritu Santo en el dicho precedente, tal como este fue situado donde está por la mención del Hijo del hombre en el dicho precedente (procedimiento de "las palabras-gancho", atestiguado en Mc 9, 38-50). El mismo dicho, se encuentra también en Mc 13, 11, lugar en que Lc sitúa, dentro del orden marcano al que ahí se atiene, un dicho semejante, aunque con una terminología muy diferente, que no incluye la mención del Espíritu Santo (Lc 21, 14-15), contexto en el cual Mt omite este tema.

Texto. Parece bastante claro que la redacción breve de Mt es debida al RMt, en cuyo texto ya habían aparecido las ideas de "entrega" y de "las sinagogas" (Mt 10, 17), por lo que, al hablar de "entregar" simplemente, estaba expresando en forma

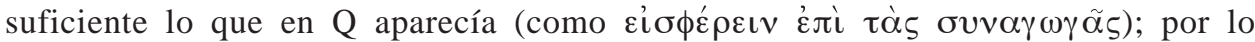
demás, el verbo $\pi \alpha \rho \alpha \delta$ ıóv $\alpha \iota$ se encuentra en Mc 13,11. En cuanto a la cláusula

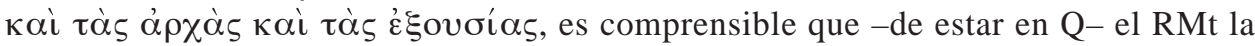

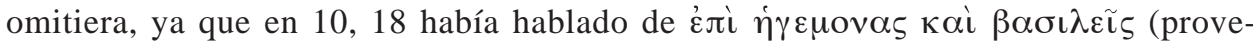
niente de Mc 13, 9); pero la combinación $\alpha \rho \xi \eta \dot{~-~ ’ \xi \xi o v \sigma i ́ ~} \alpha$ solo se encuentra, en los evangelios, en Lc 20, 20, donde es manifiestamente redaccional. Es claro que el verbo $\lambda \alpha \lambda \eta \dot{\sigma}\rceil \tau \varepsilon$ proviene en Mt de Mc; y es igualmente claro que el verbo áro$\lambda о \gamma \eta \dot{\sigma \varepsilon \sigma \theta \varepsilon}$ es debido al RLc (es el mismo que introdujo en Lc 21, 14). Se despren-

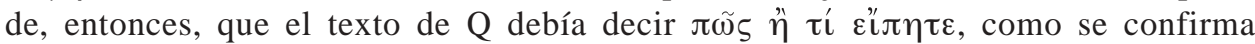
viendo el vers. 12. También es obvio que toda la última parte del vers. 19 y todo el vers. 20 de Mt están inspirados en Mc 13, 11 y son, por tanto, aquí, del RMt. Por 
consiguiente se impone pensar que el vers. 12 de Lc proviene de $\mathrm{Q}$, aunque resulte imposible decir que no contiene variaciones provenientes del RLc, sin que se pueda señalar alguna palabra o construcción característica del RLc: $\delta \varepsilon \widetilde{\imath}$ es bastante más

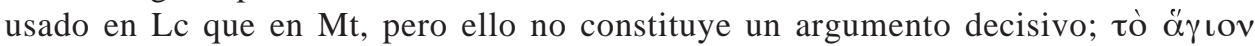
$\pi v \varepsilon \tilde{v} \mu \alpha$ podría ser la "palabra gancho" que vincula este logion con el precedente.

\section{EL ESPÍRITU AYUDARÁ A LOS DISCÍPULOS PERSEGUIDOS Lc 12, 22-34// Mt 6, 19-33}

Sinopticidad. Es patente que -con la excepción de Lc 12, 32- todo el material que tenemos en este conjunto lucano se halla situado por Mt dentro del Sermón de la Montaña, y más concretamente en Mt 6, 19-33, pero con dos particularidades: a) lo que en Lc está al final (después del omitido vers. 32) en Mt se encuentra al comienzo (Mt 6, 19-21 y Lc 12, 33-34); y b) entre Mt 6, 21 y 6, 25-33, Mt introduce dos dichos que tienen paralelo en otros lugares de Lc: Mt 6, 22-23, en Lc 11, 34-36, y Mt 6, 24, en Lc 16, 13. No cabe ninguna duda de que la actual situación en Mt del dicho sobre el tesoro celestial (Lc 12, 33-34//Mt 6, 19-21) se debe al RMt, quien lo puso en su actual lugar para crear una transición fluida con la unidad precedente en su Sermón de la Montaña, que tenía que ver con el contraste entre la recompensa humana y la divina (Mt 6, 1-18).

Texto. Lc 12, 22-23 (// Mt 6, 25). Es difícil imaginar la supresión por el RLc de los dos $\dot{v} \mu \tilde{\omega} v$, si se hubieran encontrado en Q; su presencia en Mt es, pues, una

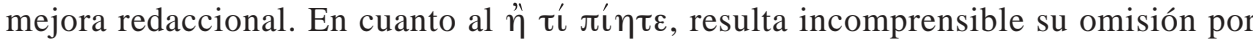
el RLc, ya que la idea reaparece en Lc 12, 29: en cambio, resulta por lo mismo comprensible que el RMt la haya añadido desde el comienzo; por lo demás, en las Bienaventuranzas, el RMt añadió la "sed" al "hambre" de Q, lo que hace más

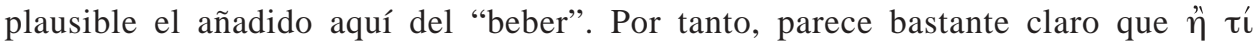
Jí $\tau \varepsilon \varepsilon$ es un añadido del RMt. Donde sí cabe una certeza es en el cambio por el RLc de la formulación como pregunta retórica del fin del vers., en una formulación asertiva.

Lc 12, 24 (//Mt 6, 26). No puede caber duda de que la comparación es originalmente con "los cuervos" (como en Lc), y que el RMt la generalizó con "las aves del cielo", basándose en lo que se dice al final de Lc 12, 24. En cuanto al verbo, Lc

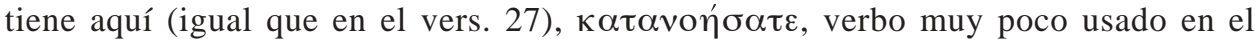
NT, pero predominantemente en Lc-Hch (8 de las 14 veces), lo que hace pensar que

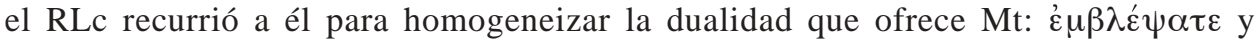
$\kappa \alpha \tau \alpha \mu \alpha \dot{\theta \varepsilon \tau \varepsilon}$ (este último, "hapax" del N.T.). La tercera línea del texto se presenta

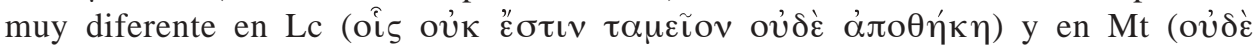

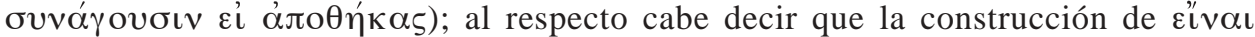
con dativo para indicar posesión se encuentra solo en Lc-Hch (Lc 2, 7; Hch10, 6; $21,23)$ y que $\tau \alpha \mu \varepsilon \tilde{\imath} o v$ solo en este caso tiene en el N.T. el sentido clásico de "despensa", y que la lógica del discurso parece pedir todavía una acción para asegurar el alimento; por estas razones me inclino a reconocer como más cercana a Q la forma mateana, reconociendo que ouváyeıv es un verbo de uso mayormente matea- 
no (24 de las 35 veces que aparece en los sinópticos), pero también usado por Q (Lc 11, 23// Mt 12, 30; Mt 3, 12// Lc 3, 17.25, s.v.1.) En la cuarta línea es seguro que Lc

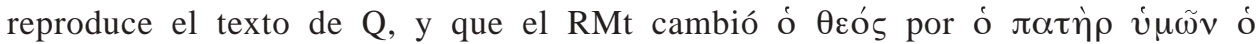

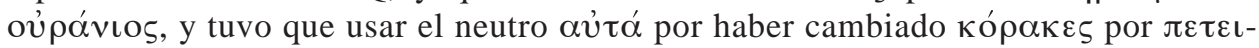
vó. En la última línea, en cambio, es Mt, con su pregunta retórica, quien conserva mejor el original; pero, naturalmente, habiendo introducido $\tau \grave{\alpha} \pi \varepsilon \tau \varepsilon \iota v \alpha ́$ desde el comienzo, aquí pudo simplemente sustituirlo por $\alpha \dot{v} \tau \tilde{v} v$.

Lc 12, 25 (// Mt 6, 27). Los textos de Mt y de Lc son idénticos, excepto en la

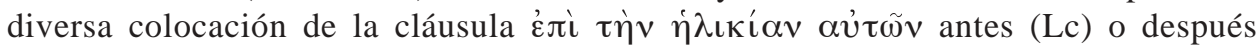
(Mt) del verbo $\pi \rho \circ \sigma \theta \varepsilon \tilde{\imath} \boldsymbol{\alpha} \alpha$, y en la presencia de "̌v $\alpha$ después de $\pi \tilde{\eta} \chi o v$ en Mt. Parece seguro que el $\stackrel{\varepsilon}{ } v \alpha$ es un añadido enfático del RMt, y este añadido llevó a cambiar el orden de la frase para que el énfasis no recayera sobre $\pi \rho 0 \sigma \theta \varepsilon \tilde{\imath} v \alpha \iota$ $\pi \tilde{\eta} \chi o v$, sino sobre $\pi \eta \chi o ̀ v ~ \check{\varepsilon v} \alpha$. Es evidente que este dicho existió independientemente del contexto en que lo insertó $\mathrm{Q}$, el cual lo hizo por la presencia en él del verbo $\mu \varepsilon \rho \iota \mu \nu \tilde{\alpha} v$, presente en toda esta unidad.

Lc 12, 26-27 (// Mt 6, 28). Parece evidente que Lc 12, 26 obedece a un afán del RLc por darle una funcionalidad dentro del conjunto al dicho precedente: a tal afán se deben, en primer lugar, toda la primera parte del versículo, y también el cambio

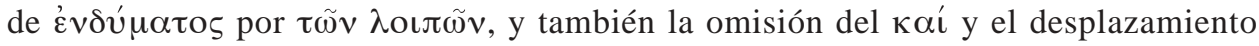
del $\tau i ́$ al comienzo de la apódosis. Parece, pues, que en la primera línea de Mt 6, 28

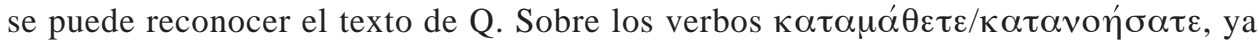

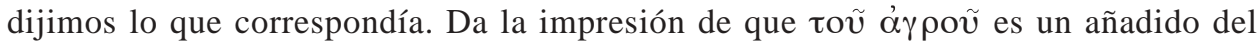

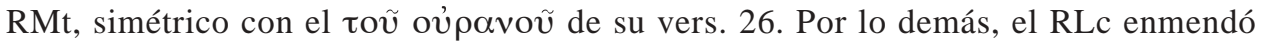
el poco correcto plural de los verbos cuyo sujeto es el neutro plural $\tau \dot{\alpha} \kappa \rho i ́ v \alpha$, y los puso en el singular que corresponde.

Lc 12, 27b-28 (//Mt 6, 29-30). La construcción asindética de Lc12, 27b, parece más primitiva que la con ö $\iota$ de Mt. En el dicho mismo, la concordancia verbal es casi total. Excepto el final, donde se le debe otorgar prioridad a la pregunta retórica de Mt, las variaciones parecen debidas al RMt: hacer de "el campo" un genitivo

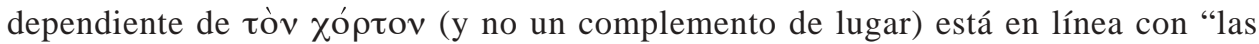

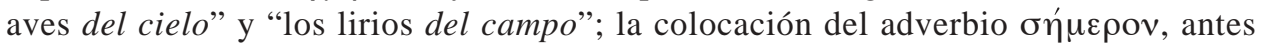

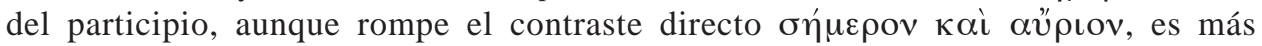

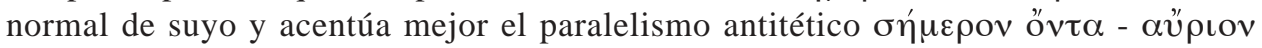
$\beta \alpha \lambda \lambda$ ó $\mu \varepsilon v o v$; finalmente, la sustitución del verbo tardío y poco ortodoxo $\alpha \dot{\mu} \phi \dot{\varepsilon} \varepsilon \zeta \alpha \iota$ por el más refinado $\alpha \dot{\mu} \phi \iota \varepsilon^{\prime} v v v \sigma \iota v$.

Lc 12, 29 (// Mt 6, 31). En Mt y Lc, estos versículos se diferencian sobre todo por el verbo determinante: en Lc, $\zeta \eta \tau \varepsilon \tilde{\imath} v$ y en Mt, $\mu \varepsilon \rho \iota \mu \nu \tilde{\alpha} v$. Mediante el verbo lucano, se señala la vinculación del vers. con lo que sigue, y mediante el mateano, con lo que precede. La presencia en ambos de la pregunta sobre qué comer y qué beber, muestra que el papel originario de este vers. lo vinculaba con lo anterior, a manera de conclusión; por consiguiente, se puede afirmar que es en

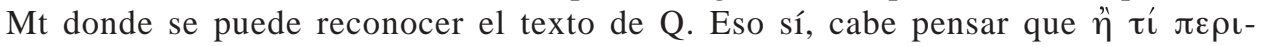

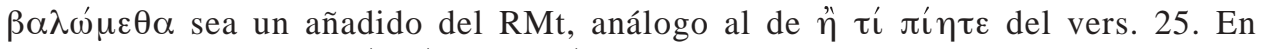

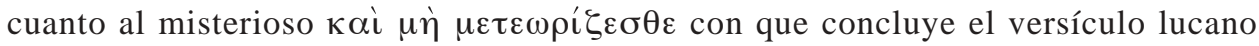
(el verbo es un "hápax legómenon" del Nuevo Testamento), nadie piensa que tenga base alguna en Q. 
Lc 12, 30-31 (// Mt 6, 32-33). En el vers. 30 de Lc es fácil detectar un añadido

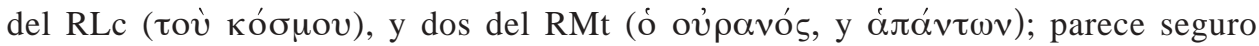
que el $\delta \dot{\varepsilon}$ de la segunda parte del vers. lucano, quiso evitar el doble $\gamma \alpha ́ \rho$ que tenemos en Mt, y que no percibió el carácter de fundamento que esta cláusula tenía respecto del versículo 31 de Mt (= Q). En cuanto al orden de la fraseología, nos atendremos al que encontramos en Lc en la primera parte y en Mt en la segunda.

Lc 12, 32. Aunque no se encuentre en Mt, pensamos que con seguridad este logion se encontraba en este lugar en Q. Hemos visto que Q juntaba textos sueltos utilizando el procedimiento de las "palabras-gancho", y este dicho incluía dos términos presentes en el precedente: ó $\pi \alpha \tau \dot{\eta} \rho \dot{v} \mu \tilde{\omega} v$ y $\beta \alpha \sigma \iota \lambda \varepsilon \dot{\imath} \alpha$. Por otra parte, es conocida la resistencia del RMt respecto de la presentación de "la Gracia" que no incluye explícitamente la respuesta libre del hombre (ver especialmente lo que ha hecho el RMt con la parábola de los invitados al banquete: Mt 22, 1-14 comparado con Lc 14, 16-24).

Lc 12, 33-34 (// Mt 6, 19-21). El RLc, a quien los paralelismos y simetrías de la retórica hebrea le parecían pleonásticos, propone en la primera parte del dicho (Lc 12, 33") una interpretación del "tesoro celestial" que lo considera como el fruto de las limosnas (ver Lc 16, 9; y Mc 10, 21 y paralelos; ya en el Antiguo Testamento, Tob 4, 8-10); por lo demás, el vocabulario empleado es muy lucano: $\pi \omega \lambda \varepsilon$ ¿̀v ( 9 veces en LcHch, sobre 22 del N.T.), $\tau \dot{\alpha}$ vं $\alpha \dot{\rho} \xi$ ov $\tau \alpha$ (9 veces en Lc-Hch, sobre 15 del N.T.),

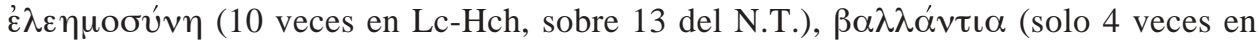
el N.T., únicamente en Lc), к $\alpha \lambda \alpha \iota$ v $\sigma \theta \alpha \iota$ (1 vez en Lc y 3 veces en Hb, sobre 4 del N.T.). Nos parece fuera de toda duda que en Mt tenemos con gran fidelidad el texto de Q. En cuanto al último vers., el RLc "homogeneiza" el número de las formas verbales y pone $\dot{u} \mu \tilde{\omega} v$ en vez del singular ooṽ que conserva Mt: procediendo análogo al que lo llevó a poner en $2^{\mathrm{a}}$ persona todas las bienaventuranzas.

\section{PREPARADOS PARA LA HORA IMPREDECIBLE Lc 12, 39-46 // Mt 24, 43-51}

Sinopticidad. Entre la unidad anterior de Q (Lc 12, 22b-34) y la presente se encuentra en Lc una unidad (Lc 12, 35-38) que tiene alguna semejanza con Mt 25, 1-13, por cuanto en ambas se trata de una hora nocturna que exige lámparas encendidas y una espera sin dormirse; pero los personajes, la acción y el vocabulario no tienen nada en común (el único término común es $\gamma \rho \eta \gamma$ o $\varepsilon \tilde{\imath} v$ ). Esto no quita la posibilidad que Lc 12, 35-38 venga de Q: su omisión por Mt podría deberse a tener él una tradición semejante pero más rica. Mt, por su parte, incluye este material Q en el quinto de sus Discursos, el escatológico, a continuación del material tomado fundamentalmente de Mc (Mt 24, 1-42), y antes de las tres grandes parábolas escatológicas del capítulo 25 (1-13, 14-30, 31-46) de tradición M.

Texto. Lc 12, 39-40 (// Mt 24, 43-44). Lo más probable es que Q no tuviera ningún demostrativo inicial, y que RMt y RLc hayan añadido (y con la misma conjunción $\delta \dot{\varepsilon}$ ) el demostrativo que les era más habitual: Mt, $\varepsilon \kappa \varepsilon \tilde{v} v o$ (54 veces,

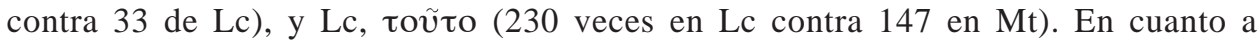
$\phi v \lambda \alpha \kappa \eta \dot{\eta} / \omega \alpha$, cabe notar que la única otra vez que en Mt aparece este término con 
el valor "temporal nocturno" (Mt 14, 25) está tomado de Mc 6, 48, por lo que puede pensarse que aquí pasa lo mismo respecto de Q. En Lc, el término, con el mismo sentido, acababa de aparecer en la unidad precedente (Lc 12, 38), y es posible que el RLc haya querido variar y no repetir $\phi v \lambda \alpha \kappa \eta$ (término que pudo ser en Q la "palabra-gancho" para poner seguidos ambos dichos). La tercera línea del versículo 39

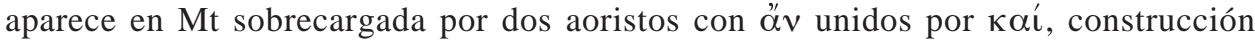
poco feliz que puede deberse al afán de vincular este dicho con el que lo precede en Mt $(24,42)$, de modo que se puede ver en Lc el texto de Q; pero esta línea tiene

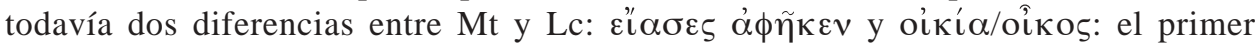
caso es muy curioso, porque ${ }^{\varepsilon} \alpha \omega$ es un verbo raro y lucano (solo 11 veces en el N.T., de las cuales 9 en Lc-Hch) que aparece aquí en Mt (y solo aquí), mientras que

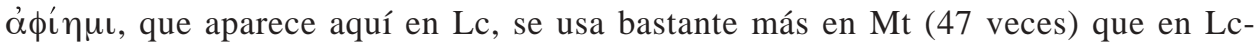
Hch (34 veces en total: 31 en Lc y 3 en Hch); sumando y restando, parece más difícil que el RMt haya cambiado éá

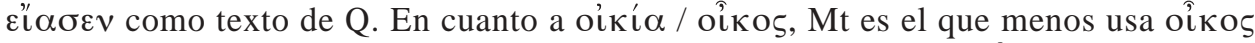
(incluso, menos que Mc), de modo que parece que él cambió el ốkos, conservado

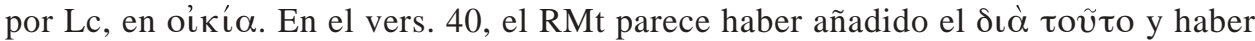

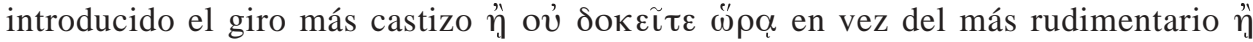


Lc 12, 41: Este vers. no aparece en Mt, y muchos han pensado que no viene de Q, sino del RLc; pero esta solución no parece convincente. En efecto, los añadidos se hacen para aclarar las cosas, mientras que aquí el vers. 41 vuelve más oscuro el texto, pues no es claro en la pregunta de Pedro a qué se refiere con "esta parábola", que pudiera afectar solo a los discípulos y no "a todos"; y es más difícil todavía ver el vers. 42 como una respuesta a esa pregunta. Parece lo más verosímil que el RMt haya optado por prescindir de un texto que le resultaba incomprensible y que, por otra parte, dejaba de Pedro una imagen más bien negativa.

Lc 12, 42-43 (// Mt 24, 45-46). Admitir que Lc 12, 41 estaba en Q, implica

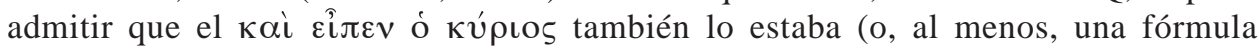
semejante). En el resto del texto se puede reconocer la mano del RLc en los térmi-

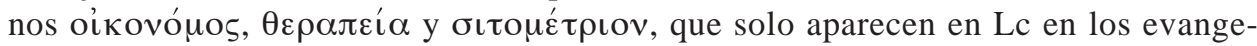

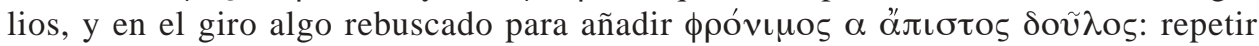

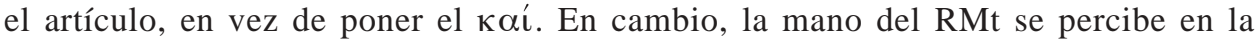
colocación del adverbio oú $\omega \varsigma \varsigma$ antes del participio.

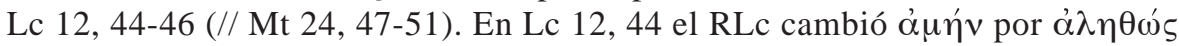

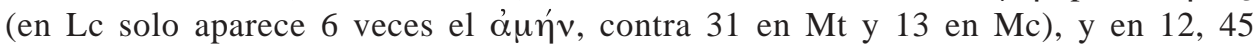
añadió el " $\varepsilon \chi \chi \varepsilon \sigma \theta \alpha \mathrm{l}$, innecesario pero evocativo para los lectores cristianos. En RMt

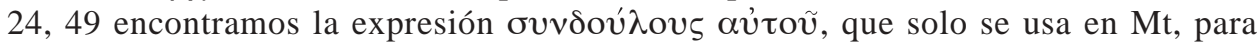

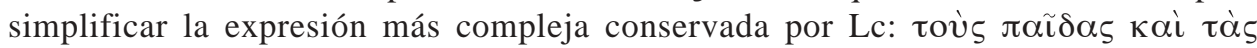
$\pi \alpha \iota \delta i ́ \sigma \kappa \alpha \varsigma$; pero la mano del RLc se reconoce en la considerable mejora introducida en la deficiente sintaxis de Mt que coordina - $i$ con $\delta \varepsilon$ !- los verbos "comer y beber" con $\alpha ̋ \xi \xi \varepsilon \tau \alpha \iota$ y no con $\tau u ́ \pi \tau \varepsilon \iota v$; el RLc ha creado una frase poco elegante, pero corrige este defecto recién nombrado e incluye un buen uso del enclítico $\tau \varepsilon$ (que reemplaza el $\delta \dot{\varepsilon}$ de Mt) y la fraseología "comer, beber y emborracharse" en vez de "comer y beber con los borrachos" (cabe señalar que el verbo $\mu \varepsilon \theta v ́ \sigma \kappa \varepsilon \sigma \theta \alpha \iota$ solo se usa aquí en los evangelios). 
En Lc 12, 46, la única diferencia con el texto de Mt es que este habla de los

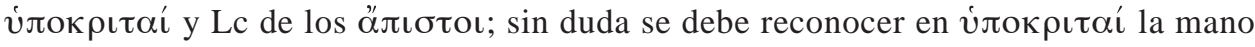
del RMt, pues se trata de una palabra muy usada en Mt (13 veces, contra 1 de Mc y

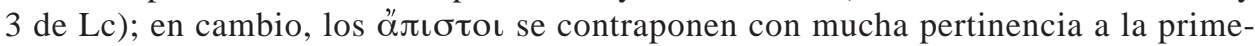

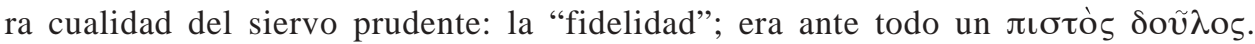
Con toda evidencia, la última frase de Mt 24, 51 es un clisé redaccional de Mt (cf. 8, $12 ; 13,42.50 ; 25,30)$.

\section{JESÚS FRENTE A SU DESTINO \\ Lc 12, 49-50}

Sinopticidad. Estamos de nuevo, en Lc 12, 49-53, ante dos dichos independientes (Lc 12, 49-50, y 51-53), vinculados entre sí -sin duda ya desde Q- por la

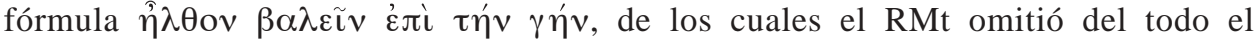
primero y situó el segundo en su Discurso de misión, a continuación del dicho que contrapone el destino de los que lo confiesan y de los que lo niegan (Mt 10, 32-33) y antes de las condiciones para ser su discípulo, con la exigencia de preferir a Jesús antes que a los propios parientes.

Texto. Da la impresión que Lc ha conservado bien este dicho con sus dos partes simétricas, cada una con una afirmación de un "destino" de Jesús y una expresión exclamativa de su actitud personal al respecto. Sobre el "bautismo" aludido por Jesús, Mc 10, 38 ha conservado una tradición independiente, omitida allí tanto por Mt como por Lc.

\section{JESÚS, FACTOR DE DIVISIÓN \\ Lc 12, 51-53 // Mt 10, 34-36}

Texto. Lo más seguro es que el contenido del vers. 51 de Lc se encuentra en Mt vaciado en una estructura redaccional idéntica a la de Mt 5, 17: "No penséis que he venido a ...; no he venido a ..., sino a ...", creada por el RMt para dar mayor realce a dichos de Jesús sobre su destino paradójico, como los que tenemos en Mc 2, 17 (y paralelos) y Mc 10, 45 (// Mt 20, 28): y ver también Mt 11, 18-19 (// Lc 7, 33-34).

No hay duda que Lc 12, 51 es una expresión de la misma índole, que destaca el carácter conflictivo del destino de Jesús, y parece que la fraseología interrogativa del texto lucano se puede considerar como original; solo que el RLc, para no repetir

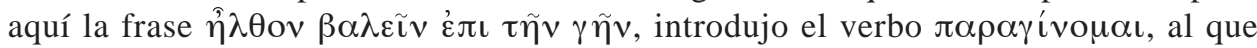
recurre tan a menudo (de los 36 usos del N.T., 28 se encuentran en Lc-Hch; y dentro de los sinópticos, 8 veces en Lc, contra 3 de Mt y 1 de Mc), y en vez de $\beta \alpha ́ \lambda \lambda \varepsilon \varepsilon \iota v$, el

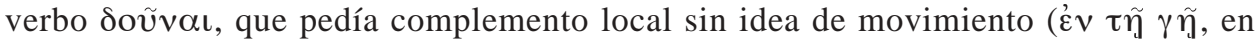

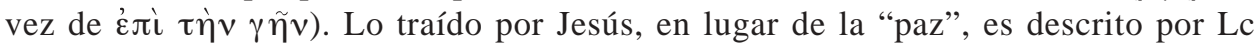

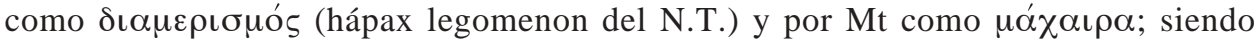
más verosímil el cambio de una palabra rara por una corriente, cabe pensar que $\mathrm{Q}$ traía el sustantivo que tenemos en Lc. La descripción de la acción "divisoria" de 
Jesús con recurso a Miq 7, 6, es muy diferente en Mt 10, 35-36 y en Lc 12, 52-53; cabe pensar que el RMt procedió a simplificar radicalmente el texto de Q, ateniéndose más de cerca de la fraseología del profeta, pues es inimaginable que el RLc se hubiera entregado a describir una situación familiar con tanto detalle. El RMt habría introduci-

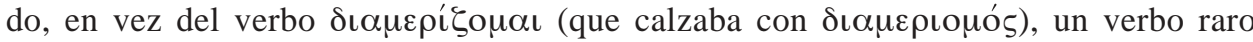

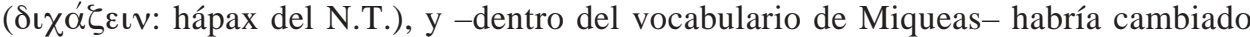
viós por $\alpha ́ v \theta \rho \omega \pi o s$, resumiéndolo en la frase redaccional del vers. 36. En la cita de

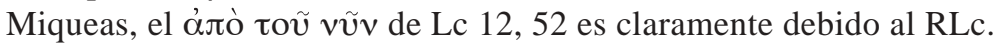

\section{INCAPACIDAD DE DISCERNIR EL PROPIO TIEMPO}

Lc 12, 54-57 // Mt 16, 2-3

Parece claro que estamos ante una misma tradición, que pondera en dos pasos la capacidad de prever el clima futuro por la correcta interpretación de ciertos fenómenos meteorológicos y que concluye con el reproche de no tener la misma capacidad de interpretar la historia. Pero es igualmente claro que las corresponden-

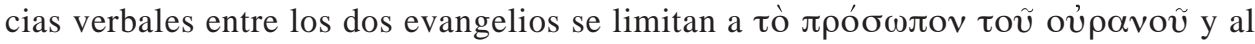
uso del término каıрós (uno en singular, y el otro en plural). Parece, entonces, que esa tradición no les llegó a Mt y a Lc por el mismo vehículo. El caso es muy semejante al de la parábola del grano de mostaza en Mc 4, 30-32 y en Lc 13, 18-19. Lo más probable es que este dicho lo hayan tomado Lc de Q (por su ubicación entre dos unidades de material Q) y Mt de su(s) fuente(s) propia(s). Naturalmente, es posible que el RLc lo haya modificado es alguna medida, sin que podamos precisar

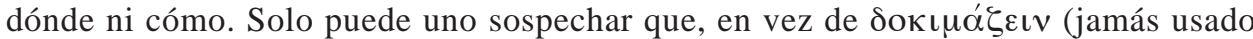
por Mt, y 3 veces por Lc), el texto de Q haya traído $(\delta \iota \alpha) \kappa \rho i ́ v \varepsilon \iota v$, que podría haber sido la "palabra-gancho" que ligaba este dicho al siguiente.

\section{MAÑANA PUEDE SER DEMASIADO TARDE}

Lc 12, 58-59 // Mt 5, 25-26

Sinopticidad. En Lc llama la atención la aparición de este dicho en segunda persona singular, después de la constante secuencia de dichos de $\mathrm{Q}$ en segunda persona plural. En Mt, este dicho está situado dentro del Sermón de la Montaña, donde recibe la función de reforzar la exigencia de reconciliación (Mt 5, 21-22), ya ilustrada con un dicho perteneciente al material propio de Mt (5, 23-24).

Texto. En Lc 12, 58 (// Mt 5, 25) se debe ciertamente al RLc la conjunción $\gamma \alpha \dot{\rho} \rho$, con lo que establece una relación (bastante oscura, por lo demás) con la unidad precedente, y al RMt el hecho de comenzar el dicho por la exhortación a "abuenarse" cuanto antes con el adversario, dada la función que a esto le asigna en su contexto. Parece más original el orden de Lc, donde se describe primero la situación; pero en cuanto a la terminología, sin duda es más original el "̌ $\omega \varsigma$ ö $\pi 0 v$ de Mt que el $\omega \varsigma$ de Lc (el uso del $\omega \varsigma s$ como conjunción temporal es característico de LcHch, y también de Jn). Parece, asimismo, que el RLc explicitó más la situación con 


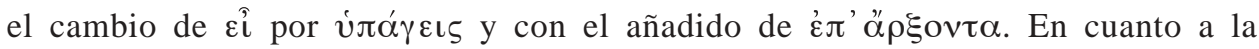
terminología de la exhortación, parece más probable que Mt retenga la de Q, pues

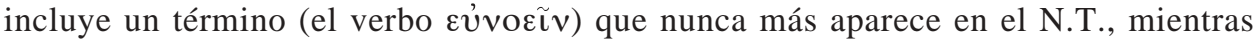

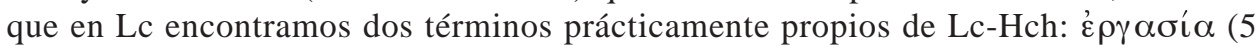
veces en Lc-Hch, sobre 6 usos en el N.T.) y $\alpha \pi \alpha \lambda \lambda \alpha \dot{\alpha} \sigma \sigma \varepsilon \iota v$ ( 2 veces en Lc-Hch, sobre 3 veces en todo el N.T.). En la fraseología de la parte final del vers. 58, debe atribuirse al RLc el cambio del subjuntivo al indicativo futuro en las dos últimas acciones, lo que constituye la introducción de un matiz literario bastante sofisticado; tal cambio estilístico no podía llevarse a cabo sin repetir el verbo inicial (pero en otro modo) o sin introducir uno nuevo; así puede atribuirse al RLc el uso del verbo

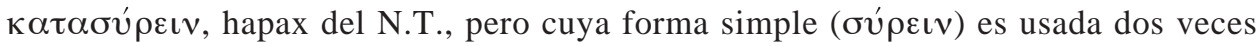
en Hch. Lo que parece un añadido mateano es la repetición de ó áv $\tau \iota \delta$ íkos a esta altura del texto. En cuanto al uso de $\pi \rho \alpha ́ \kappa \tau \omega \rho$ (que solo aquí se usa en el N.T.), es más probable que el RMt haya cambiado esta palabra bastante técnica por la más corriente $\dot{\tau} \varepsilon \varepsilon \rho \dot{\tau} \tau\rceil$. Sin duda alguna, el RLc ha cambiado la voz pasiva que tenemos en Mt, recurriendo a una voz activa que homogeniza el estilo. También es claro

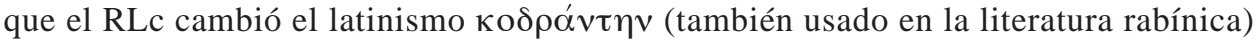
que hay en Mt por el nombre griego $\lambda \varepsilon \pi \tau o ́ v$. Puede atribuirse al RMt el añadido de $\not ̋ v$ a $\check{\varepsilon} \omega \varsigma$ (se encuentra en Mt tres veces más que en Lc), y al RLc el añadido del

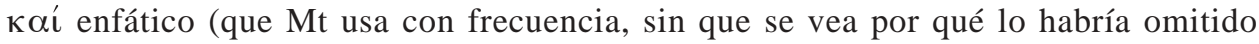
aquí). En cuanto a la colocación del verbo $\alpha \operatorname{\pi } \delta \delta \tilde{a}$ (que Mt pone al comienzo, y Lc al final), es imposible decidir la originalidad de uno u otro. Optamos, casi adivinando, por el orden de Mt.

\section{EL GRANO DE MOSTAZA Y LA LEVADURA \\ Lc 13, 18-21 // Mt 13, 31-32}

Sinopticidad. En Lc, entre el precedente material -presente también en Mt- y este, se encuentran tres unidades de material propio: sobre la necesidad para todos de conversión (Lc 13, 1-5), la parábola de la higuera estéril (6-9), y la curación de una mujer encorvada (10-17). En Mt esta parábola se encuentra en su tercer gran Discurso: el de las Parábolas (13, 1-52), correspondiente a Mc 4, 1-34, texto marcano que incluía también esta parábola del grano de mostaza (Mc 4, 30-32). Estamos, por tanto, frente a otro caso de traslapo Mc-Q: caso en el que es dable ver cómo Mt combina Mc y Q para redactar su propio texto; el fenómeno más significativo es que, mientras que en Mc estamos ante un "cuadro figurativo" (con verbos en presente) y en Lc ante un "relato significativo" (verbos en aoristo), en Mt nos encontramos con una "hibridación" de los géneros: comienza como "relato" y pronto se convierte en "cuadro".

Texto. La única diferencia del texto mateano respecto del de Lc que no resulta explicable por el uso de $\mathrm{Mc}$, es lo referente al lugar donde se pone la semilla: en Mc, tenemos "(sembró) $\varepsilon \pi i \tau \tilde{\eta} \varsigma \gamma \tilde{\eta} \varsigma$ ”; en Mt, en cambio, “(sembró)

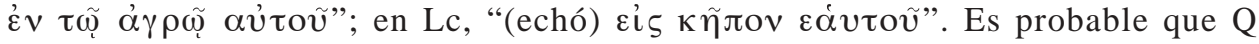

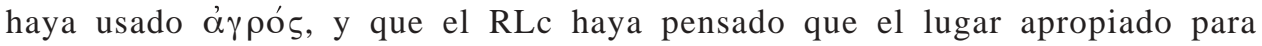


sembrar un grano de mostaza no era el "campo", sino un "huerto", y que lo haya definido mediante el pronombre reflejo ( $\dot{\varepsilon} \alpha v \tau o \tilde{v})$, como es más correcto y más frecuente en Lc.

\section{ENCONTRAR LA PUERTA ESTRECHA Lc 13, 24 // Mt 7, 13-14}

Sinopticidad. En Lc esta unidad está separada de la anterior por un "sumario" evidentemente redaccional (Lc 13, 22); y el vers. 23 es también manifiestamente redaccional, y corresponde a la costumbre del RLc de crear situaciones que convierten un "dicho" tradicional en una "anécdota". En Mt el texto se encuentra situado en el Sermón de la Montaña, como la primera de las cuatro unidades que constituyen su conclusión: las dos puertas (7, 13-14), los dos tipos de profetas $(7,15-20)$, las dos layas de discípulos $(7,21-23)$, y los dos constructores $(7,24-27)$.

Texto. En cuanto al dicho mismo, parece claro que el RMt lo alteró considerablemente al cambiar la $\theta \dot{u} \rho \alpha$ (puerta de casa) por $\pi u ́ \lambda \eta$ (puerta de ciudad), para vincularla con la $\theta u ́ \rho \alpha$ del texto siguiente, donde ya la "angostura" no desempeña ningún papel (de lo que se trata es de que la "puerta" esté abierta o cerrada). Por lo mismo, el RLc redujo considerablemente el contenido de la parábola. Pensamos, por consiguiente, que es en Mt donde se encuentra mejor el texto de Q; pero creemos que el RMt a la idea de las dos puertas le añadió el tema clásico de "los dos caminos", y de ella tenemos dos indicios muy claros: todos los participios, formas verbales y pronombres están en singular y solo de las "puertas" se puede hablar de "entrar a través de ella". Cabe señalar que la "estrechez" de la puerta no tiene tanto que ver con la capacidad de "pasar" por ella como con la dificultad de "encontrarla", es decir, de reconocerla entre las estructuras del muro de la ciudad. En otras palabras, el RMt para darle lugar a la idea de "los dos caminos" (ajena al núcleo de la parábola) cambió $\theta \dot{v} \rho \alpha$ por $\pi \dot{u} \lambda \eta$.

\section{CUANDO LA PUERTA SE CIERRA}

Lc 13, 25-27 // Mt 25, 10-12; 7, 22-23

Estos versículos de Lc tienen cierta unidad, pero claramente suponen un comienzo que permite comprender quién es ese "dueño de casa" (con artículo definido) que en un momento dado va a "despertarse". Ya dijimos que el RLc trató -sin gran éxito- de dibujar una situación forzando la parábola de la puerta estrecha. Es posible que todo este conjunto se encontrara ya en Q, y en el contexto conservado por Lc; pero las briznas de la fraseología de los versículos 25-27 que encontramos, por una parte en Mt 25, 10-12 y por otra en Mt 7, 22-23, no me parecen exigir que el RMt hubiera debido tener a la vista, para redactarlos, los trozos de Q que podrían estar detrás de Lc 13, 25-27. O sea, estamos ante un fenómeno análogo al que encontramos a propósito de Lc12, 54-57: tradiciones semejantes transmitidas en "vehículos" diferentes. 


\section{SUSTITUCIÓN DE LOS HIJOS DEL REINO}

Lc 13, 28-29 // Mt 8, 11-12

Sinopticidad. La situación cambia por completo cuando llegamos a Lc 13, 2830 , donde la semejanza de vocabulario y de fraseología salta a la vista, a pesar del orden diferente con que se ha estructurado el conjunto, al que el RMt le asignó como contexto la curación del criado del centurión (Mt 8, 5-10), con el que lo unió

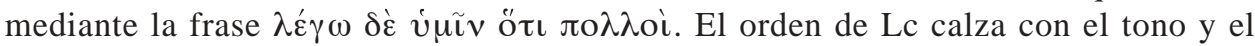
contexto de Lc 13, 25-27, y el orden de Mt calza con el contexto en que aparece situado. Pero es esencial observar que en Lc pueden distinguirse los versículos 28 y 29 como dos unidades autónomas (unidas por la "palabra-gancho" Reino de Dios), teniendo el vers. 28 el carácter de una predicción amenazante en segunda persona plural (ö $\alpha \alpha$ ő $\phi \eta \sigma \theta \varepsilon \ldots$ ), y el vers. 29, el de una promesa bastante general. De esto se desprende que la estructura mateana es secundaria, ya que no es imaginable "desarmar" la imbricación orgánica que ella ofrece. Pero es probable que sean debi-

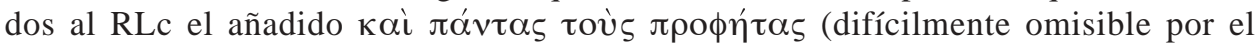
RMt) y el cambio del hebraísmo "los hijos del Reino" por "vosotros"; y es posible que en vez de la construcción participial (muy lucana) haya habido en $\mathrm{Q}$ un infiniti-

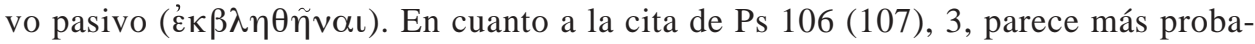
ble que se haya querido completar los puntos cardinales, y no que se haya querido omitir el norte y el sur.

\section{3. ÚLTIMOS PRIMEROS Y PRIMEROS ÚLTIMOS \\ Lc 13, 30 // Mt 20, 16}

Este dicho ha sido conservado tanto por Q como por Mc, y es así como lo encontramos una vez en el contexto marcano (Mc 10, 31; Mt 19, 30), y otra vez en un contexto diverso, como conclusión de la parábola de los operarios de la viña (Mt 20, 16). En este segundo uso se reconoce en la fraseología mateana la que encontramos en Lc: es decir, el orden "últimos/primeros-primeros/últimos", a diferencia de Mc (y Mt 19), donde aparece el orden inverso. Es visible que el RMt, manteniendo el orden que presenta Lc, simplifica la redacción pesada que tenemos en Lc, la que, por tanto, debe ser considerada primaria y más cercana a $\mathrm{Q}$.

\section{APÓSTROFE A JERUSALÉN}

Lc 13, 34-35 // Mt 23, 37-39

Sinopticidad. Entre la precedente unidad atribuible a Q y la presente, Lc sitúa una tercera mención del viaje a Jerusalén (cf. 9, 51 y 13, 22) con ocasión de las intenciones de Herodes (13, 31-33), siendo "Jerusalén" la última palabra de una unidad y la primera de la que ahora encontramos. Mt, en cambio, le da una mejor ubicación: desde luego, en la unidad misma, y además, como conclusión del Discurso contra los escribas y fariseos (Mt 23, 1-36). 
Texto. Las diferencias son pocas, y en general de poca importancia.

En Lc 13, 34 (// Mt 23, 37) encontramos cinco diferencias: a) en Mt tenemos el

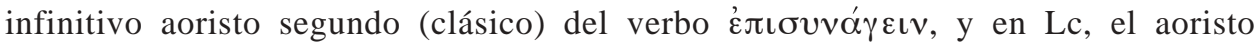
sigmático (tardío) del mismo verbo; como el texto mateano mejora la calidad del texto, consideramos como primario el texto lucano; b) en Mt se repite este verbo cuando se menciona la gallina, y en Lc queda tácito; aquí la mejora es de Lc, pues el texto resulta más liviano e igualmente claro; por tanto consideramos como primario el texto mateano; c) en Mt el plural neutro $\tau \dot{\alpha}$ voбoí $\alpha$, y en Lc el singular femenino

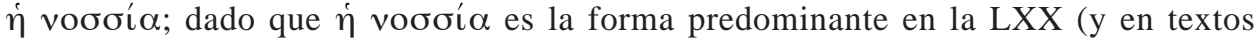
tan conocidos como Dt 32,11), se puede presumir que el RLc recurrió a ella para evitar la forma muy rara que presenta $\mathrm{Mt}$, y en la que se debe reconocer el texto de Q; d) en Mt tenemos el pronombre simple $\alpha \dot{\tau} \tau \tilde{\eta} \varsigma$, y en Lc, el reflejo $\dot{\varepsilon} \alpha v \tau \tilde{\eta} \varsigma$, que corresponde a una frecuente corrección llevada a cabo por el RLc; e) en Mt el pronombre posesivo está después del sustantivo, y en Lc, antes; también aquí se reconoce la mano más elegante del RLc.

En Lc 13, 35 (// Mt 23, 38-39) hay de nuevo cinco diferencias: a) la presencia (en Mt) o ausencia (en Lc) del predicativo; es impensable la omisión de este predicativo por el RLc si él se hubiera encontrado en Q, por consiguiente hay que reconocer que el RMt lo añadió para hacer más explícita la idea del "abandono" en que les quedaría su casa a los oyentes; b) la conjunción que relaciona la segunda parte de la frase con la primera, es en Lc la vaga $\delta \dot{\varepsilon}$, y la más precisa $\gamma \alpha \dot{\rho}$ en Mt; parece que la mayor precisión es debida al RMt; c) en Mt el pronombre personal $\mu \varepsilon$ está antes del verbo, y en Lc después; parece que el orden lucano corresponde al deseo de evitar el $\mu \eta \dot{~} \mu \varepsilon$ que tenemos en Mt; d) en Mt aparece un $\alpha \dot{\jmath}{ }^{\prime} \alpha \rho^{\prime} \rho \tau$ que no tiene correspondencia en Lc; es claro que se trata de un mayor énfasis que quiso darle a la frase el

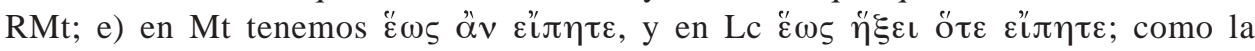
construcción lucana es pesada y poco correcta, parece claro que la fraseología mateana es debida al RMt.

\section{INVERSIÓN DE ROLES}

Lc 14, $11 / /$ Mt 23, 12

Sinopticidad. Este dicho se encuentra dos veces en Lc: aquí y en Lc 18, 14, con una sola diferencia, y es que en el segundo miembro del dicho se comienza una vez

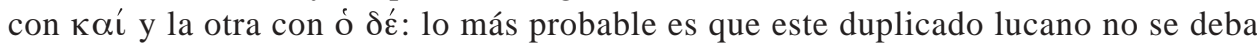
a una duplicidad de fuentes, sino a una repetición doctrinal de este dicho como colofón de la parábola del fariseo y del publicano.

Texto. Es evidente que en Mt este dicho está tomado de Q, pues la correspondencia de vocabulario y fraseología es casi total. La única diferencia es que en Mt tenemos la construcción de ő $\sigma \tau \iota \varsigma$ con futuro indicativo, y en Lc la construcción participial; como la construcción participial es muy característica de Lc, pensamos que Mt nos conserva el texto de $\mathrm{Q}$. 


\section{EL GRAN BANQUETE Y LOS INVITADOS DISPLICENTES \\ Lc 14, 16-21// Mt 22, 7-10}

Sinopticidad. Es demasiado claro que en el fondo se trata en ambos evangelios de una sola y misma parábola, que en Lc aparece situada en el curso de un banquete como reacción de Jesús ante la frase de uno de los comensales acerca de la dicha de participar en el banquete del Reino de Dios (Lc 14, 1-15), y que en Mt figura a continuación de la parábola marcana de los viñadores homicidas (Mt 21, 33-46 // Mc 12, 1-22 // Lc 20, 9-19).

Texto. Tan clara como el hecho de estar ante la misma parábola, es la gran diversidad que se constata al comparar ambos textos. a) En Lc el protagonista es un hombre que da una gran cena y que dispone de un servidor; en Mt es un rey que celebra el banquete de bodas de su hijo y que dispone de numerosos siervos. b) En Lc hay un solo envío del siervo antes de la cena, y dos envíos del siervo después de la negativa de los invitados: uno dentro de la ciudad y otro fuera de ella; en Mt hay dos envíos de siervos antes de la cena y un solo envío después de la negativa de los invitados. c) En Mt se habla de vejaciones y homicidios por parte de algunos invitados contra los siervos del rey, de todo lo cual no hay vestigio alguno en Lc.

No menos claro que la unidad de fondo y la diversidad de los relatos, es el hecho de una muy considerable correspondencia en el vocabulario empleado, lo que parece suponer el uso de una misma fuente escrita: Q, pero reconociendo que ambos introdujeron algunos cambios considerables por razones teológicas. El cambio más considerable del RLc fue el de poner dos envíos a raíz del rechazo de los invitados: uno dentro de la ciudad y otro a los caminos y cercados, con lo que en la parábola los "invitados originales" eran los hombres más religiosos del judaísmo, siendo su lugar ocupado, primero por los "publicanos y pecadores" y luego por los gentiles. Y el cambio más considerable del RMt fue el de poner como protagonista no a "un hombre" sino a un "rey" (ipero ver la extraña construcción: "un hombre rey"!), lo que le permitió meter en la parábola el envío de ejércitos para destruir la ciudad de los invitados homicidas, alusión evidente - ex post facto- a la ruina de Jerusalén. Y parece bastante claro que el RMt tomó algunos rasgos de la parábola de los viñadores homicidas: el envío sucesivo (e infructuoso) de diversos "siervos", y las vejaciones que les fueron infligidas por los destinatarios. No se puede negar que la parábola como aparece en Mt adolece de varias incoherencias (sin contar el añadido de Mt 22, 11-14) de los cuales no es la menor el que el rey, después de saber que los invitados "no querían venir", les envía emisarios para decirles que "todo estaba preparado" y que "vinieran a la boda". Por todo esto nos parece que se puede reconocer a Q en Lc 14, 16-21" (sin perjuicio de posibles cambios menores, indetectables para nosotros); a partir de Lc 14, 22b hay que reconocer que el RLc "desdobló" el envío de sus siervos a buscar reemplazantes de los invitados originales, y -por lo mismo- ha debido modificar la fraseología de su fuente. Conjeturalmente, podría pensarse en la siguiente fraseología como la de Q:

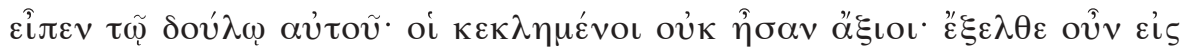

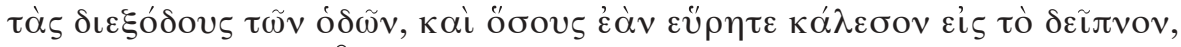

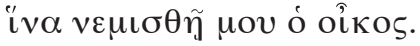




\section{CUANDO LA SAL SE REVIENE}

Lc 14, 34-35 // Mt 5, 13

Sinopticidad. En Mt se encuentra este dicho en la introducción del Sermón de la Montaña, inmediatamente después de las Bienaventuranzas, para expresar (junto con la imagen de la luz) la responsabilidad de ser discípulos de Jesús; en Lc se lo encuentra después de una nueva formulación de las condiciones para ser discípulo de Jesús (Lc 14, 33), usada como conclusión de las parábolas del constructor sin capital suficiente y del rey sin ejército suficiente (Lc 14, 28-32). Una versión más breve de este dicho se encuentra en Mc 9, 50", entre dos dichos que tiene en común la raíz correspondiente a "sal" (Mc 9, 50 y 51b), al final de una colección de dichos unidos mediante el procedimiento de las "palabras-gancho". Tanto Mt como Lc, que estaban allí siguiendo a Mc, omiten en ese contexto tal dicho.

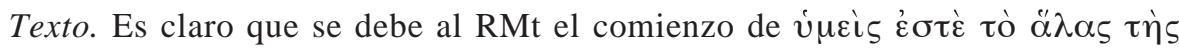

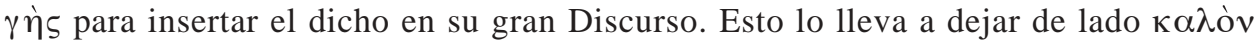

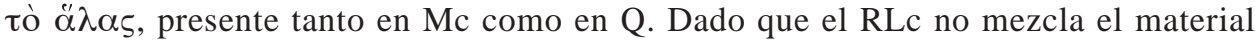
no marcano con el marcano, y que Mc 9, 50 trae también el verbo $\alpha \rho \tau u ́ \varepsilon \iota v, ~ p a r e c e$ seguro que fue el RMt quien cambió este verbo por $\alpha \lambda i ́ \zeta \varepsilon \iota v$ usado en Mc 9, 49 (el RMt suele combinar Q con Mc). Parece claro también que al RMt se le debe la

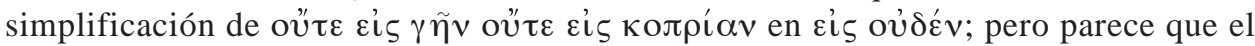

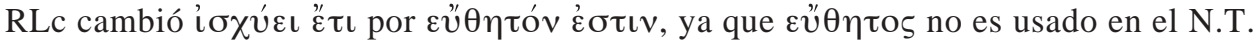
más que por Lc-Hch. En cambio, la línea final de Lc, con su construcción asindética, con el uso impersonal de la tercera persona plural, y con su brevedad, parece más primitiva que la de Mt, más sofisticada en su sintaxis.

\section{LA OVEJA Y LA DRACMA PERDIDAS \\ Lc 15, 4-9 // Mt 18, 12-14}

Sinopticidad. En Mt la primera de estas parábolas está situada en el Discurso comunitario, y aparece como una expresión de la preocupación que debe darse en la comunidad por "los pequeños" (Mt 18, 11 y 14b, que constituyen una "inclusión"). En Lc, ella es la primera de las tres "parábolas de la misericordia", con las que Jesús responde a la acusación de "acoger a los pecadores" y de "comer con ellos" (Lc 15, 1-3). Estas tres parábolas tienen en común la alegría festiva de quienes han encontrado algo suyo que estaba perdido. Pero aunque es clara la relación de fondo que existe entre las tres, es más claro todavía el paralelismo literario que existe entre las dos primeras de Lc, que constituyen un caso de "parábolas gemelas", como las del tesoro y la perla (Mt 13, 44-45) y las del grano de mostaza y de la levadura (Mt 13, 31-33 // Lc 13, 18-21). Dada la poca propensión del RLc a las estructuras retóricas basadas en el paralelismo, resulta impensable que él hubiera creado una segunda parábola a imagen y semejanza de la primera; a esto se añade el hecho de que el RMt desplazó manifiestamente el centro de interés de la parábola de la oveja perdida, situándola en la actitud comunitaria y no en la de Dios, de acuerdo con su tendencia a no enfatizar la "gratuidad" de la acción salvífica de Dios (pensar en la 
transformación de las bienaventuranzas, en la omisión de Lc 12, 32, o en el añadido de Mt 22, 11-14).

La admisión de la pertenencia a Q de Lc 15, 8-9 proporciona un criterio importante para la reconstrucción del texto de Lc 15, 4-6, tanto o más que la comparación con Mt 18, 12-14. No hemos mencionado Lc 15, 7 y 10, porque pensamos que son obra del RLc, ya que lo propio de las parábolas es dejar que los auditores saquen su significado "real" por sí mismos.

Texto. La forma interrogativa de ambas parábolas en Lc tiene a su favor un rasgo muy característico del "estilo" de Jesús, que invita a los oyentes a pensar personalmente. Otra cosa que parece segura en Lc 15, 4 es que el verbo original fue $\kappa \tau \alpha \lambda \varepsilon i ́ \tau \varepsilon \iota v$ (como

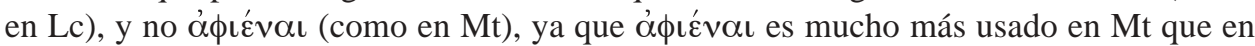
Lc; igualmente seguro es que Q haya usado عُ $\rho \eta \mu o s$, ya que őpos no figura en el

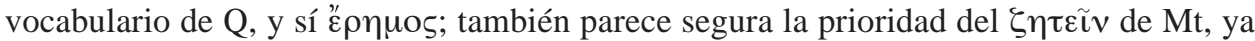
que se lo encuentra en la parábola paralela de Lc 15, 8; y sin duda alguna el RMt simplificó considerablemente lo que hace el agente de la acción dramática al encontrar su oveja perdida, sin que resulte posible opinar con seguridad que el texto de Lc reprodujo sin cambio alguno el texto de Q; pero en todo caso, las dos últimas líneas de Lc 15, 6 constituyen un importante elemento simétrico con la parábola simétrica $(15,9)$.

Somos conscientes de que el texto que proponemos no goza de idéntico valor en todas sus partes.

\section{DOS AMOS ENTRE QUIENES ELEGIR: DIOS Y MAMÓN Lc 16, 13 // Mt 6, 24}

Sinopticidad. En Lc este dicho aparece situado en el conjunto más heterogéneo, donde fuera de dos parábolas $(16,1-12$ y 16, 19-31) y de un milagro $(17,11$ 19), se encuentran dichos inconexos (16, 13.14-15-16-17.18; 17, 1-2.3-4.5-6. 7-10). En Mt, en cambio, aparece en el Sermón de la Montaña, dentro de un contexto inmediato que le da gran relieve (Mt 6, 19-34).

Texto. Idéntico en ambos, con la sola excepción de la palabra oíćtๆร, que aparece en Lc como aclaratorio útil, pero no indispensable, por lo que reconocemos el texto de $\mathrm{Q}$ en $\mathrm{Mt}$.

\section{EL REINO DE DIOS EXPUESTO A LA VIOLENCIA \\ Lc 16, 16 // Mt 11, 12-13}

Sinopticidad. Para Lc, ver lo dicho en el $\mathrm{N}^{\circ}$ 59. Mt situó este dicho en el contexto del testimonio de Jesús sobre el Bautista (Mt 11, 7-19), que fundamentalmente viene de QLc 7, 24-28.

Texto. Es visible, en cuanto al orden, que en Lc lo referente a "hasta Juan" aparece al comienzo del dicho, mientras que en Mt aparece al final del mismo; en 
cambio, en Mt se comienza por lo referente a "después de Juan", mientras que en Lc se termina con ello. Parece evidente que el orden natural es el que ofrece Lc; y el texto del comienzo original parece también mejor conservado en Lc, ya que es obvio el añadido mateano de la idea de "profetizar", lo que trajo consigo poner antes a los profetas que a la Ley y añadirle "todos" a los profetas. Entre "ع $\omega \varsigma$ (Mt) у $\mu \varepsilon^{\prime} \chi \rho \iota$ (Lc) se debe preferir el $\mu \varepsilon^{\prime} \chi \rho \iota$ de Lc, que solo aparece aquí en su evange-

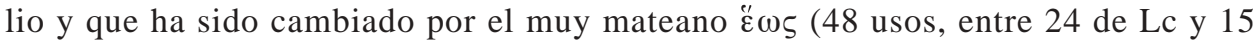
de Mc). En cuanto al inicio de la segunda parte del dicho, es evidente que la redacción larga de Mt se debe al hecho de comenzar el logion con esta idea, la que queda suficientemente expresada con el ảjò $\tau o ́ \tau \varepsilon$ de Lc. Es obvio que el RMt

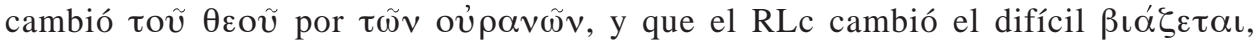
como predicado de "el Reino de Dios", por el muy lucano $\varepsilon \dot{v} \alpha \gamma \gamma \varepsilon \lambda i ́\} \varepsilon \tau \alpha \iota$ (25 veces en Lc-Hch, contra 1 en Mt: en la cita de Is 61,1), pero lo mantuvo en la oración destinada a expresar "qué se debe hacer" con ese Reino de Dios. En Lc, todo resulta muy claro: contra ese Reino de Dios que se evangeliza, $\pi \tilde{\alpha} \varsigma$ عi $\varsigma$

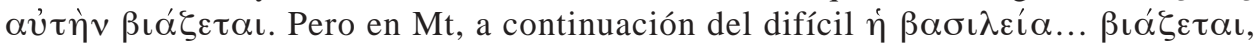

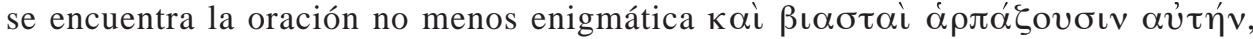
que debe considerarse como primitiva.

\section{VIGENCIA ETERNA DE LA LEY \\ Lc 16, 17 // Mt 5, 18}

Sinopticidad. Para Lc, ver lo dicho en No 59. Mt situó este dicho en el Sermón de la Montaña como afirmación básica de su exposición sobre el papel de la Ley para los discípulos de Jesús (Mt 5, 17-48). En Mc 13, 31 se encuentra un dicho bastante semejante a este, solo que en él la eterna validez se predica de las palabras de Jesús, y no de la Ley: indicio claro de la mayor antigüedad de la tradición de Q comparada con la de Mc, cuyo texto en el lugar citado es reproducido con gran exactitud tanto por Mt $(26,37)$ como por Lc $(21,33)$.

Texto. Es importante comenzar señalando una anomalía visible en el texto de

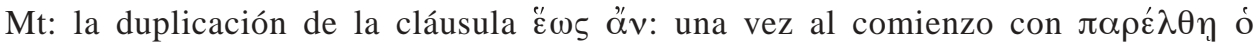

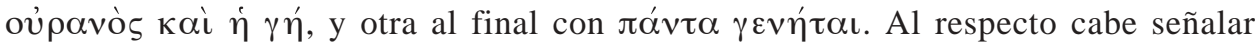
dos cosas: a) que las afirmaciones proféticas de Jesús con la cláusula $\varepsilon \omega_{\varsigma}$ őv, la traen invariablemente después del oủ ứ (Mc 9, 1; 14, 25; Mt 5, 26; 10, 23; Jn 13,

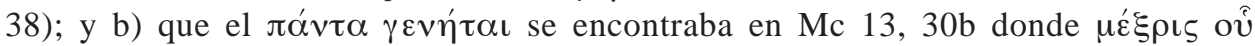

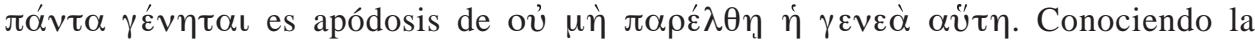
tendencia del RMt a combinar Mc con Q, es posible que haya querido darle a la

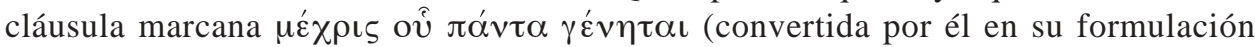
habitual $\check{\varepsilon} \omega \varsigma \alpha ̋ v . . .:$ cf Mt 24,34) la idea de que no quedará nada de la Ley sin cumplirse, lo que lo llevó a construir la idea de la eternidad de la Ley con la fórmula

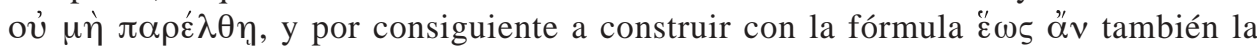
primera parte del dicho tomado de Q. Pensamos, por consiguiente, que la forma del dicho en Q es la tenemos en Lc (forma atestiguada en dichos de Mc: 2, 9 y paralelos y 10,25 y paralelos); pero parece obvio que $\mathrm{Q}$ repetía el verbo $\pi \alpha \rho \varepsilon \lambda \theta \varepsilon \tilde{\imath} v$, y que el 
RLc lo cambió la segunda vez por $\pi \varepsilon \sigma \varepsilon \tilde{\imath} v$; y es también más probable que el RLc haya suprimido $i \tilde{\omega} \tau \alpha$ है $v$, y no que el RMt lo haya añadido.

\section{PROSCRIPCIÓN DEL DIVORCIO}

\section{Lc 16, 18 // Mt 5, 32}

Sinopticidad. Sobre Lc, ver lo dicho en $\mathrm{N}^{0}$ 59. En Mt el dicho se encuentra dos veces: en 19, 9 en contexto paralelo con Mc 10, 11-12, y en el Sermón de la Montaña a continuación del tema del adulterio $(5,27-30)$ e introducido mediante la repetida contraposición "Fue dicho (...), pero yo os digo" $(5,21.27 .33 .38 .43)$. Es obvio que el duplicado se explica por el uso de dos fuentes que incluían el dicho: Mc y Q, esta última usada por Lc 16, 18. Y es bien sabido que el RMt introdujo las dos veces su famosa "cláusula exceptiva" que exceptúa de la norma la situación de лopveía. Las mayores diferencias entre las dos formas del dicho son que Mc la

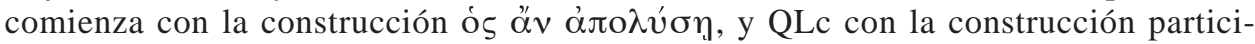

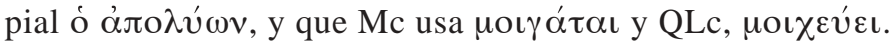

Texto. Así como en 19, 9 el RMt cambió la segunda parte del dicho (Mc 10, 12), e

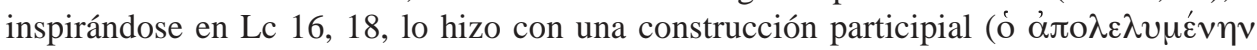

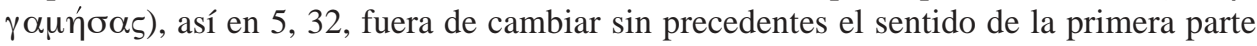
del dicho, introduce en la segunda parte modificaciones que vienen de Mc: el ös ćóv con subjuntivo (en vez del participio) y el uso de $\mu$ oı $\chi \tilde{\alpha} \tau \alpha \iota$. Por consiguiente, todo indica que Lc 16, 18 conserva fielmente el texto de Q conocido por el RMt.

\section{3. ¡AY DE QUIEN ESCANDALIZA! \\ Lc 17, 1 // Mt 18, 7}

Sinopticidad. Sobre Lc, ver $N^{\circ}$ 59. En Mt el dicho se encuentra en el Discurso comunitario, integrando una unidad mayor sobre el escándalo, tomada de Mc 9, 4248 (Mt 18, 6-9). Lo que en Mt no puede de ninguna manera explicarse a partir de Mc y que coincide con Lc 17, es lo que en Mt se encuentra al final y que en Lc se encuentra al comienzo. Pero hay algunos indicios de que Mt 18, 6 supone el conocimiento de lo que está en Lc 17, 2.

Texto. La mayor diferencia entre los dos textos está en que la venida del escándalo es en uno una necesidad (Mt), y en el otro, "inevitable" (Lc). Ambas

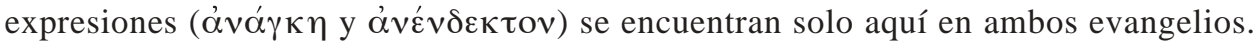
Pero, sin duda alguna, la lectio difficilior es la mateana, y por tanto debe reconocerse en la lucana la preocupación por "mejorar" el sentido. Pero en cambio, se percibe

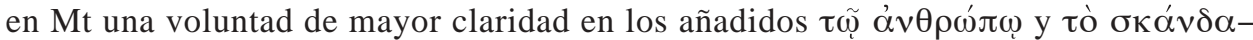
$\lambda o v$. Dado que el $\pi \lambda \eta \dot{v}$ es más usado por Lc que por Mt (15 veces contra 5); su presencia en el texto mateano resulta inexplicable como una corrección por parte del RMt de un texto que no la incluyera; el RLc pudo pensar que la frase resultaba más

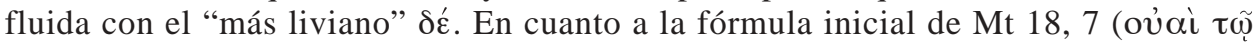
кó $\mu\left(\omega_{1 . . .)}\right)$, parece ser una construcción generalizadora del RMt. 


\section{DESTINO DE QUIEN ESCANDALIZA A UN PEQUEÑO \\ Lc 17, 2 // Mt 18, 6}

Los indicios de un conocimiento, por parte del RMt, de lo que tenemos en Lc 17, 2 (y, por tanto, de su pertenencia a Q) son los dos siguientes: el uso del demostrativo $\tau o u ́ \tau \omega \nu$ para determinar a $\tau \tilde{\omega} v \mu \iota \kappa \rho \tilde{\omega} v$, y el uso de la conjunción ív $\alpha$ en vez de $\varepsilon \grave{i})$. No es mucho, pero basta para considerar probable la pertenencia de Lc 17, 2 a $\mathrm{Q}$, aunque resulte imposible precisar su tenor exacto en cuanto diferente del de $\mathrm{Mc}$ $9,42-43$, con el que tiene en cualquier caso gran nivel de correspondencia verbal

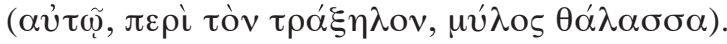

\section{PERDONAR SIN LÍMITES \\ Lc 17, 3-4 // Mt 18, 15.21-22}

Sinopticidad. Sobre Lc, ver No 59. En Mt está inserto este dicho en el Discurso comunitario, pero no como una unidad, sino en dos unidades separadas: lo correspondiente a Lc 17, 3 figura como comienzo de una unidad que abarca tres versículos (Mt 18, 15-17) y que se encuentra precedida por la parábola de la oveja perdida, y seguida por el dicho sobre el alcance celestial de lo "desatado" por los discípulos en la tierra $(18,18)$; y lo correspondiente a Lc 17,4 figura como parte de una anécdota en que Pedro pregunta y Jesús responde (18, 21-22).

Texto. Lc 17, 3 (//Mt 18, 15). Se debe reconocer que el centro de interés del dicho en los dos evangelios es diferente, como se confirma por la forma en que cada uno lo prolonga: Lc con su versículo 4, y Mt con sus versículos 16-17, y como la correspondencia verbal entre Lc 17, 3 y Mt 18, 15 es bastante limitada, no hay razones suficientes para afirmar que lo que ellos nos ofrecen provenga de una misma fuente: solo nos constaría que habría tradiciones en las comunidades sobre qué hacer cuando un hermano peca contra otro.

Lc 17, 4 (//Mt 18, 21-22). De nuevo estamos ante dos enfoques de fondo diferentes y con semejanzas de terminología significativas pero limitadas. Por consiguiente no tiene suficiente base afirmar que los textos de Mt y de Lc tienen detrás una misma fuente utilizada por ambos. De nuevo estaríamos en presencia de variaciones en la tradición de los dichos de Jesús cristalizados en fuentes diversas antes de su uso por nuestros evangelistas.

\section{LA FUERZA DE LA FE}

Lc 17, 6 // Mt 17, 20b

Sinopticidad. Sobre Lc, ver No 59. En Mt el dicho aparece situado como conclusión del relato sobre la curación del niño epiléptico que les había resultado imposible a los discípulos (Mt 17, 14-20"): relato tomado de Mc 9, 14-29, pero que en Mc terminaba de otra manera. Pero Mt tiene además otro dicho semejante en 21, 20, en contexto paralelo a Mc 11, 20-25 (ver sobre todo verss. 22-23). 
Texto. Tomando en cuenta que el RMt suele combinar elementos de Mc y de Q en su redacción, la comparación de los dos textos mateanos con Lc 17, 6 nos permite reconocer con bastante seguridad al menos una parte importante de un texto de Q. Lo más seguro es que el dicho consistía fundamentalmente en una condicional en que se decía que una fe tan pequeña como un grano de mostaza bastaba para decirle a una morera que se echara al mar para que se cumpliera. La condición parece no haber sido la "eventual" ( $\varepsilon \alpha ́ v$ con subjuntivo), sino la "irreal" ( $\varepsilon$ i con imperfecto en la prótasis e imperfecto con $\alpha$ ”v en la apódosis), corregida por el RMt

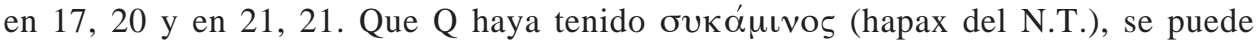
presumir con mucha seguridad, pues, de tener o’pos, nadie lo habría cambiado; como

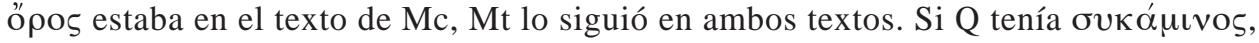

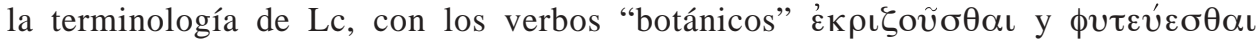
resulta coherente, y es lógico que el RMt la cambiara por la más neutra $\mu \varepsilon \tau \alpha ́ \beta \alpha$

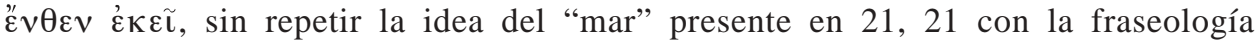
marcana. La frase final del dicho parece mejor conservada en Lc, pues la de Mt hace alusión al contexto narrativo en que está inserto el dicho.

\section{LA MANIFESTACIÓN DEL DÍA DEL HIJO DEL HOMBRE Lc 17, 22-24 // Mt 24, 26-28}

Sinopticidad. En Lc esta unidad, caracterizada por el tema del "Día del Hijo del hombre", está situada dentro de un conjunto algo mayor de clara índole escatológica (Lc 17, 20-37, que, junto con las parábolas del juez inicuo $(18,1-8)$ y del fariseo y el publicano (18, 9-14), preceden el "reencuentro" de Lc con Mc en contenido y orden (Lc 18, 15). En Mt, este material (con algunas omisiones) se encuentra inserto en el Discurso marcano que se suele llamar "Apocalipsis sinóptico" (Mc 13 // Mt 24). Pero cabe señalar dos fenómenos: a) en Mt jamás aparece la expresión "Día (s) del Hijo del hombre", y b) la primera parte del material presente en Lc (23-24) se encuentra en Mt (26-28) añadida a la acción marcana que alerta contra los falsos profetas o Mesías (Mc 13, 21-23 // Mt 24, 23-25), y la segunda parte de Lc (26-30) aparece en Mt (37-39) después de haber agotado el material marcano.

Texto. Lc 17, 22. Aunque este versículo no tiene paralelo en Mt, lo consideramos perteneciente a Q, pues, por una parte, está vinculado orgánicamente con Lc 17, 23 ss., y, por otra parte, es muy explicable que, dada su dificultad u oscuridad, el RMt lo haya omitido.

Lc 17, 23-24 (//Mt 24, 26-27). El comienzo de esta unidad (Lc 17, 23 // Mt 24, 26) constituye un caso de traslapo con Mc 13, 21, donde, mientras que Lc lo omite, Mt lo reproduce con bastante fidelidad (Mt 24, 23), creando un verdadero duplicado con su vers. 26. En cuanto a la fraseología, sin duda alguna el RMt cambió el comienzo de su vers. 26 para darle el carácter de conclusión de lo precedente;

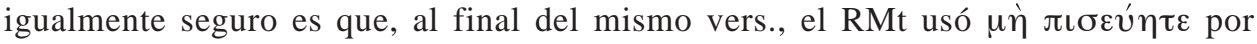
influjo de Mc 13, 21. En cuanto al centro del vers. que estamos analizando, parece que la redacción que ofrece Lc (y que coincide con la de Mc 13, 21), más breve y 
con un orden menos "lógico", es más primitiva que la presentada por Mt, más elaborada y mejor ordenada; además, si las precisiones topográficas de Mt se hubieran encontrado en Q, es muy difícil concebir que el RLc las hubiera omitido para incurrir en una mera repetición de lo que había dicho en 17, 21. Por lo que toca a Lc 17, 24 (// Mt 24, 27), parece probable que la redacción complicada y poco clara de Lc haya sido radicalmente simplificada (aunque con discutible exactitud meteorológica) por el RMt a quien también se le debe la introducción de la "Parusía" del hijo del hombre, y la omisión de su "Día".

\section{COMPARACIÓN CON LOS DÍAS DE NOÉ}

Lc 17, 26-30 // Mt 24, 37-39

En Lc esta unidad consta de dos estrofas (en torno a Noé y a Lot, respectivamente), y en Mt figura solo la primera. Parece claro que no fue el RLc quien añadió la segunda, sino el RMt quien la omitió: en efecto, el RLc tiende más bien a evitar tal rasgo de la retórica hebrea aficionada al paralelismo; además, la repetición en Mt 24, 39b de lo ya dicho en 24, 37b, y en 24, 27b, sugiere que algo ha sido omitido. En cuanto a la fraseología, parece seguro que es primario el $\kappa \alpha i$ $\kappa \alpha \theta \omega ́ \varsigma$ de Lc, y no el $\omega \prime \sigma \pi \varepsilon \rho \gamma \alpha \dot{\rho}$ de Mt (debido a la función que se le atribuye en su nuevo contexto, y que reproduce la formulación de Mt 24, 27). Es más impor-

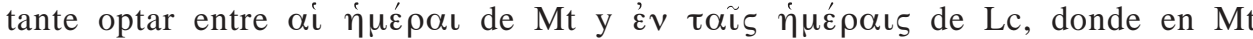
tenemos una lectio difficilior preferible al texto más claro de Lc. También la segunda parte del vers. 37 de Mt parece conservar mejor el texto de base, con la

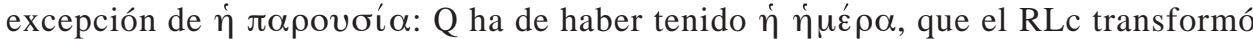
de acuerdo con las modificaciones que había introducido en la primera parte del vers. Las aclaraciones del difícil texto de Q, que el RLc introdujo modificándolo, el RMt las colocó en la primera parte de su versículo 38, evidentemente redaccional. Por lo que toca al versículo 27 de Lc, es obvio su carácter primario (¡el RLc no habría cambiado la construcción con participio de Mt 38b!), como también es

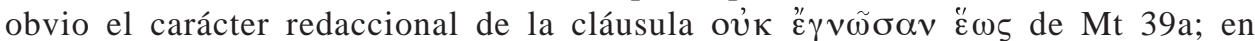

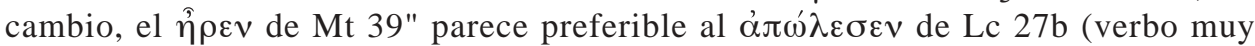
lucano). En cuanto a $\pi \alpha ́ v \tau \alpha \varsigma$ (Lc) o $\alpha ँ \pi \alpha v \tau \alpha \varsigma(\mathrm{Mt})$, debe preferirse el texto lucano, ya que $\alpha$ $\pi \alpha \varsigma$ es muy usado en Lc, y el RLc no lo habría cambiado de encontrarlo en $\mathrm{Q}$.

\section{[68. RECOMENDACIONES PARA LA HORA ÚLTIMA}

Lc 17, 31-32

Este texto tiene una semejanza muy notable con Mc 13, 15-16 (reproducido con gran fidelidad por Mt 24, 17-18). Lo curioso que Lc, que en 21, 21 a corresponde al contenido de Mc 13, 14b, difiere considerablemente de Mc 13, 15-16 en sus versículos 31-32. No hay ningún indicio de que el texto mateano haya conocido (o usado) un texto semejante al de Lc 17, 31-32; por tanto, nada induce a pensar que detrás de Lc 17, 31-32 (y de Lc 21, 21b) esté presente la fuente Q.] 


\section{PERDER Y ENCONTRAR LA VIDA \\ Lc 17, 33 // Mt 10, 39}

Sinopticidad. En Lc se encuentra este dicho después de otro (31-32) que constituye un caso de traslapo de L con Mc (13, 15), seguido este, por Mt 24, 17 con bastante fidelidad, sin que haya en el texto mateano nada que exija por parte del

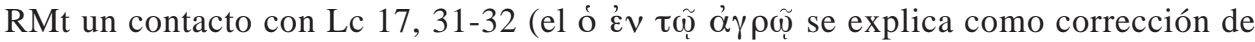
un texto incorrecto); pero esa fidelidad no excluye algunas diferencias en Lc. En Mt se encuentra situado este texto en el Discurso misionero, en el contexto del "costo" de seguir a Jesús (Mt 10, 34-39). Pero se trata de un dicho que tanto en Mt como en Lc aparece dos veces en cada uno: una vez en contexto y paralelismo marcano (Mc 8, 35 // Mt 16, 25 // Lc 9, 24), y otra vez en los lugares recién descritos. El dicho aparece también en Jn 12, 25.

Pertenencia a $Q$. A la verdad, no hay ningún indicio de que Lc 17, 33 y Mt 10, 39 provengan de una misma fuente, pues en lo más sustantivo ambos difieren de Mc de manera diversa: en vez de "querer salvar su alma" y del "salvarla" marcanos, Mt nos presenta "encontrar su alma", y Lc "buscar poseer su alma" y "vivificarla". Por lo demás, Mt nos presenta una construcción participial (ó cú $\tilde{\omega} v$ ) que es de suyo lucana (el RLc no la habría cambiado si la hubiera encontrado, y el RMt no la habría introducido si no la hubiera encontrado). Pensemos, pues, que estamos ante un traslapo $\mathrm{M}$ y L, y que el RMt le añadió a su fuente $\mathrm{M}$ un rasgo tomado de Mc: el

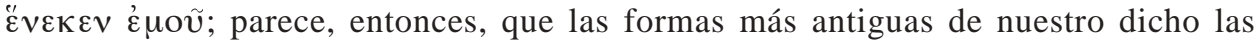
tendríamos en $\mathrm{M}$ y en $\mathrm{L}$.

\section{UNO SÍ, OTRO NO}

Lc 17, 34-35 // Mt 24, 40-41

Sinopticidad. En Lc se encuentra este díptico casi al final del conjunto escatológico lucano (Lc 17, 20-37). En Mt, al final de su capítulo "apocalíptico", inmediatamente antes de las tres grandes parábolas escatológicas (Mt 25, 1-13;14-30, y 31 46). Es bien sabido que las ediciones críticas no consideran primitivo el vers. 36 de Lc (idéntico a Mt 24, 40).

Texto. Parece claro que en Lc viene de $\mathrm{Q}$ el $\lambda \dot{\varepsilon} \gamma \omega$ vंũ̃v inicial (con el que señala el comienzo de una nueva unidad) y que el RMt lo ha cambiado por el $\tau o ́ \tau \varepsilon$ con que vincula este dicho con lo precedente. En cuanto a la primera mitad del primer cuadro, parece claro que es el RMt quien cambió la situación (que podría parecer escabrosa) presentada en el texto lucano e inimaginable el proceso contrario; en cambio, en la segunda mitad del mismo cuadro parece evidente que fue el RLc quien introdujo el futuro (en vez del presente que tiene Mt) y quien cambió el $\varepsilon \hat{i} \varsigma . .$.

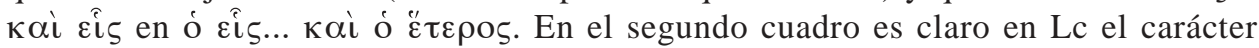

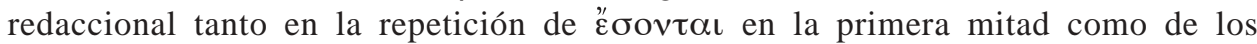
cambios de la segunda (futuro en vez de presente, y $\dot{\eta} \mu \varepsilon^{\prime} \alpha . . \dot{\eta} \delta \dot{\varepsilon} \dot{\varepsilon} \tau \dot{\varepsilon} \rho \alpha$ ). Lo que es

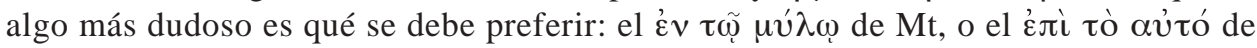




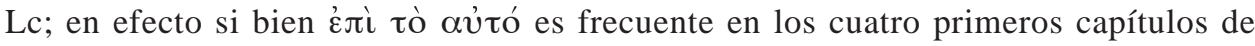

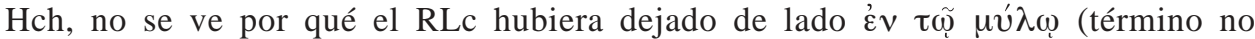
clásico, pero usado ampliamente por los autores helenísticos y por la LXX); por otra

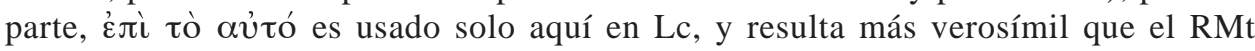
hubiera buscado una expresión más concreta. Pero no es posible llegar a una certeza.

\section{EL CADÁVER CONGREGA A LAS ÁGUILAS Lc 17, 37 // Mt 24, 28}

Es evidente el carácter redaccional del segundo "relato" con que el RLc (como tan a menudo) convierte un dicho aislado en una "anécdota". Este dicho es el último de la sección escatológica de Lc; en Mt, en cambio, es situado tópicamente en función del cómo y del dónde de la Parusía (Mt 24, 23-28).

En cuanto a la construcción, es claramente primitiva la epigramática de Lc (sin

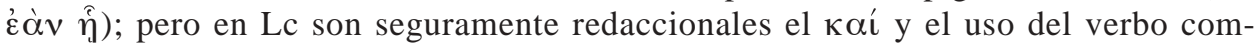
puesto; es asimismo probable que se deba al RLc el cambio de $\pi \tau \tilde{\omega} \mu \alpha$ por el término más digno $\sigma \tilde{\omega} \mu \alpha$ : también en el relato de la sepultación de Jesús, donde Mc $(15,45)$ usa $\pi \tau \tilde{\omega} \mu \alpha$, Lc recurre a $\sigma \tilde{\omega} \mu \alpha(\operatorname{Lc} 23,52-53)$.

\section{[72. DE LA PARÁBOLA DEL DINERO CONFIADO A VARIOS SIERVOS} Lc 19, 12-25 // Mt 25, 14-28

Sinopticidad. Esta parábola, en Lc, junto con la perícopa de Zaqueo que le precede (Lc 19, 1-11), constituye una pequeña inserción de material no marcano dentro del gran conjunto en que corre paralelo con Mc (Lc 18, 15-21, 33), con las normales omisiones y una pequeña adición (Lc 19, 39-44). En Mt, en cambio, es la segunda de tres parábolas escatológicas que el RMt le añadió a su versión, en el capítulo 24, del “Apocalipsis sinóptico" (Mt 25, 1-46).

Pertenencia a $Q$. Es demasiado evidente que se trata de la misma parábola: un hombre que al partir de viaje les confía a varios siervos cierta cantidad de dinero, y que al regreso felicita y premia a los que han entregado su dinero con ganancias y reprende y castiga al que se limitó a cuidar ese dinero sin hacerlo rendir. Pero las diferencias entre ambos son enormes: en Mt se trata de un hombre cualquiera, y en Lc de un "noble"; en Mt, el hombre parte de viaje sin mayores especificaciones, mientras que en Lc parte en busca de obtener la realeza, con oposición de sus conciudadanos; en Mt figuran solo tres siervos, mientras que en Lc, se mencionan diez (aunque al fin solo actúan tres); en Mt se habla de "talentos", y en Lc de "minas" (una "mina" era un 1/60 de un talento); en Mt se le da a cada siervo -según su capacidad- una diferente cantidad de "talentos" (uno, tres, cinco), mientras que en Lc, cada uno recibe la misma cantidad (una "mina"); en Mt, los dos primeros siervos duplican su capital, mientras que en Lc el primero multiplica por diez su capital y el segundo solo por cinco; en Mt la parábola termina con la atribución al siervo que más ganó, del dinero confiado al que menos ganó, mientras que en Lc 
termina con la ejecución de los que se opusieron a que "el rico" fuera nombrado Rey. A estas diferencias "reales" se añade una gran diversidad en el vocabulario ocupado: la "densidad" de vocabulario común se hace un poco mayor en la felicitación del propietario al primer siervo (Lc 19, 17 y Mt 25, 21) y sobre todo en el diálogo con el tercer siervo (Lc 19, 20-25 y Mt 25, 24-28).

Es fácil establecer la estructura primitiva de la parábola (un propietario cualquiera, tres siervos, misma cantidad de dinero a los tres - una "mina"-, uno obtiene una buena ganancia mientras que los otros se limitan a devolver, sin ganancias ni intereses, el dinero confiado a su iniciativa, reprensión a los carentes de iniciativa y premio al que fue capaz de arriesgar). Pero las modificaciones que aparecen en nuestros evangelios, ¿son obra de sus redactores sobre la misma fuente $(\mathrm{Q})$, o estamos ante un traslapo de $\mathrm{M}$ y de L? No es verosímil que ambos hayan usado a Q y además, cada uno, una fuente propia (traslapo Q-M-L); así es que no parece haber término medio entre Q y un traslapo M-L. Me parece menos inverosímil que se trate de variaciones en la transmisión oral de la parábola, y no que llegara cristalizada en formas diferentes a ambos evangelistas. En otras palabras, no creemos que estamos aquí ante un texto proveniente de Q.]

\section{RETRIBUCIÓN PARADÓJICA}

\section{Lc 19, 26 // Mt 25, 29}

Aquí estamos ante una correspondencia casi total entre Mt y Lc. Las únicas diferencias son: el añadido del $\gamma \alpha \dot{\rho}$ en Mt (ciertamente debido al RMt), y luego del

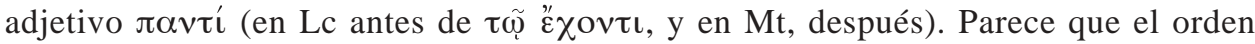
mateano se debe a la introducción del $\gamma \alpha \dot{\rho} \rho$.

\section{PROMESA DE JESÚS A LOS SUYOS \\ Lc 22, 28-30 // Mt 19, 28}

Sinopticidad. En Mt el dicho es introducido en el contexto marcano de la pregunta de Pedro por la recompensa que tendrían él y sus compañeros que lo habían dejado todo para seguir a Jesús (Mc 10, 28-30 // Mt 19, 27). En Lc, en cambio, figura en el pequeño "Sermón de la Última Cena" (Lc 22, 24-30), de carácter obviamente redaccional en cuanto unidad estructurada.

Pertenencia a Q. Estamos evidentemente dentro de un "núcleo duro" de Q, que contenía una promesa de Jesús a sus discípulos fieles: la de "juzgar a las doce tribus de Israel, sentados sobre tronos". Parece obvio que la calificación de los

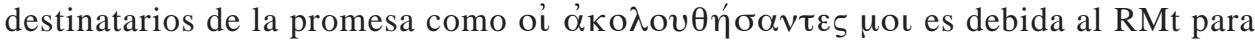
asegurar la función del dicho en el contexto marcano que escogió (cf. Mc 10, 28), y se debe reconocer que el texto lucano de los verss. 28-29 y la primera línea del vers. 30 se vinculan orgánicamente con la formulación de la promesa final, y podría haber figurado en $\mathrm{Q}$ y haber sido omitida por el RMt; pero es solo una posibilidad verosímil. 


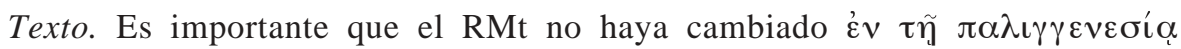
(término que solo aquí aparece en los evangelios); y hay que reconocer que fue el

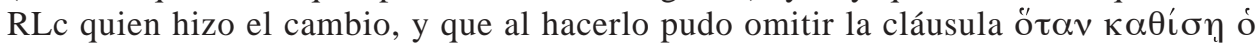

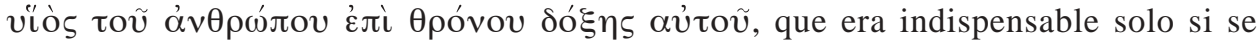

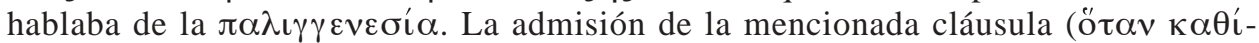

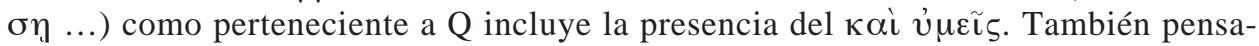
mos que en Q estaba $\varepsilon j i \quad \delta \omega ́ \delta \varepsilon \kappa \alpha \theta \rho o ́ v o v \varsigma$, y que fue su omisión por el RLc la que determinó el violento hipérbaton.

\section{EL TEXTO DE Q}

1. EL MENSAJE DEL BAUTISTA

Lc 3, 7-9 // Mt 3, 7-10

$7 \quad \gamma \varepsilon v v \eta \dot{\mu} \alpha \tau \alpha \dot{\varepsilon} \chi\llcorner\delta v \tilde{\omega} v$,

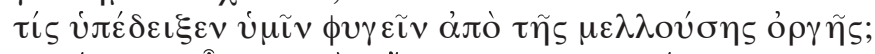

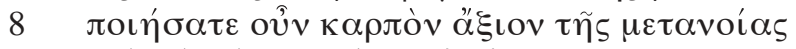

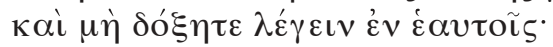

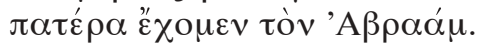

$\lambda \dot{\varepsilon} \gamma \omega \gamma \dot{\alpha} \rho \dot{v} \mu \tilde{\imath} v$ ö $\tau$

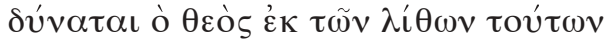

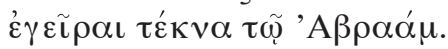

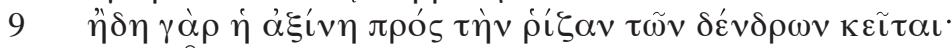

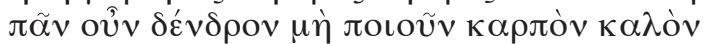

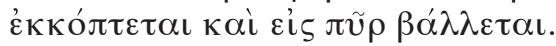

2. EL BAUTISMO ANUNCIADO POR JUAN

Lc 3, 16b-17 // Mt 3, 11b-12

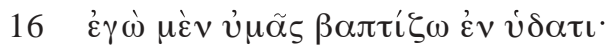

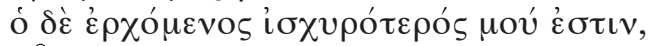

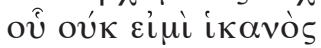

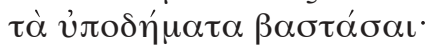

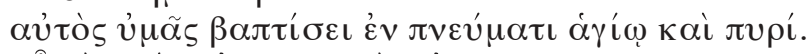

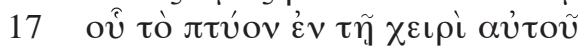

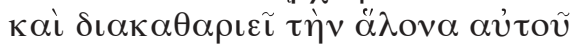

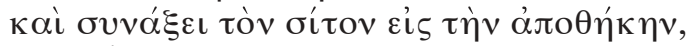

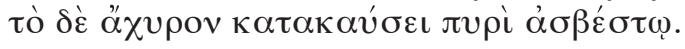

3. LAS TENTACIONES DE JESÚS Lc 4, 2-12 // Mt 4, 2-12

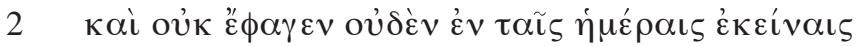

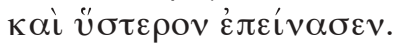




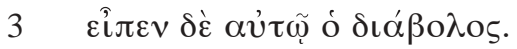

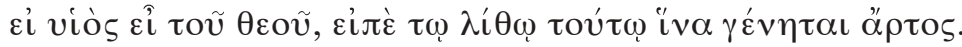

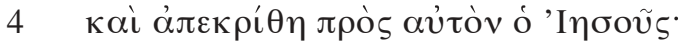

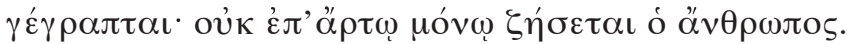

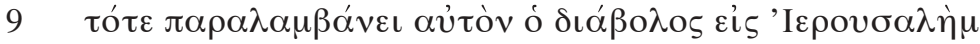

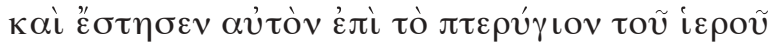
$\kappa \alpha i \lambda \varepsilon^{\prime} \gamma \varepsilon \iota \alpha \dot{v} \tau \tilde{\omega}$.

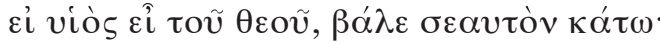

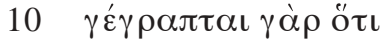

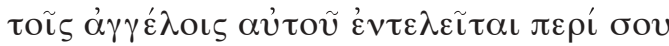

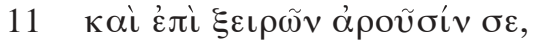

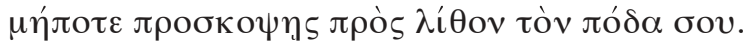

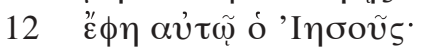

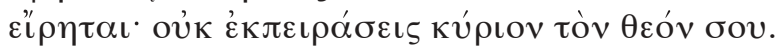

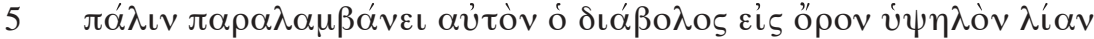

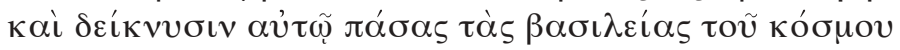

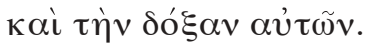

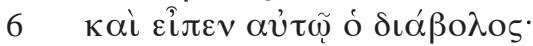
$\tau \alpha \tilde{v} \tau \alpha$ ool $\pi \alpha \dot{v} \tau \alpha \delta \omega \dot{\sigma} \omega$,

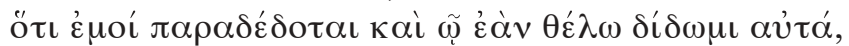

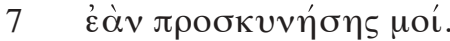

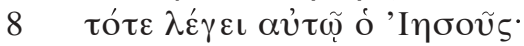
$\gamma^{\prime} \dot{\gamma} \rho \alpha \pi \tau \alpha \iota$.

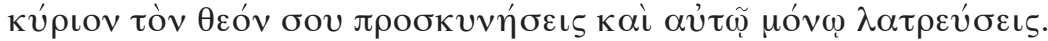

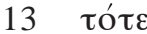

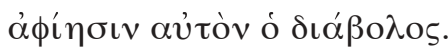

4. LAS BIENAVENTURANZAS

Lc 6, 20-23 // Mt 5, 3.12

$20 \mu \alpha \kappa \alpha ́ \rho ı ⿻$ oi $\pi \tau \omega \chi o i$,

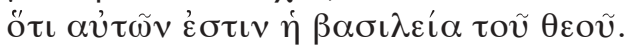

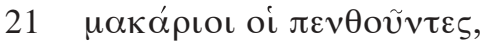

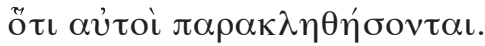

$\mu \alpha \kappa \alpha ́ \rho ı$ oi $\pi \varepsilon เ v \tilde{\omega} v \tau \varepsilon \varsigma$,

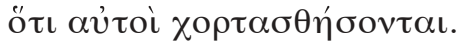

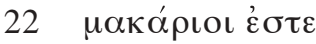

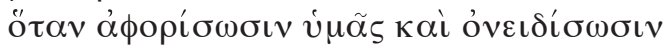

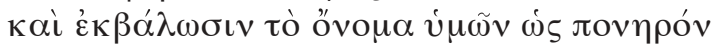

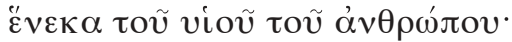

$23 \chi \alpha i \rho \varepsilon \tau \varepsilon \kappa \alpha i \dot{\alpha} \gamma \alpha \lambda \lambda \iota \tilde{\alpha} \sigma \theta \varepsilon$

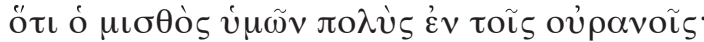

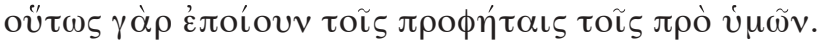


5. EL AMOR A LOS ENEMIGOS

Lc 6, 27-36 // Mt 5, 39-48 + 7, 12

$27 \varepsilon \dot{\varepsilon} \gamma \omega \dot{\omega} \delta \dot{\varepsilon} \lambda \dot{\varepsilon} \gamma \omega \dot{v} \mu \iota v$.

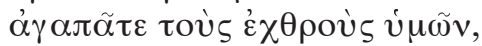

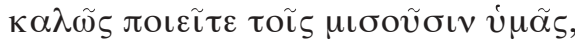

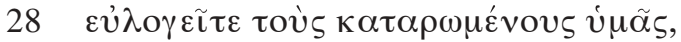

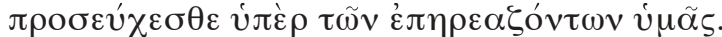

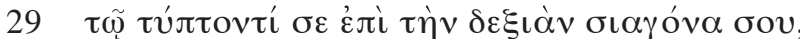

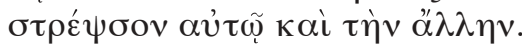

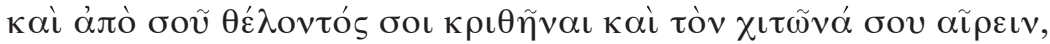

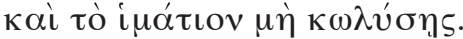

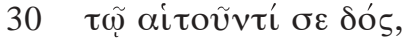

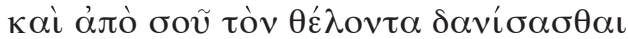

$\mu \grave{\eta} \alpha \dot{\pi} \sigma \tau \tau \alpha \phi \tilde{\eta} s$.

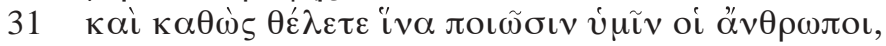

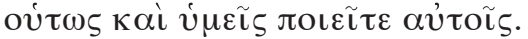

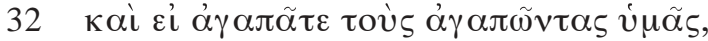

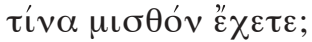

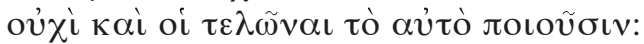

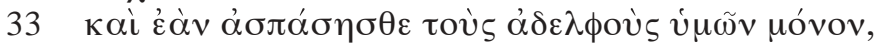

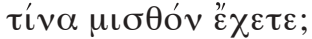

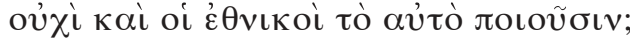

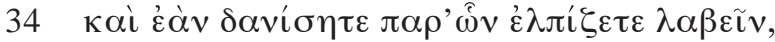

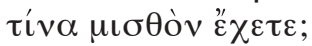

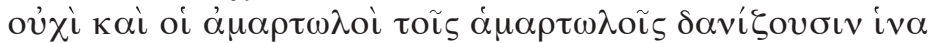

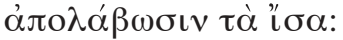

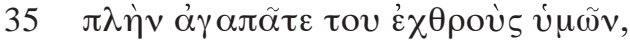
$\kappa \alpha i \dot{\alpha} \sigma \pi \alpha \dot{\zeta} \varepsilon \sigma \theta \varepsilon$

$\kappa \alpha i \delta \alpha v^{\prime} \zeta \varepsilon \sigma \theta \varepsilon \mu \eta \delta \dot{\varepsilon} \nu$ $\varepsilon \lambda \pi i \zeta o v \tau \varepsilon \varsigma$

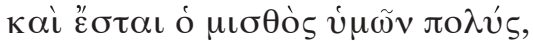

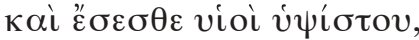

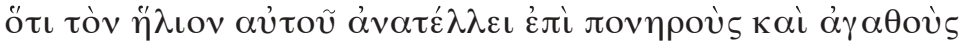

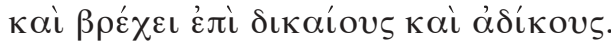

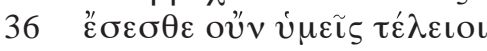

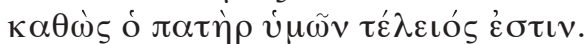

6. CON LA MISMA MEDIDA

Lc 6, 37-38 // Mt 7, 1-2

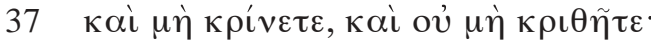

$\alpha \dot{\pi} \mathrm{o} \lambda v_{\varepsilon} \tau \varepsilon, \kappa \alpha i \dot{\alpha} \pi \mathrm{o} \lambda v \theta \dot{j} \sigma \theta \varepsilon$.

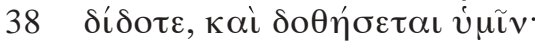

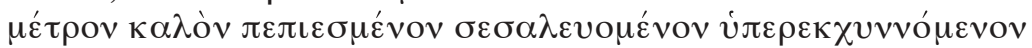

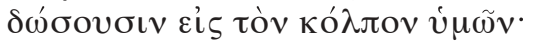

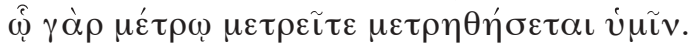


7. CIEGO GUÍA DE CIEGO

Lc 6, 39 // Mt 15, 14

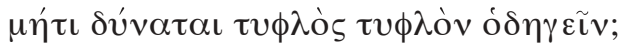

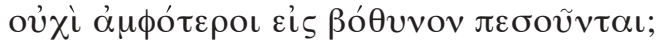

8. EL LÍMITE DEL DISCÍPULO

Lc 6, 40 // Mt 10, 24-25

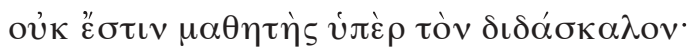

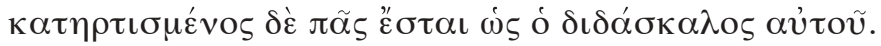

9. LA MOTA Y LA VIGA EN EL OJO

Lc 6, 41-42 // Mt 7, 3-5

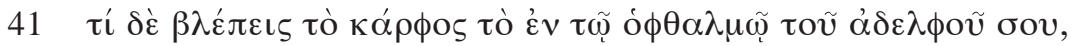

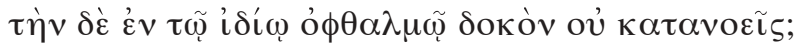

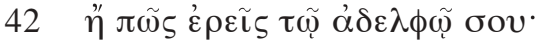

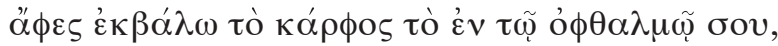

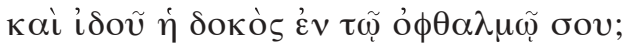

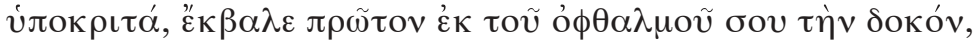

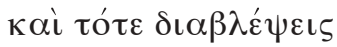

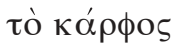

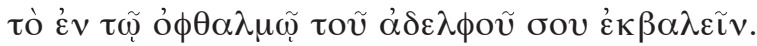

10. EL ÁRBOL JUZGADO POR SU FRUTO

Lc 6, 43-44 // Mt 7, 16-18

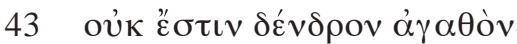

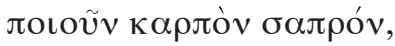

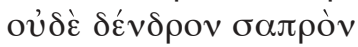

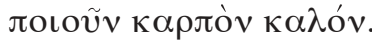

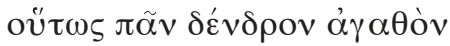

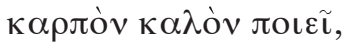

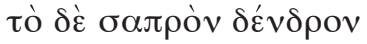

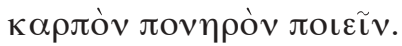

$44 \pi \tilde{\alpha} v \delta \varepsilon^{\prime} v \delta \rho o v$

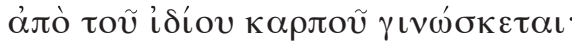

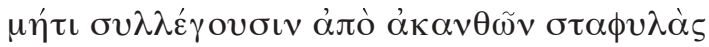

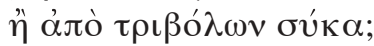


11. EL CORAZÓN, FUENTE DEL BIEN Y DEL MAL

Lc 6, 45 // Mt 12, 34b-35

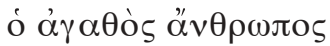

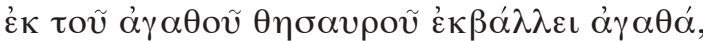

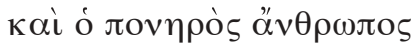

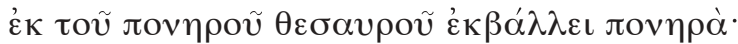

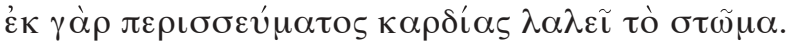

12. DECIR “SEÑOR, SEÑOR”, Y NO HACER

Lc 6, 46 // Mt 7, 21

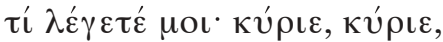

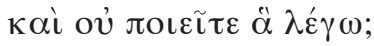

13. CONSTRUIR SOBRE ROCA O SOBRE ARENA

Lc 6, 47-49 // Mt 7, 24-27

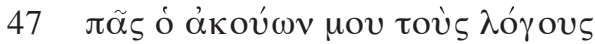

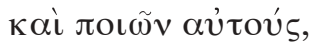

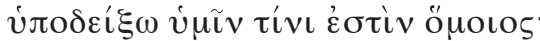

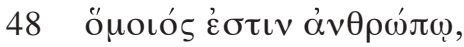

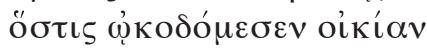

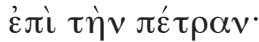

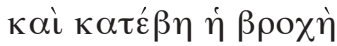

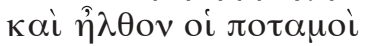

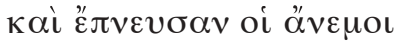

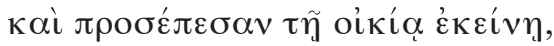

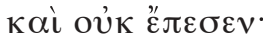

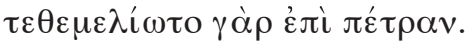

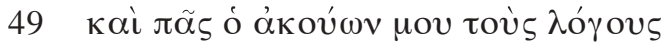

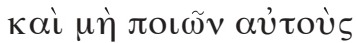

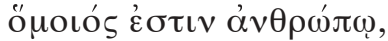

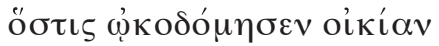

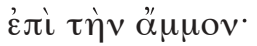

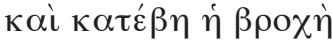

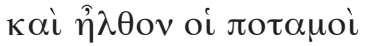

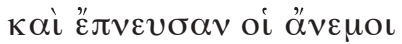

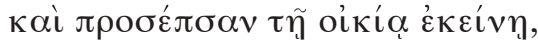

$\kappa \alpha i$ " $\pi \varepsilon \sigma \varepsilon v$,

$\kappa \alpha i \grave{\eta} v \dot{\eta} \pi \tau \tilde{\omega} \sigma \iota \varsigma \alpha \dot{\tau} \tau \tilde{\eta} \varsigma \mu \varepsilon \gamma \alpha \dot{\lambda} \lambda \eta$. 


\section{DESPLAZAMIENTO A CAFARNAÚM}

Lc 7, 1 // Mt 7, 28a

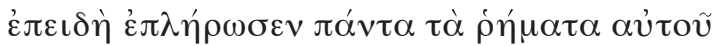

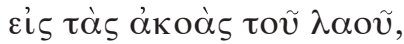

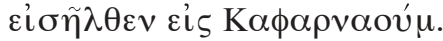

\section{EL SIERVO DEL CENTURIÓN}

Lc 7, 6b-9 // Mt 8, 8-10

$6 \quad$ ó $\dot{\varepsilon} \kappa \alpha \tau o ́ v \tau \alpha \rho \chi o \varsigma$ है $\phi \eta$.

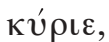

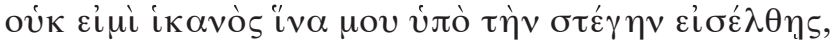

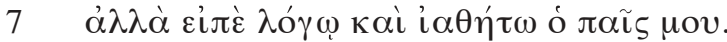

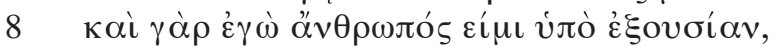

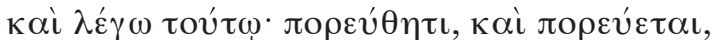

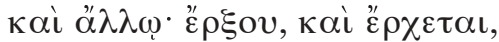

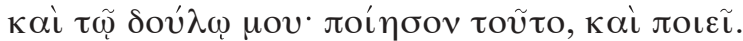

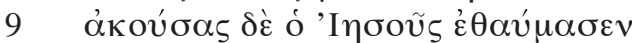

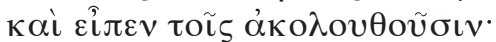
$\lambda \varepsilon^{\prime} \gamma \omega \dot{v} \mu \tilde{\imath} v$.

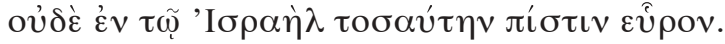

\section{LA PREGUNTA DEL BAUTISTA}

Lc 7, 18-23 // Mt 11, 7-11

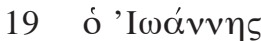

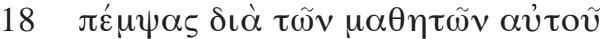

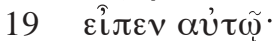

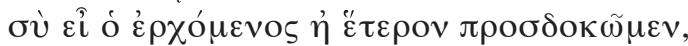

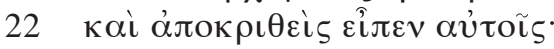

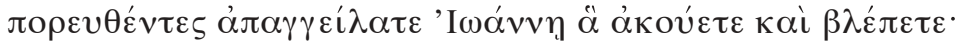

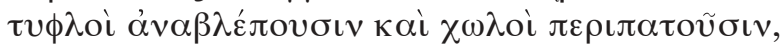

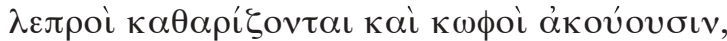

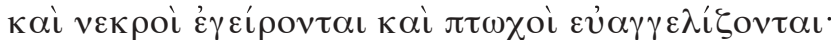

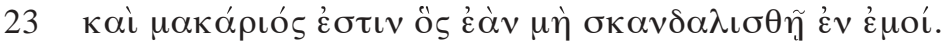

17. GRANDEZA Y LUGAR DEL BAUTISTA Lc 7, 24-28 // Mt 11, 7-11

$24 \tau o u ́ \tau \omega v \delta \dot{\varepsilon} \pi \circ \rho \varepsilon v o ́ v \tau \omega \nu$

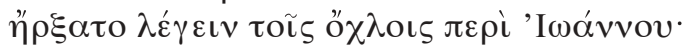

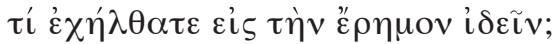




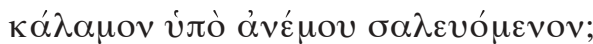

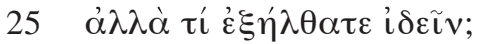

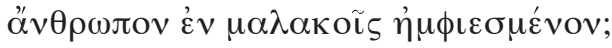

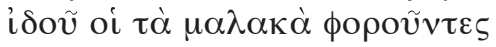

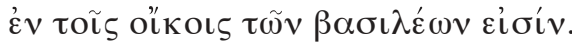

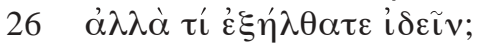

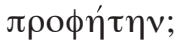

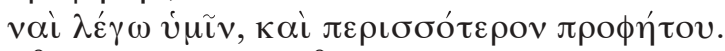

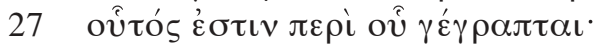

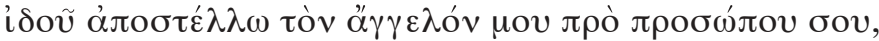

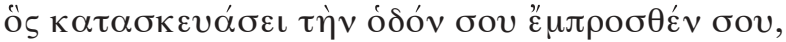

$28 \lambda \dot{\varepsilon}^{\prime} \gamma \omega \dot{v} \mu \tilde{\imath} v$.

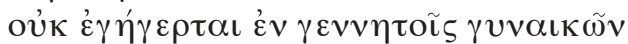

$\mu \varepsilon i \zeta \omega v$ 'I $\omega \alpha \dot{v} v o v$.

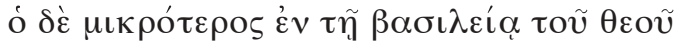

$\mu \varepsilon i \xi \omega v \alpha \dot{\tau} \tau \tilde{v} \dot{\varepsilon} \sigma \tau \iota v$.

18. UNA GENERACIÓN DE NIÑOS TAIMADOS

Lc 7, 31-35 // Mt 11, 16-19

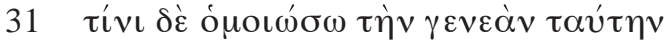

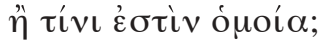

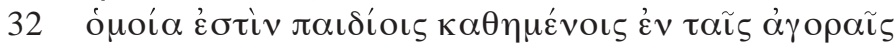

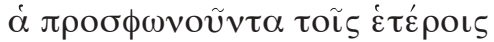

$\lambda \varepsilon^{\prime} \gamma$ ov $\sigma \mathrm{\iota v}$.

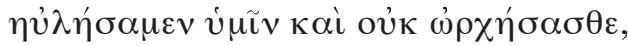

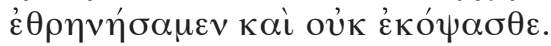

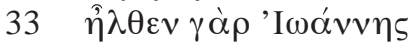

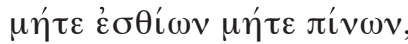

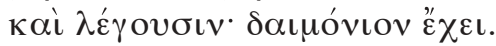

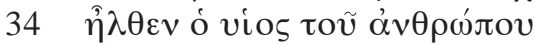

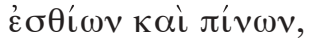

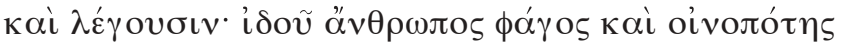

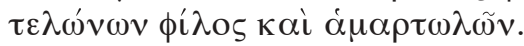

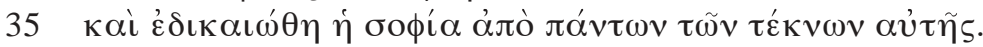

19. EXIGENCIAS DEL SEGUIMIENTO DE JESÚS

Lc 9, 57-60 // 8, 19-22

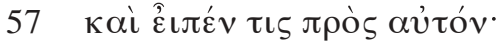

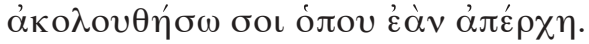

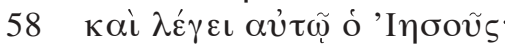

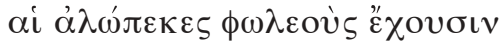

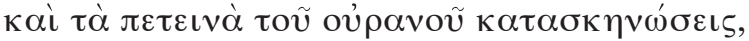




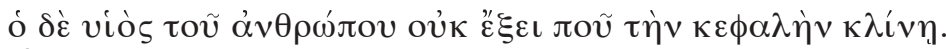

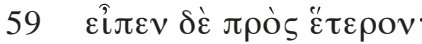

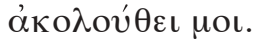

ó $\delta \dot{\varepsilon} \varepsilon \hat{\imath} \pi \varepsilon v$.

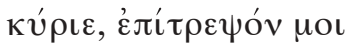

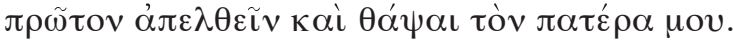

$60 \varepsilon \hat{\imath} \pi \varepsilon v \delta \dot{\varepsilon} \alpha \dot{\tau} \tau \tilde{\omega}$.

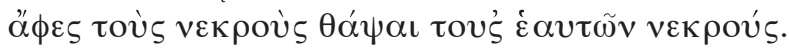

20. SIEGA GRANDE, OBREROS POCOS

Lc 10, 2 // Mt 9, 37-38

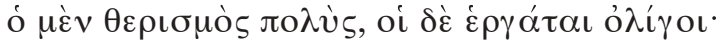

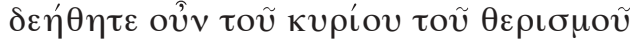

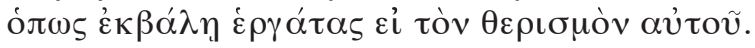

\section{CONSIGNAS PARA LA MISIÓN}

Lc 10, 3-12 // Mt 10, 7-16

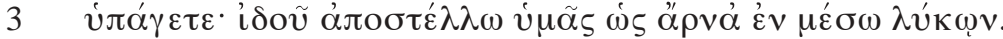

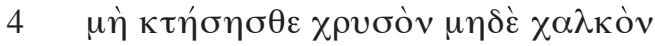

$\varepsilon i \varsigma \tau \dot{\alpha} \varsigma \xi \tilde{\omega} v \alpha \varsigma \dot{v} \mu \tilde{\omega} v$

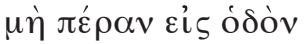

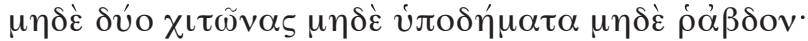

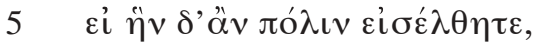

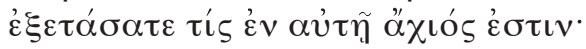

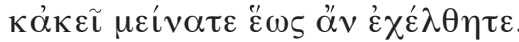

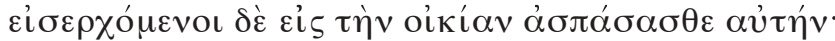

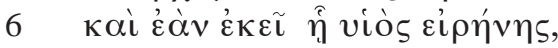

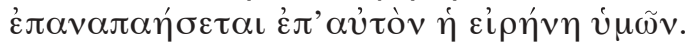

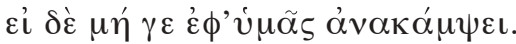

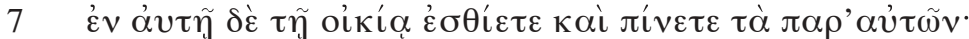

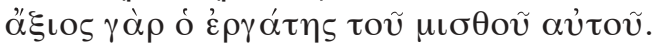

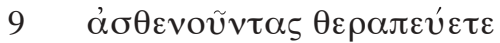

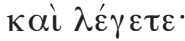

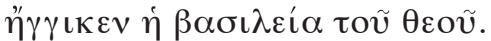

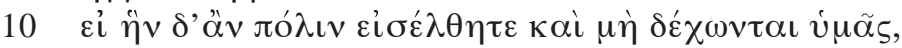

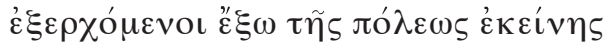

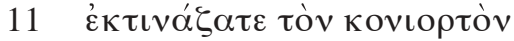

$\tau \tilde{\omega} v \pi \circ \delta \tilde{\omega} v \dot{v} \mu \tilde{\omega} v$.

$12 \lambda \dot{\varepsilon}^{\prime} \gamma \omega \dot{v} \mu \tilde{\nu} v$.

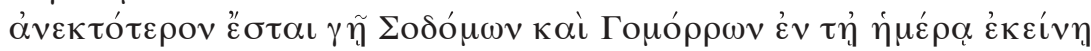

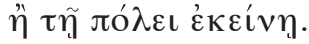


22. AYES CONTRA LAS CIUDADES DE GALILEA

Lc 10, 13-15 // Mt 11, 21-23

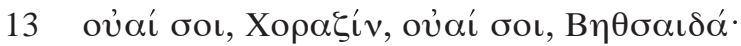

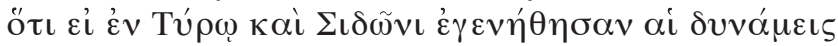

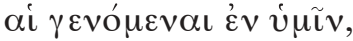

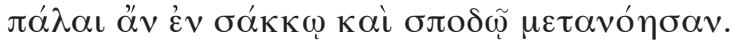

$14 \pi \lambda \dot{\eta} v$

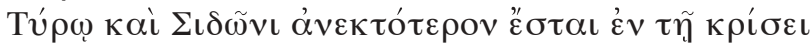

ทेंนัน̃v.

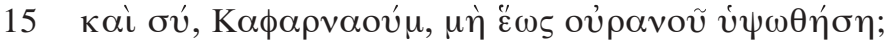

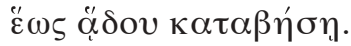

23. ACOGER A JESÚS EN SUS DISCÍPULOS Y EN JESÚS AL PADRE

Lc 10, 16 // Mt 10, 40

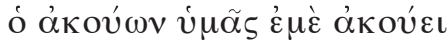

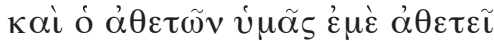

ó $\delta \dot{\varepsilon} \dot{\varepsilon} \mu \dot{\varepsilon} \alpha \dot{\alpha} \theta \varepsilon \tau \tilde{\omega} v$

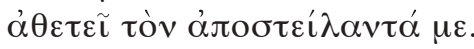

24. JESÚS, HIJO DEL PADRE

Lc 10, 21-22 // Mt 11, 25-27

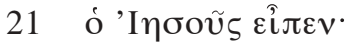

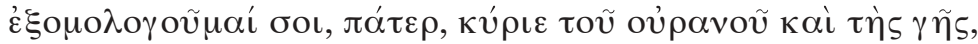

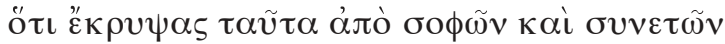

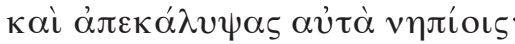

vai ò $\pi \alpha \tau \eta \dot{\rho} \rho$.

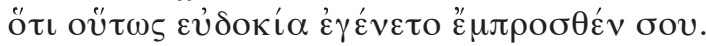

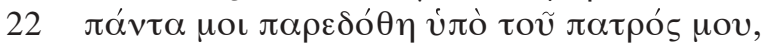

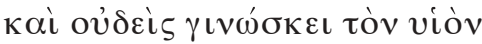

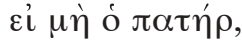

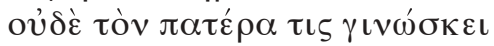

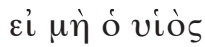

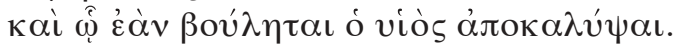

25. DICHOSOS LOS QUE VEN LO QUE PROFETAS Y REYES QUISIERON VER Lc 10, 23-24 // Mt 13, 16-17

$23 \mu \alpha \kappa \alpha ́ \rho ı$ oi ỏ $\phi \theta \alpha \lambda \mu о i$

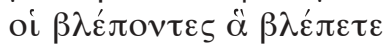

$\kappa \alpha i \tau \dot{\alpha} \hat{\omega} \tau \alpha$

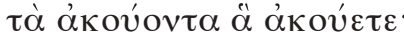




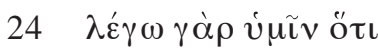

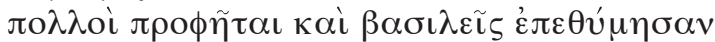

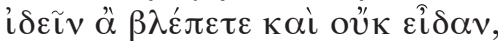

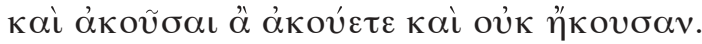

26. LA ORACIÓN ENSEÑADA POR JESÚS

Lc 11, 2-4 // Mt 6, 9-13

2 ó $\tau \alpha \nu \pi \rho \circ \sigma \varepsilon v \chi \eta \sigma \theta \varepsilon \lambda \varepsilon^{\prime} \gamma \varepsilon \tau \varepsilon$.

$\pi \alpha \dot{\tau \varepsilon \rho,}$

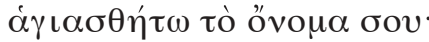

$\dot{\varepsilon} \lambda \theta \dot{\varepsilon} \tau \omega \dot{\eta} \beta \alpha \sigma \iota \lambda \varepsilon \dot{c} \alpha$ oov

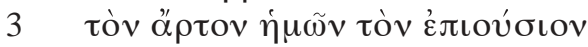

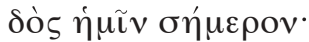

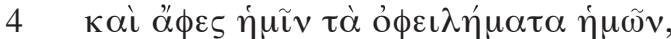

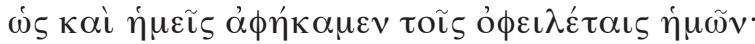

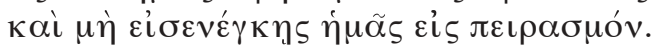

27. LA PETICIÓN DE LOS HIJOS CIERTAMENTE ACOGIDA POR EL PADRE Lc 11, 9-13 // Mt 12, 22-30

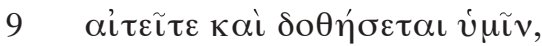

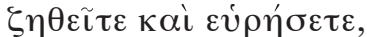

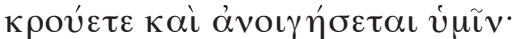

$10 \pi \tilde{\alpha} \varsigma \gamma \dot{\alpha} \rho$ ó $\alpha i \tau \tilde{\omega} v \lambda \alpha \mu \beta \alpha \dot{v} v \varepsilon$

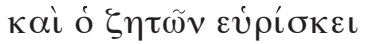

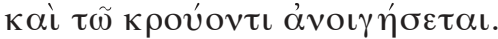

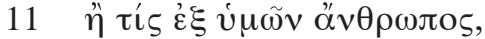

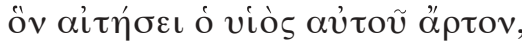

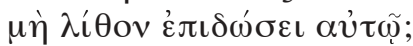

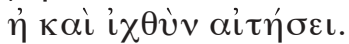

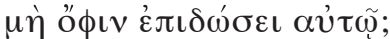

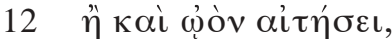

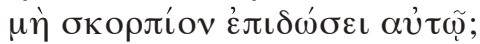

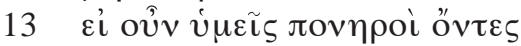

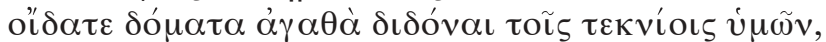

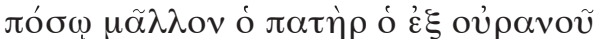

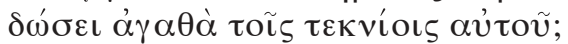

28. ¿QUIÉN ESTÁ DETRÁS DE LOS EXORCISMOS DE JESÚS?

Lc 11, 14-20 // Mt 12, 22-28

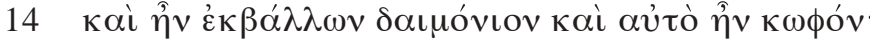

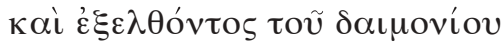




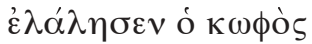

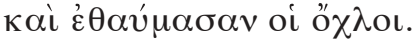

$15 \tau \iota v \dot{\varepsilon} \varsigma \delta \dot{\varepsilon} \varepsilon \xi \alpha u \dot{\tau} \tau \tilde{\omega} v \varepsilon \hat{\varepsilon} \pi \mathrm{ov}$.

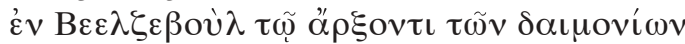

$\varepsilon \kappa \beta \alpha ́ \lambda \lambda \varepsilon \iota \tau \dot{\alpha} \delta \alpha \iota \mu o ́ v \iota \alpha$.

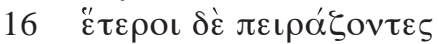

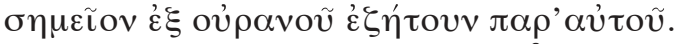

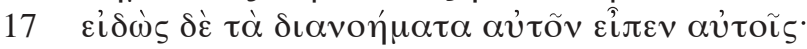

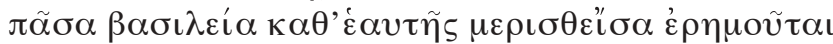

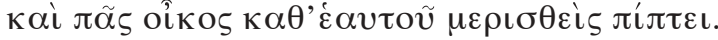

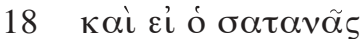

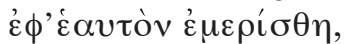

$\pi \tilde{\omega} \varsigma \sigma \tau \alpha \theta \dot{\sigma} \sigma \varepsilon \tau \alpha \iota \dot{\eta} \beta \alpha \sigma \iota \lambda \varepsilon \dot{\imath} \alpha \alpha \dot{\tau} \tau o \tilde{v} ;$

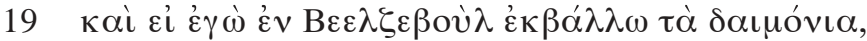

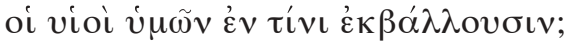

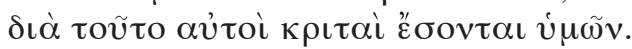

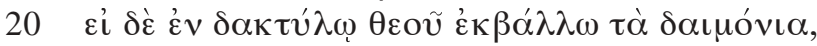

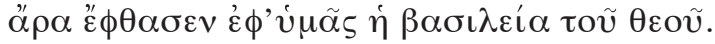

29. EL FUERTE Y EL MÁS FUERTE

Lc 11, 21-22 // Mt 12, 29

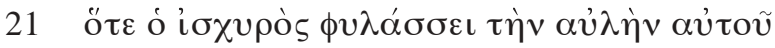

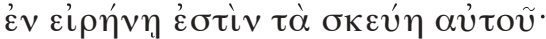

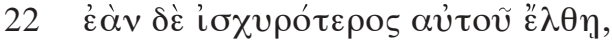

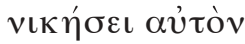

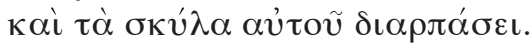

30. NO ESTAR CON JESÚS

Lc 11, 23 // Mt 12, 30

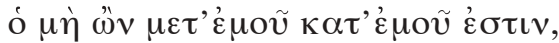

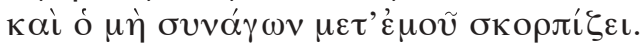

31. LA VENGANZA DEL DEMONIO DESALOJADO Lc 11, 24-26 // Mt 12, 43-45

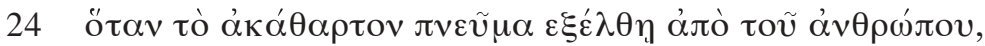

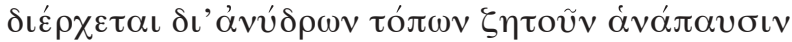

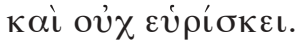

$\tau o ́ \tau \varepsilon \lambda \varepsilon^{\prime} \gamma \varepsilon \iota$.

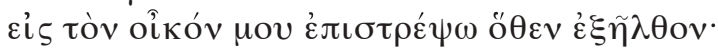

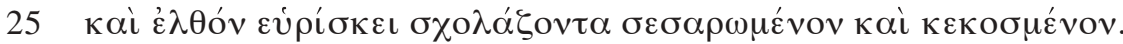




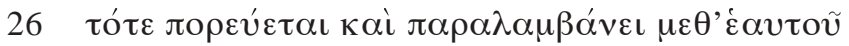

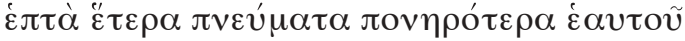

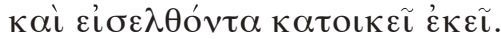

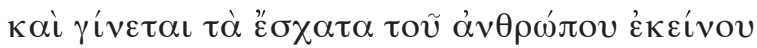
$\chi \varepsilon i \rho \rho v \alpha \tau \tilde{\omega} v \pi \rho \omega ́ \tau \omega v$.

32. EL SIGNO DE JONÁS

Lc 11, 29-32 // Mt 12, 39-42

$29 \gamma \varepsilon v \varepsilon \grave{\alpha} \pi 0 v \eta \rho \grave{\alpha}$

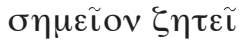

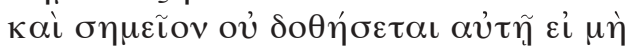

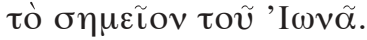

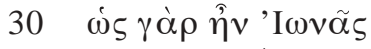

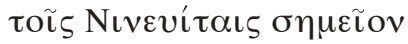

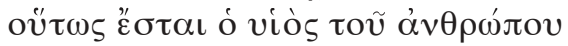

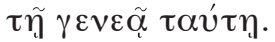

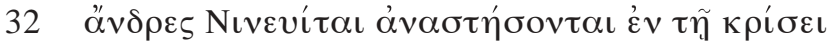

$\mu \varepsilon \tau \dot{\alpha} \tau \tilde{\jmath} \varsigma \gamma \varepsilon v \varepsilon \tilde{\alpha} \varsigma \tau \alpha u ́ \tau \eta \varsigma$

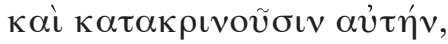

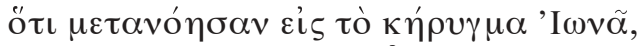

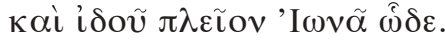

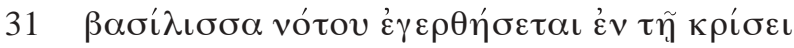
$\mu \varepsilon \tau \dot{\alpha} \tau \tilde{\eta} \varsigma \gamma \varepsilon v \varepsilon \tilde{\alpha} \varsigma \tau \alpha u ́ \tau \eta \varsigma$

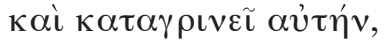

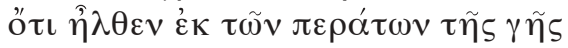

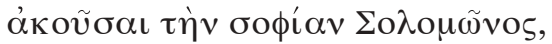

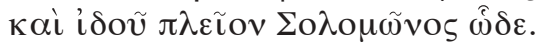

33. LA LÁMPARA, PARA ALUMBRAR

Lc 11, 33 // Mt 5, 15

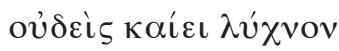

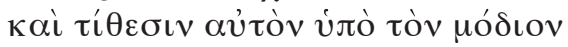

$\alpha \lambda \lambda^{\prime}{ }^{\prime} \varepsilon \pi i \tau \eta \dot{v} v \lambda v \chi v i ́ \alpha v$,

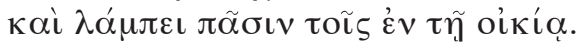

\section{OJO SANO Y OJO ENFERMO}

Lc 11, 34-35 // Mt 6, 22-23

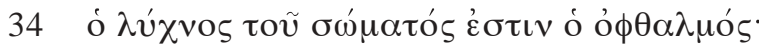

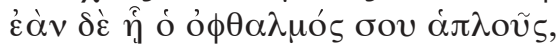

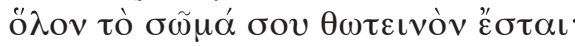




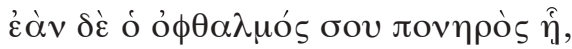

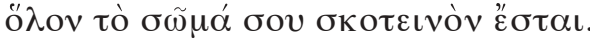

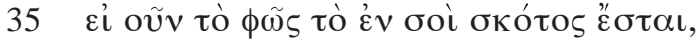

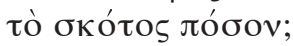

35. PRIMEROS “AYES” CONTRA LOS ESCRIBAS Y FARISEOS Lc 11, 39-44 // Mt 23, 23-27 + 6-7

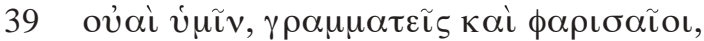

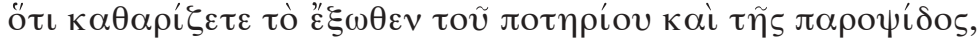

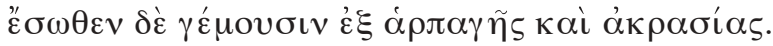

$40 \phi \alpha \rho \iota \sigma \alpha \tilde{\varepsilon} \varepsilon \tau \phi \lambda \dot{\varepsilon}$,

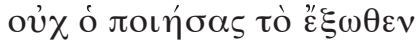

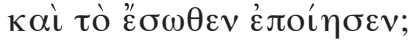

41 ? ? ?

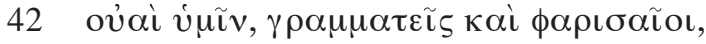

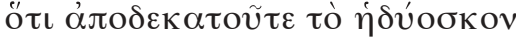

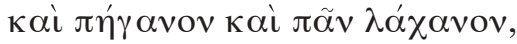

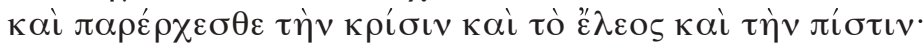

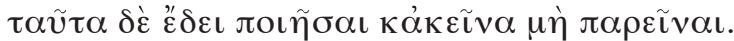

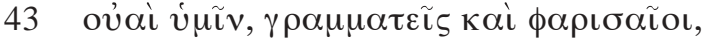

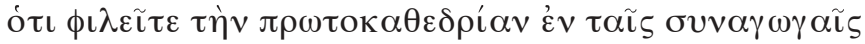

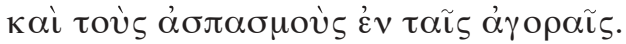

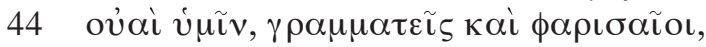

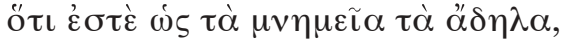

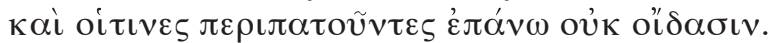

36. MÁS “AYES” CONTRA ESCRIBAS Y FARISEOS Lc 11, 46-48 // Mt 23, 29-32

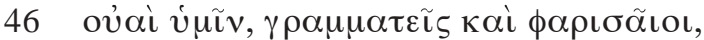

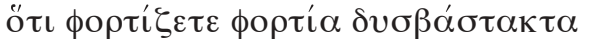

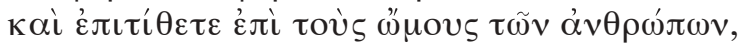

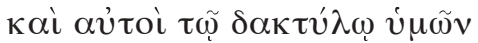

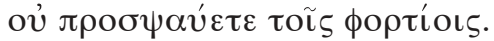

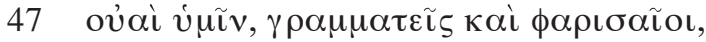

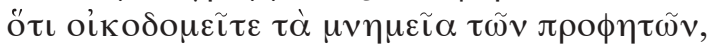

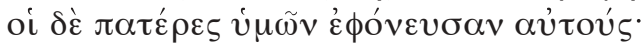

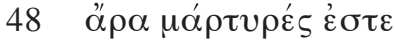

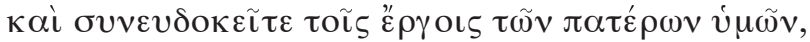

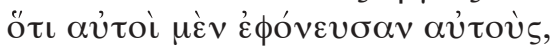

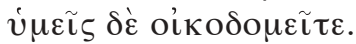


37. LA SABIDURÍA Y SUS ENVIADOS

Lc 11, 49-51 // Mt 23, 34-36

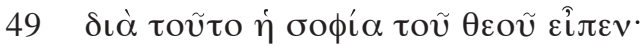

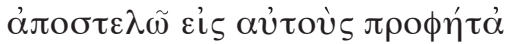

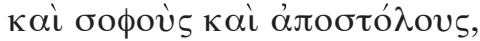

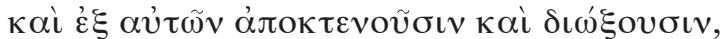

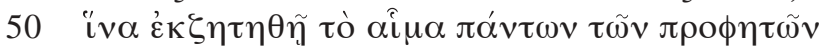

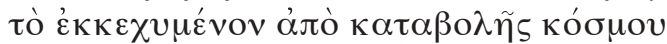

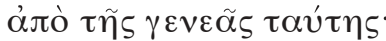

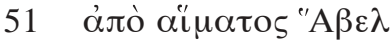

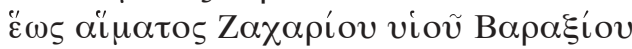

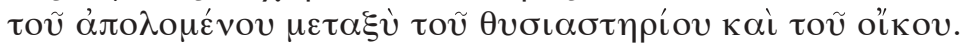

vai $\lambda \dot{\varepsilon} \gamma \omega \dot{v} \mu \tilde{\imath} v$.

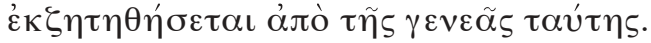

38. ÚLTIMO “AY” CONTRA ESCRIBAS Y FARISEOS

Lc 11, 52 // Mt 23, 13

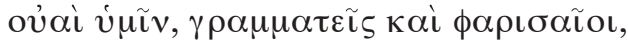

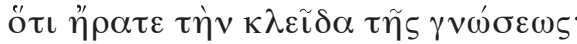

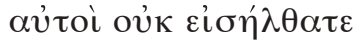

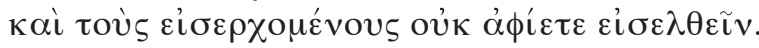

39. LA LUZ SE IMPONDRÁ

Lc 12, 2-7 // Mt 10, 26-31

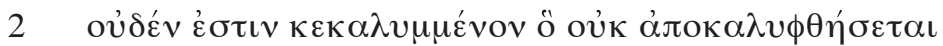

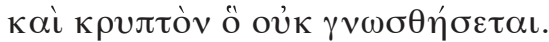

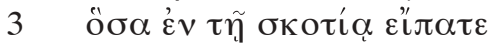

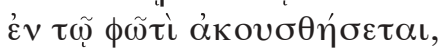

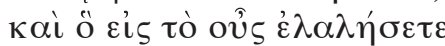

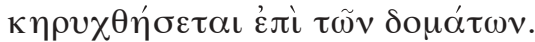

$4 \lambda \varepsilon_{\varepsilon} \gamma \omega \delta \dot{\varepsilon} \dot{v} \mu \tilde{\imath} v$.

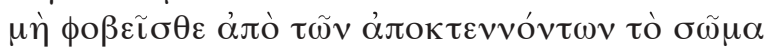

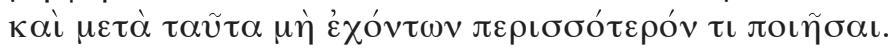

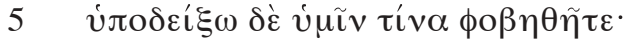

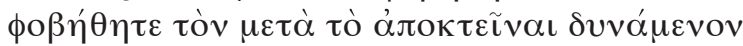
$\dot{\varepsilon} \mu \beta \alpha \lambda \varepsilon \tilde{\imath} v \varepsilon \dot{\varepsilon} \varsigma \tau \grave{\eta} v \gamma \dot{\varepsilon} \varepsilon v v \alpha v$. vai $\lambda \dot{\varepsilon} \gamma \omega \dot{v} \mu \tilde{\imath} v, \tau o \tilde{\tau} \tau$ ov $\phi о \beta \eta \dot{\theta} \theta \eta \tau \varepsilon$.

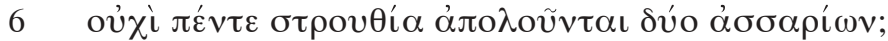

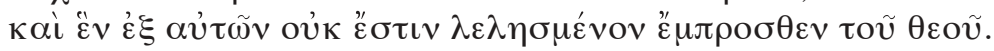

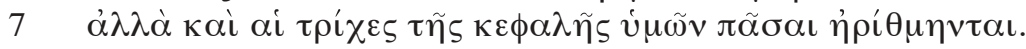

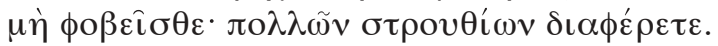


40. CONFESAR O NEGAR A JESÚS

Lc 12, 8-9 // Mt 10, 32-33

$8 \lambda \hat{\varepsilon}^{\prime} \gamma \mathrm{o} \delta \dot{\varepsilon} \dot{v} \mu \tilde{\imath} v$,

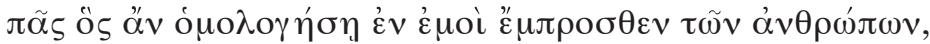

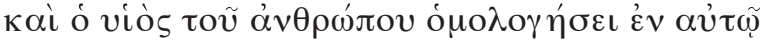

$\iota^{\prime} \mu \pi \rho \circ \sigma \theta \varepsilon v \tau \tilde{\omega} v \dot{\alpha} \gamma \gamma \dot{\varepsilon} \lambda \omega \nu \tau \sigma \tilde{v} \theta \varepsilon о \tilde{v}$.

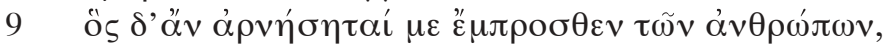

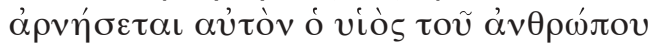

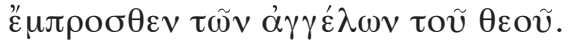

41. LA PALABRA IMPERDONABLE CONTRA EL ESPÍRITU SANTO Lc 12, 10 // Mt 12, 32

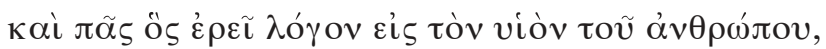
$\alpha \dot{\phi} \theta \dot{\eta} \sigma \varepsilon \tau \alpha \iota \alpha u \dot{\tau} \tilde{\omega}$.

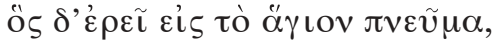

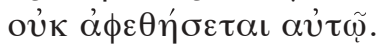

42. EL ESPÍRITU AYUDARÁ A LOS DISCÍPULOS PERSEGUIDOS

Lc 12, 11-12 // Mt 10, 19-20

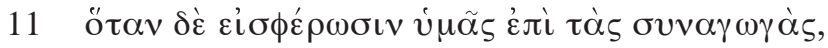

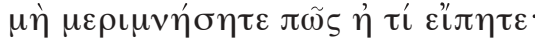

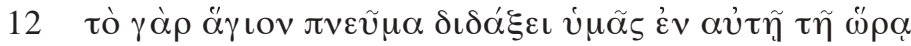
$\ddot{\alpha} \delta \varepsilon \hat{\imath} \varepsilon \dot{\imath} \pi \varepsilon \tilde{\imath} v$.

43. CONFIANZA EN LA PROVIDENCIA DEL PADRE

Lc 12, 22-34 // Mt 6, 19-33

$22 \delta \iota \dot{\alpha} \tau o \tilde{\tau} \tau o \lambda \hat{\varepsilon}^{\prime} \omega \omega \dot{v} \mu \tilde{\imath} v$.

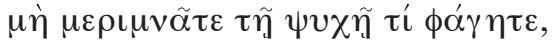

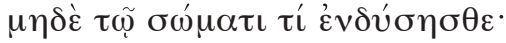

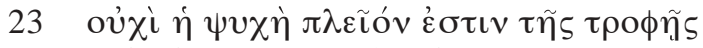

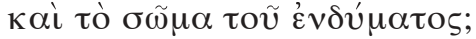

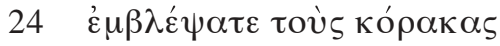

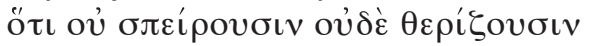

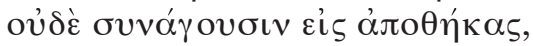

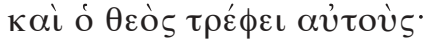

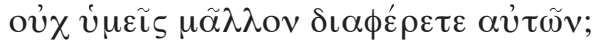

$25 \tau i \varsigma \varsigma \delta \dot{\varepsilon} \dot{\varepsilon} \xi \dot{v} \mu \tilde{\omega} v \mu \varepsilon \rho \iota \mu \nu \tilde{\omega} v$

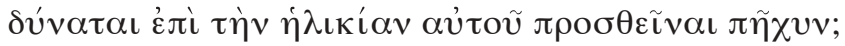

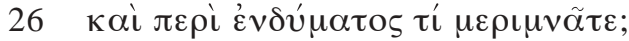




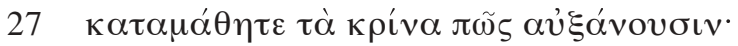

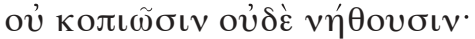

$\lambda \dot{\varepsilon} \gamma \omega \delta \dot{\varepsilon} \dot{v} \mu \tilde{\imath} v$,

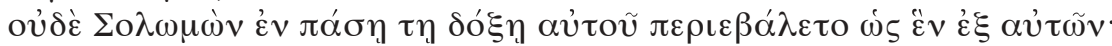

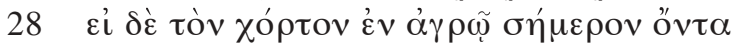

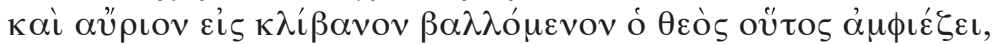

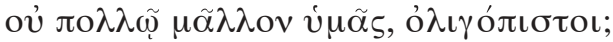

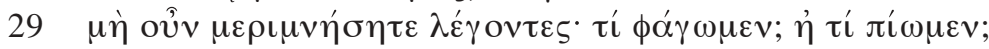

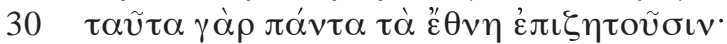

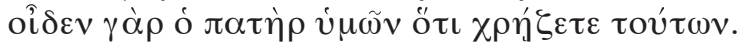

$31 \xi \eta \tau \varepsilon \tilde{\imath} \tau \varepsilon \delta \dot{\varepsilon} \tau \dot{\eta} v \beta \alpha \sigma \iota \lambda \varepsilon i \alpha \nu \alpha u ̛ \tau o \tilde{v}$,

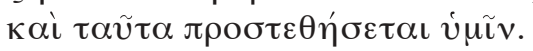

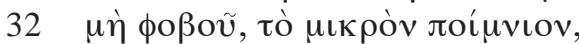

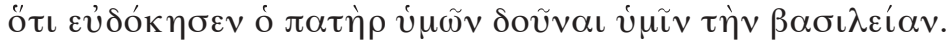

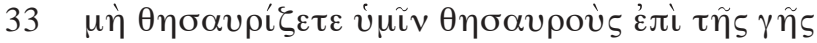

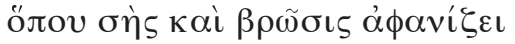

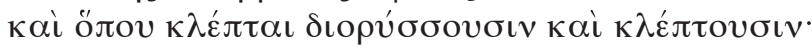
$\theta \eta \sigma \alpha v \rho i ́ \zeta \varepsilon \tau \varepsilon \delta \dot{\varepsilon} \dot{v} \mu \tilde{\imath} v$

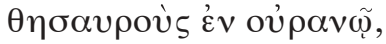

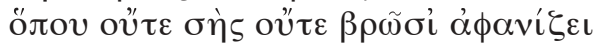

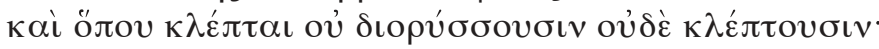

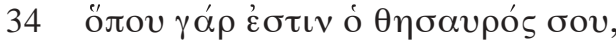

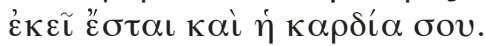

44. PREPARADOS PARA LA HORA IMPREDECIBLE Lc 12, 39-46 // Mt 24, 43-51

$39 \gamma \iota \omega \omega ́ \sigma \kappa \varepsilon \tau \varepsilon \delta \dot{\varepsilon}$

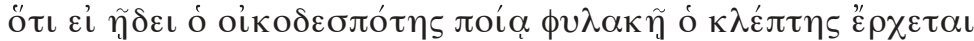

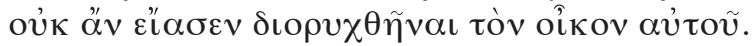

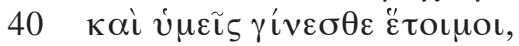

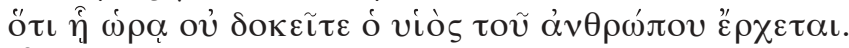

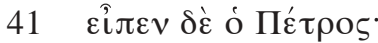

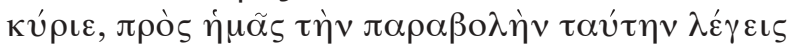

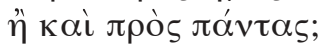

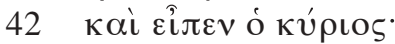

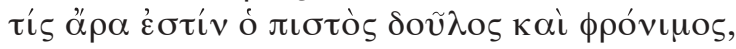

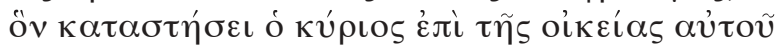

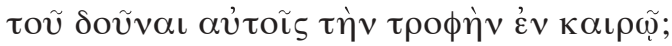

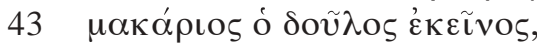

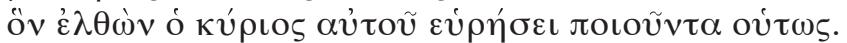

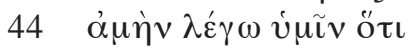

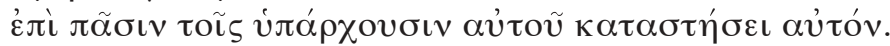

$45 \dot{\varepsilon} \dot{\alpha} \nu \delta \dot{\varepsilon}$ हैı

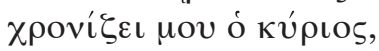




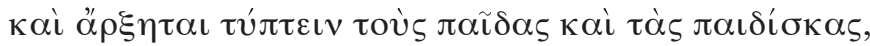

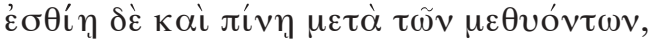

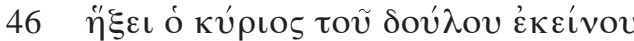

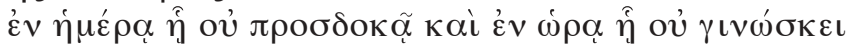

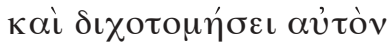

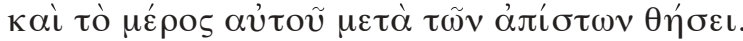

45. JESÚS FRENTE A SU DESTINO

Lc 12, 49-50 (no presente en Mt)

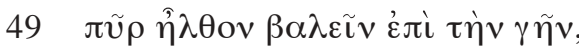

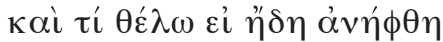

$50 \beta \alpha \dot{\tau} \tau \iota \sigma \mu \alpha \delta \dot{\varepsilon}$ " $\chi \omega \beta \alpha \pi \tau \iota \sigma \theta \tilde{\eta} \nu \alpha l$,

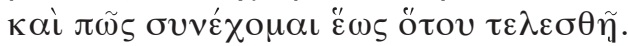

46. JESÚS, FACTOR DE DISOCIACIÓN

Lc 12, 51-53 // Mt 10, 34-36

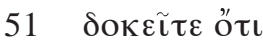

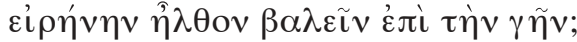

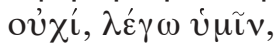

$\dot{\alpha} \lambda \lambda \dot{\alpha} \delta \iota \alpha \mu \varepsilon \rho \iota \sigma \mu o ́ v$.

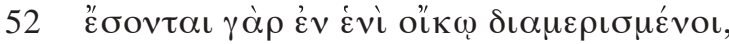

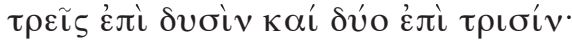

$\delta \iota \alpha \mu \varepsilon \rho \iota \sigma \theta \eta \dot{\sigma o v \tau \alpha \iota ~}$

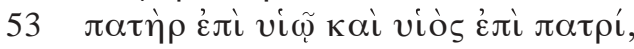

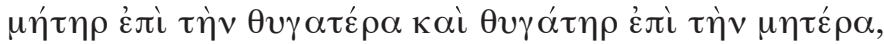

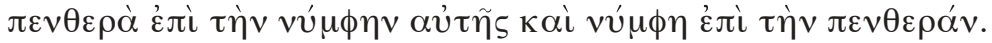

47. INCAPACIDAD DE DISCERNIR EL PROPIO TIEMPO Lc 12, 54-57 // Mt 16, 2-3

$54{ }^{\prime \prime} \lambda \varepsilon \gamma \varepsilon v \delta \dot{\varepsilon} \tau o \tilde{\varsigma} \varsigma$ o $\chi \lambda \mathrm{o \iota \varsigma}$.

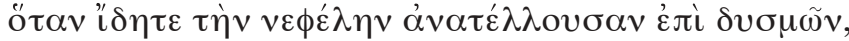

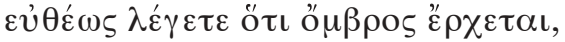

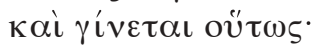

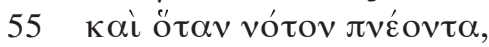

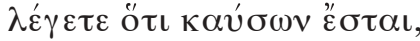

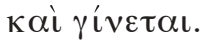

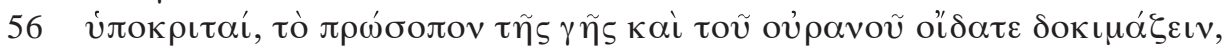

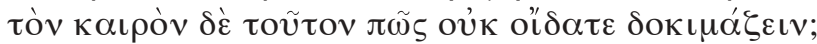

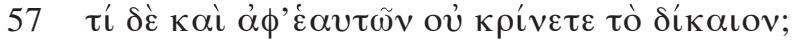


48. MAÑANA PUEDE SER DEMASIADO TARDE

Lc 12, 58-59 // Mt 5, 25-26

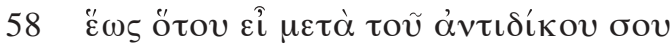

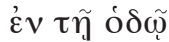

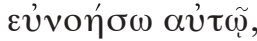

$\mu \eta \dot{\pi} \tau \sigma \varepsilon \dot{\varepsilon} \sigma \varepsilon \pi \alpha \rho \alpha \delta \tilde{\omega} \tau \tilde{\varphi} \kappa \rho \iota \tau \tilde{\eta}$

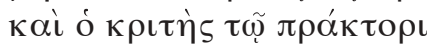

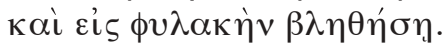

$59 \lambda \varepsilon^{\prime} \gamma \omega$ ool,

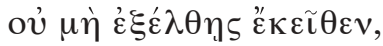

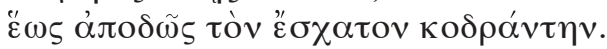

49. EL GRANO DE MOSTAZA Y LA LEVADURA

Lc 13, 18-21 // Mt 13, 31-33

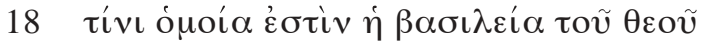

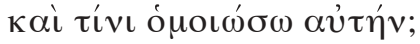

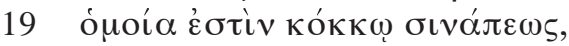

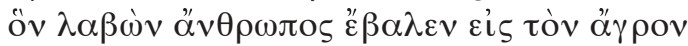

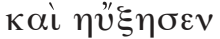

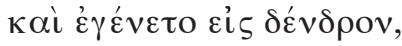

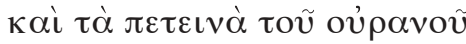

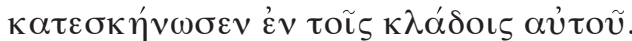

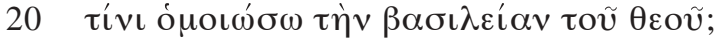

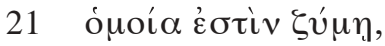

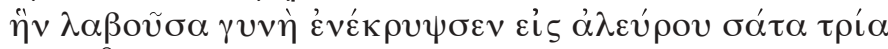

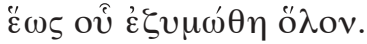

50. ENCONTRAR LA PUERTA ESTRECHA

Lc 13, 24 // Mt 7, 13-14

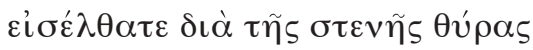

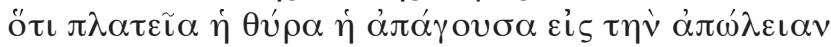

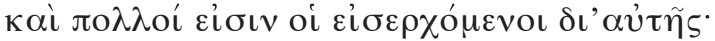

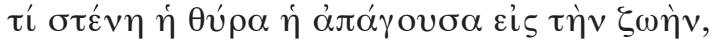

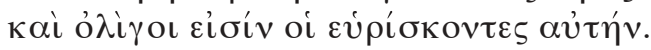

51. CUANDO LA PUERTA SE CIERRA

Lc 13, 25-27 // Mt 25, 10-12; 7, 22-23

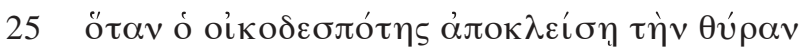

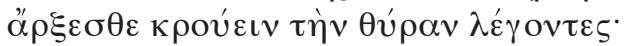


$\kappa \cup ́ \rho \iota \varepsilon, \alpha ̋ v o เ \xi o v \dot{\eta} \mu \tilde{\imath} v$,

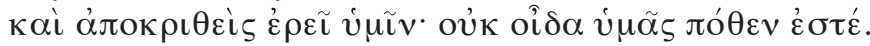

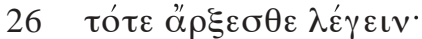

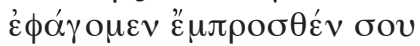

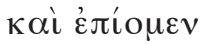

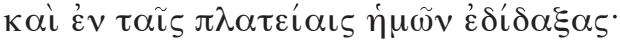

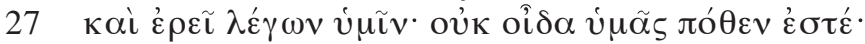

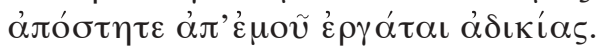

52. SUSTITUCIÓN DE LOS HIJOS DEL REINO

Lc 13, 28-29 // Mt 8, 11-12

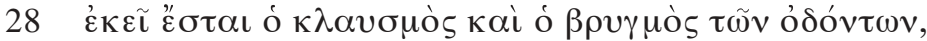

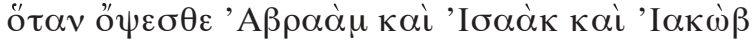

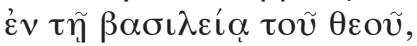

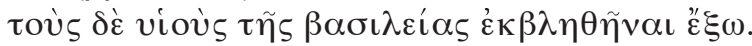

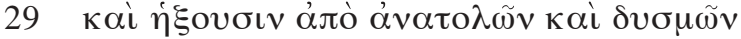

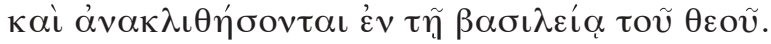

53. ÚLTIMOS PRIMEROS, Y PRIMEROS ÚLTIMOS

Lc 13, 30 // Mt 20, 16

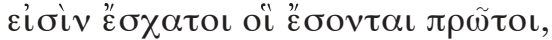

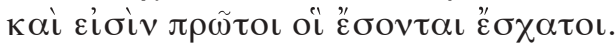

54. APÓSTROFE A JERUSALÉN

Lc 13, 34 -35 // Mt 23, 37-39

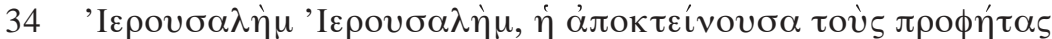

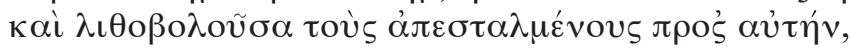

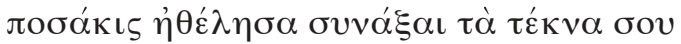

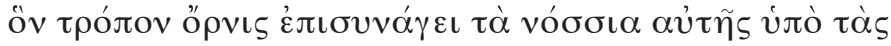
$\pi \tau \dot{\varepsilon} \rho v \gamma \alpha \varsigma$,

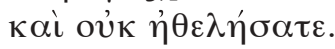

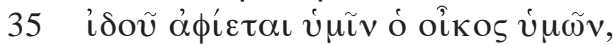

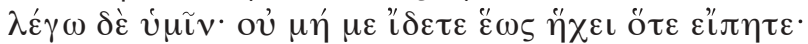

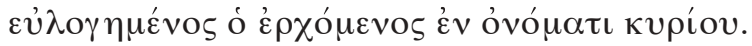

55. INVERSIÓN DE ROLES

Lc 14, $11 / /$ Mt 23, 12

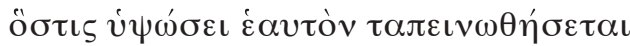

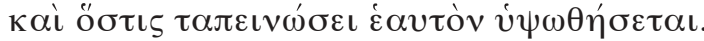


56. EL GRAN BANQUETE Y LOS INVITADOS DISPLICENTES

Lc 14, 16-21 // Mt 22, 2-10

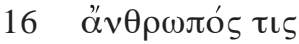

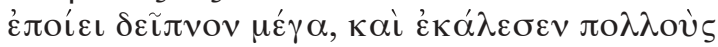

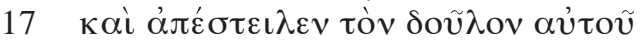

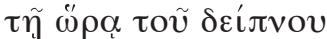

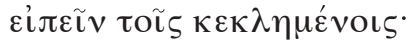

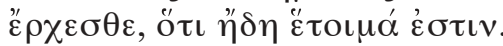

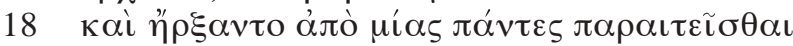

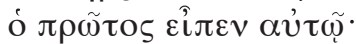

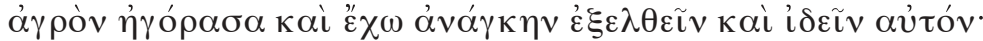

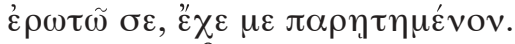

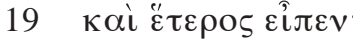

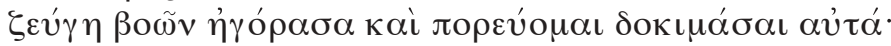

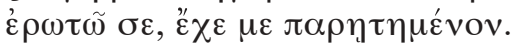

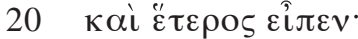

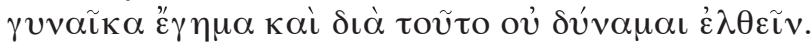

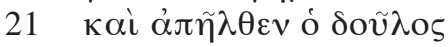

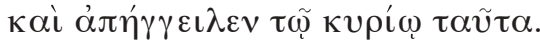

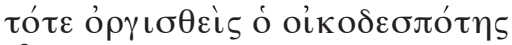

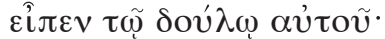

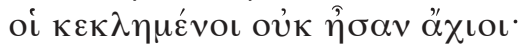

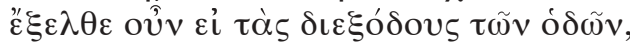

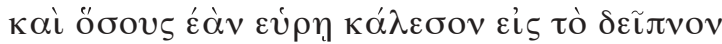

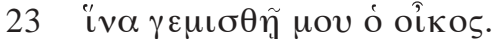

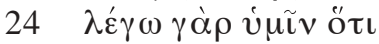

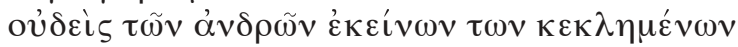

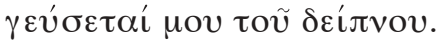

57. CUANDO LA SAL SE REVIENE

Lc 14, 34-35 // Mt 5, 13

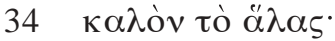

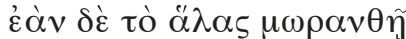

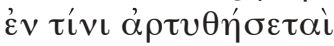

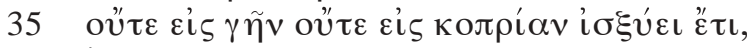

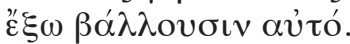

58. LA OVEJA Y LA DRACMA PERDIDAS

Lc 15, 4-9 // Mt 18, 12-14

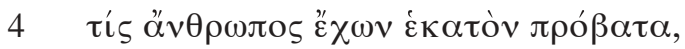
$\dot{\varepsilon} \dot{\alpha} \nu \pi \lambda \alpha \nu \eta \theta \tilde{\eta} \tilde{\varepsilon} \nu$ ध่ $\xi \alpha \dot{v} \tau \tilde{\omega} v$

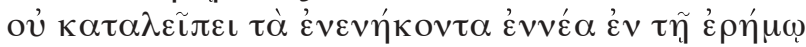




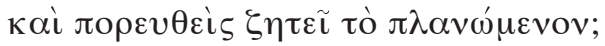

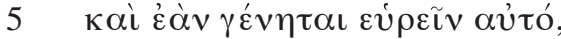

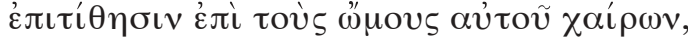

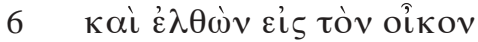

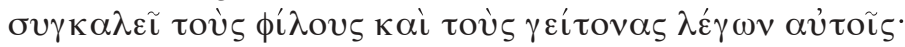

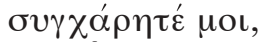

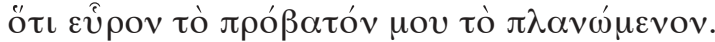

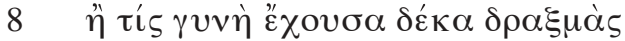

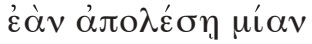

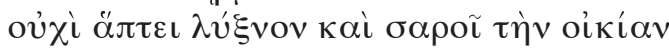

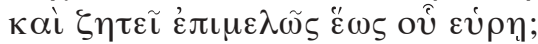

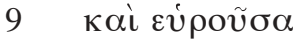

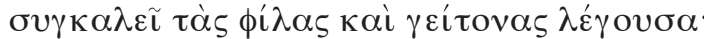

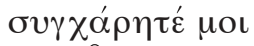

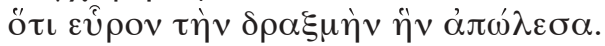

59. DOS AMOS ENTRE QUE ELEGIR: DIOS Y MAMÓN Lc 16, 13 // Mt 6, 24

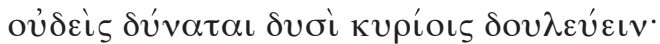

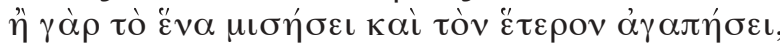

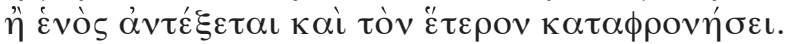

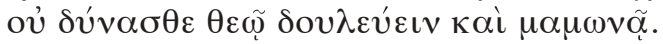

60. EL REINO DE DIOS EXPUESTO A LA VIOLENCIA

Lc 16, 16 // Mt 11, 12-13

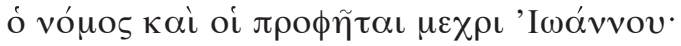

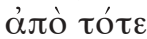

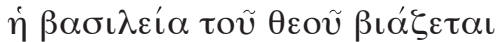

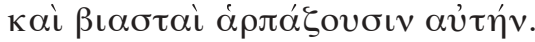

61. VIGENCIA ETERNA DE LA LEY

Lc 16, 17 // Mt 5, 18

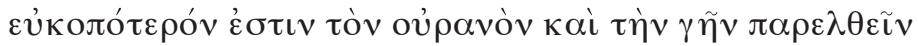

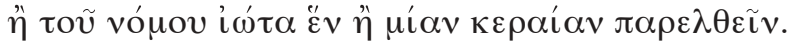

\section{PROSCRIPCIÓN DEL DIVORCIO}

Lc 16, 18 // Mt 5, 32

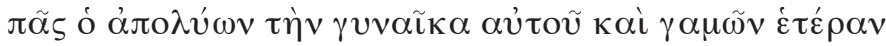

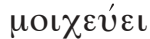




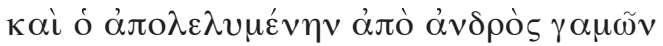

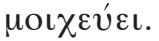

63. ¡AY DE QUIEN ESCANDALIZA!

Lc 17, 1 // Mt 18, 7

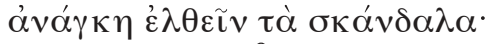

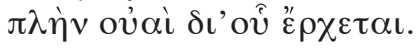

64. DESTINO DE QUIEN ESCANDALIZA A UN PEQUEÑO

Lc 17, 2 // Mt 18, 6

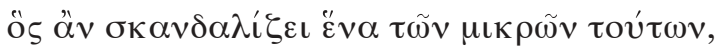
$\lambda v \sigma \iota \tau \varepsilon \lambda \varepsilon \tilde{\iota} \alpha \dot{v} \tau \tilde{\omega}$

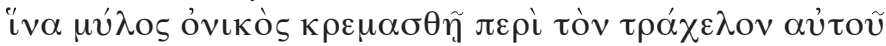

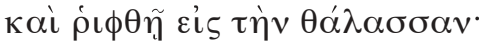

65. PERDONAR SIN LÍMITES

Lc 17, 3-4 // Mt 18, 15.21-22

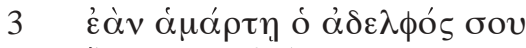

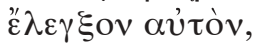

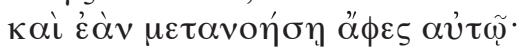

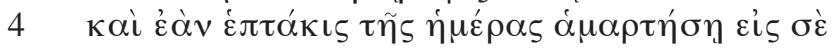

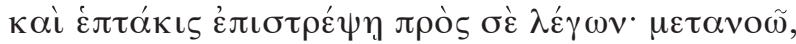

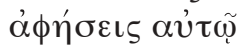

66. LA FUERZA DE LA FE

Lc 17, 6 // Mt 17, 20

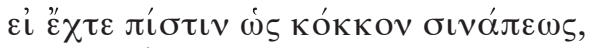

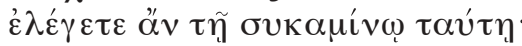

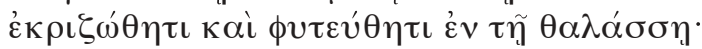

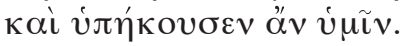

67. LA MANIFESTACIÓN DEL DÍA DEL HIJO DEL HOMBRE

Lc 17, 22-24 // Mt 24, 26-27

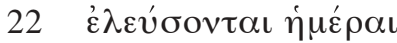

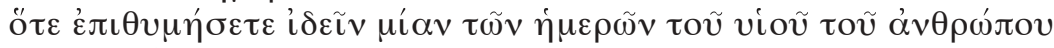

каі оưк оै $\psi \varepsilon \sigma \theta \varepsilon$.

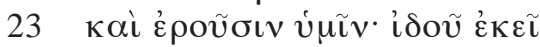

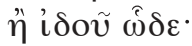


$\mu \grave{\eta} \alpha \dot{\alpha} \lambda \theta \eta \tau \varepsilon$

$\mu \eta \delta \dot{\varepsilon} \delta \iota \omega^{\prime} \xi \eta \tau \varepsilon$.

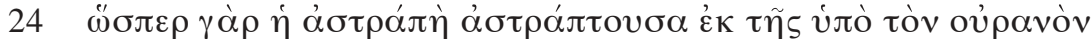

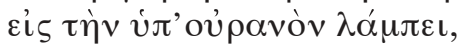

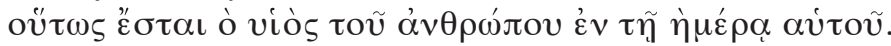

68. COMPARACIÓN CON LOS DÍAS DE NOÉ Y DE LOT

Lc 17, 26-30 // Mt 24, 37-39

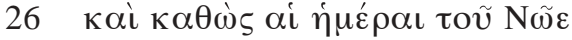

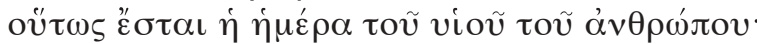

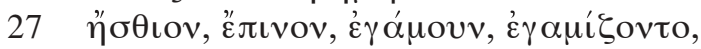

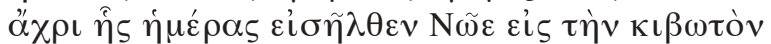

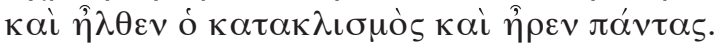

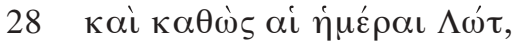

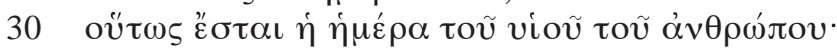

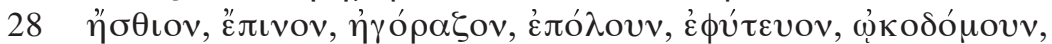

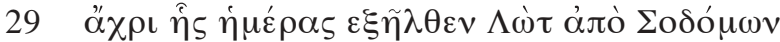

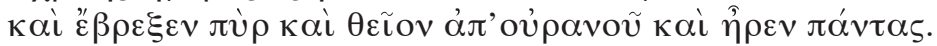

69. PERDER Y ENCONTRAR LA VIDA

Lc 17, 33 // Mt 10, 39

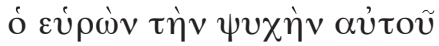

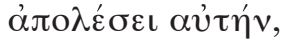

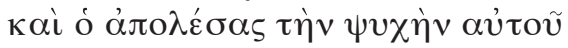

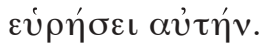

70. UNO SÍ, OTRO NO

Lc 17, 34-35 // Mt 24, 40-41

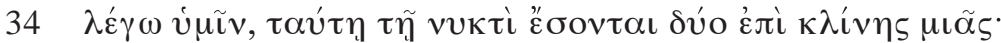

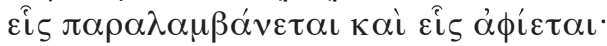

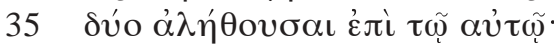
$\mu i \alpha \pi \alpha \rho \alpha \lambda \alpha \mu \beta \alpha \dot{v \varepsilon \tau \alpha \iota ~ \kappa \alpha i ~ \mu i ́ \alpha ~ \alpha ่ \phi i ́ \varepsilon \tau \alpha \iota . ~}$

71. EL CADÁVER CONGREGA LAS ÁGUILAS

Lc 17, 37 // Mt 24, 28

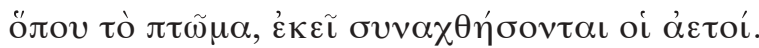


72. DE LA PARÁBOLA DEL DINERO CONFIADO A VARIOS SIERVOS Lc 19, 12-24 // Mt 25, 14-28

12-21 ?????????????????

$22 \lambda \lambda \varepsilon^{\prime} \gamma \varepsilon \iota \dot{u} \tau \tilde{\omega}$.

$\pi \circ \vee \eta \rho \dot{\varepsilon} \delta o \tilde{\lambda} \lambda \varepsilon, \eta \eta$

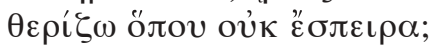

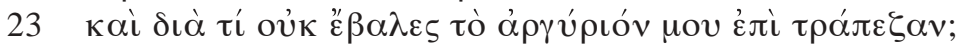

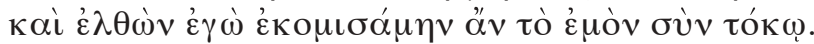

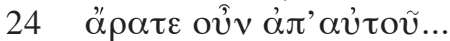

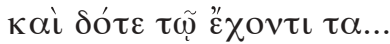

73. RETRIBUCIÓN PARADÓJICA

Lc 19, 26 // Mt 25, 29

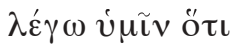

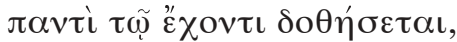

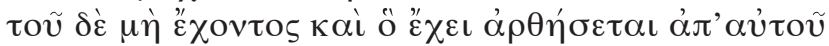

\section{PROMESA DE JESÚS A LOS SUYOS}

Lc 22, 28-30 // Mt 19, 28

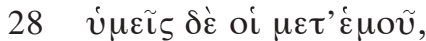

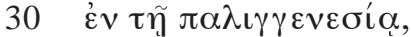

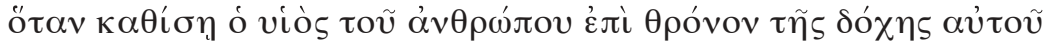

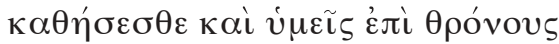

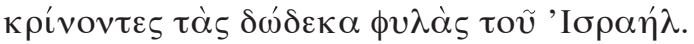

